Supporting Information

\title{
Early diagnosis of cerebral ischemia reperfusion injury and revelation of its regional development by a $H_{3} R$ receptor-directed probe
}

Junda Wang, ${ }^{\dagger,} \|$ Yuanjun Zhu,,\|\| Lingfei Yang, ${ }^{\dagger}$ Hui Liu, ${ }^{\dagger}$ Tongliang Zhou, ${ }^{\dagger}$ Fengrong $\mathrm{Xu},{ }^{\dagger}$ Ping Xu, ${ }^{*}{ }^{\dagger}$ Lan Yuan, ${ }^{\S}$ Lei Liang ${ }^{*}, \dagger$

\section{Content}

1. General experimental information

2. Characterization of pyridazinone compounds

3. Pharmacokinetic and metabolic properties

4. Photophyscial properites

5. CCK-8 assay

6. Cell imaging

7. OGD and OGD/R cellular model

8. Animals for in vivo imaging

9. MCAO model in mice

10. In vivo imaging of MCAO mouse brain

11. Ex vivo imaging of brain tissues

12. Western Bolt

13. Transmission electron microscopy (TEM)

14. NMR spectra of isolated compounds

15. References 


\section{General experimental information}

All solvents and chemicals were purchased from Alfa Aesar and J\&K and used without further purification, unless specifically mentioned. Cellular imaging trackers were purchased from Invitrogen (Life Technologies). The ${ }^{1} \mathrm{HNMR}$ spectroscopic measurements were carried out using a Bruker-400 NMR spectrometer at $400 \mathrm{MHz}$. Tetramethysilane (TMS) was used as the internal reference. Electrospray ionization (ESI) mass spectra were performed on a Fourier Transform Ion Cyclotron Resonance Mass Spectrometer (FT-ICR, Bruker, USA). FT-IR spectra were taken on a Nicolet iN10 MX Fourier Transform Infrared Spectrometer. The steady-state absorption spectra were attained on an Agilent 8453 UV-vis spectrophotometer in 1 $\mathrm{cm}$ path length quartz cells. Single-photon luminescence spectra were recorded using fluorescence lifetime and steady state spectrophotometer (Edinburgh Instrument FLS920). Quantum yields of one photon emission of all the synthesized compounds were measured relative to the fluorescence of fluorescein in $0.1 \mathrm{M} \mathrm{NaOH}$ aqueous solution. The two-photon absorption cross section of the probes was calculated at each wavelength relative to fluorescein as standard. Two-photon fluorescence data was acquired using a Tsunami femtosecond Ti: Sapphire laser (pulse width $\leq 100 \mathrm{fs}, 80 \mathrm{MHz}$ repetition rate, tuning range 700-900 nm, Spectra Physics Inc., USA). Confocal fluorescent images of living cells were performed using Nikon A1R-si Laser Scanning Confocal Microscope (Japan), equipped with lasers of 405/488/561/633 nm. Several lasers and channels were used to obtain images. Two- photon fluorescence microscopy images were performed on a modified Olympus Fluoview FV1000MPE microscope system equipped with an excitation light laser provided by a modelocked Ti: sapphire laser, (Mai Tai, Spectra-Physics Inc., USA). 


\section{Characterization of pyridazinone compounds}

Synthesis of $\mathbf{3}$

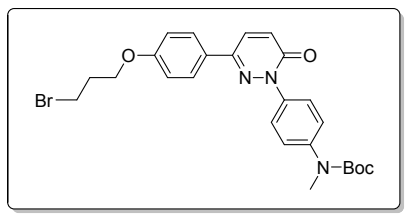

2 (786 mg, $2 \mathrm{mmol}$ ), 1,3-dibromopropane (1212 mg, $6 \mathrm{mmol}$ ), potassium carbonate ( $828 \mathrm{mg}, 6 \mathrm{mmol}$ ) were mixed in $10 \mathrm{~mL}$ acetonenitrile, and then refluxed for $18 \mathrm{~h}$. The mixture was concentrated by vacumm evaporatery and then 3 ( $846 \mathrm{mg}, 82 \%$ ) was obtained as yellow solid by column chromatography with eluent petroleum/ethyl acetate $=2: 1$.

${ }^{1} \mathrm{H}$ NMR $\left(400 \mathrm{MHz}, \mathbf{C D C l}_{3}\right) \delta$ ppm $7.79(\mathrm{~d}, J=8.9 \mathrm{~Hz}, 2 \mathrm{H},-\mathrm{ArH}), 7.74(\mathrm{~d}, J=6.9 \mathrm{~Hz}, 1 \mathrm{H},-\mathrm{ArH}), 7.72(\mathrm{~d}, J=6.2 \mathrm{~Hz}, 2 \mathrm{H},-$ ArH), $7.40(\mathrm{~d}, J=8.8 \mathrm{~Hz}, 2 \mathrm{H},-\mathrm{ArH}), 7.13(\mathrm{~d}, J=9.7 \mathrm{~Hz}, 1 \mathrm{H},-\mathrm{ArH}), 7.01(\mathrm{~d}, J=8.9 \mathrm{~Hz}, 2 \mathrm{H},-\mathrm{ArH}), 4.18(\mathrm{t}, J=5.8 \mathrm{~Hz}, 2 \mathrm{H}$, $\left.-\mathrm{OCH}_{2}\right), 3.64\left(\mathrm{t}, J=6.4 \mathrm{~Hz}, 2 \mathrm{H},-\mathrm{NCH}_{2}\right), 3.33\left(\mathrm{~s}, 3 \mathrm{H},-\mathrm{NCH}_{3}\right), 2.37$ (p, $\left.J=6.1 \mathrm{~Hz}, 2 \mathrm{H},-\mathrm{CH}_{2}\right), 1.51\left(\mathrm{~s}, 9 \mathrm{H},-\mathrm{CH}_{3}\right)$.

${ }^{13}$ C NMR (101 MHz, CDCl $) \delta$ ) ppm 159.98, 159.35, 154.52, 144.55, 143.34, 138.64, 131.30, 129.97, 127.47, 125.47, 125.32, $115.14,114.91,80.67,65.45,37.23,32.21,29.87,28.37$

HRMS m/z (ESI) calcd for $\left[\mathrm{C}_{25} \mathrm{H}_{28} \mathrm{BrN}_{3} \mathrm{O}_{4}\right]: 513.1263,515.1243$, found: 536.1152, $538.1137(\mathrm{M}+\mathrm{Na})^{+}$

Synthesis of $\mathbf{4 a}$

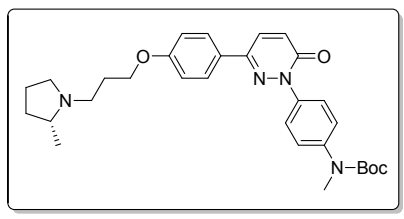

3 (258 mg, $0.5 \mathrm{mmol}),(R)$-2-methylpyrolidine $(125 \mathrm{mg}, 1.5 \mathrm{mmol})$, potassium carbonate $(207 \mathrm{mg}, 1.5 \mathrm{mmol})$, potassium iodide (94 mg, $0.5 \mathrm{mmol}$ ) were dissolved in $10 \mathrm{~mL}$ acetonenitrile, and then refluxed for $36 \mathrm{~h}$. The mixture was concentrated and $4 \mathbf{a}(227 \mathrm{mg}, 88 \%)$ was obtained as yellow oil by column chromatography with eluent dichloromethane/methanol = 40:1.

${ }^{1} \mathrm{H}$ NMR (400 MHz, $\left.\mathbf{C D C l}_{3}\right) \delta \mathrm{ppm} 7.74(\mathrm{~d}, J=8.1 \mathrm{~Hz}, 2 \mathrm{H},-\mathrm{ArH}), 7.71(\mathrm{~s}, 1 \mathrm{H},-\mathrm{ArH}), 7.68(\mathrm{~d}, J=7.5 \mathrm{~Hz}, 2 \mathrm{H},-\mathrm{ArH}), 7.36$ (d, $J=8.2 \mathrm{~Hz}, 2 \mathrm{H},-\mathrm{ArH}), 7.08(\mathrm{~d}, J=9.7 \mathrm{~Hz}, 1 \mathrm{H},-\mathrm{ArH}), 6.95(\mathrm{~d}, J=8.2 \mathrm{~Hz}, 2 \mathrm{H},-\mathrm{ArH}), 4.09\left(\mathrm{~s}, 2 \mathrm{H},-\mathrm{OCH}_{2}\right), 3.41(\mathrm{~s}, 1 \mathrm{H},-$ $\mathrm{NCH}), 3.29\left(\mathrm{~s}, 3 \mathrm{H},-\mathrm{NCH}_{3}\right), 2.96\left(\mathrm{~d}, J=172.7 \mathrm{~Hz}, 2 \mathrm{H},-\mathrm{NCH}_{2}\right), 2.62-2.42\left(\mathrm{~m}, 2 \mathrm{H},-\mathrm{NCH}_{2}\right), 2.18\left(\mathrm{~d}, J=34.9 \mathrm{~Hz}, 2 \mathrm{H},-\mathrm{CH}_{2}\right)$, $2.08-1.90\left(\mathrm{~m}, 2 \mathrm{H},-\mathrm{CH}_{2}\right), 1.73\left(\mathrm{~d}, J=77.5 \mathrm{~Hz}, 2 \mathrm{H},-\mathrm{CH}_{2}\right), 1.48\left(\mathrm{~s}, 9 \mathrm{H},-\mathrm{CH}_{3}\right), 1.28\left(\mathrm{~d}, J=6.0 \mathrm{~Hz}, 3 \mathrm{H},-\mathrm{CH}_{3}\right)$.

${ }^{13}$ C NMR (101 MHz, $\mathbf{C D C l}_{3}$ ) $\delta$ ppm 160.02, 159.28, 154.48, 144.52, 138.62, 131.23, 129.97, 127.40, 125.42, 125.25, 114.84, $80.61,77.40,65.96,61.73,53.51,50.50,37.19,32.12,29.63,28.33,27.19,21.49,17.48$

HRMS m/z (ESI) calcd for $\left[\mathrm{C}_{30} \mathrm{H}_{38} \mathrm{~N}_{4} \mathrm{O}_{4}\right]: 518.2893$, found: $519.2936(\mathrm{M}+\mathrm{H})^{+}$ 


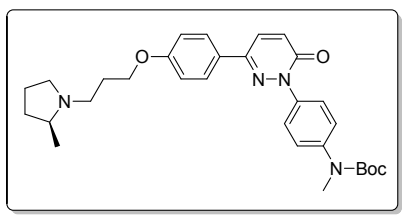

$3(258 \mathrm{mg}, 0.5 \mathrm{mmol}),(\boldsymbol{S})$-2-methylpyrolidine $(125 \mathrm{mg}, 1.5 \mathrm{mmol})$, potassium carbonate $(207 \mathrm{mg}, 1.5 \mathrm{mmol})$, potassium iodide (94 mg, $0.5 \mathrm{mmol}$ ) were dissolved in $10 \mathrm{~mL}$ acetonenitrile, and then refluxed for $36 \mathrm{~h}$. The mixture was concentrated and $\mathbf{4 b}(202 \mathrm{mg}, 78 \%)$ was obtained as yellow oil by column chromatography with eluent dichloromethane/methanol $=40: 1$. ${ }^{1} \mathbf{H}$ NMR (400 MHz, $\left.\mathbf{C D C l}_{3}\right) \delta \mathrm{ppm} 7.67(\mathrm{dd}, J=20.2,8.8 \mathrm{~Hz}, 5 \mathrm{H},-\mathrm{ArH}), 7.32(\mathrm{~d}, J=8.3 \mathrm{~Hz}, 2 \mathrm{H},-\mathrm{ArH}), 7.01(\mathrm{~d}, J=9.7 \mathrm{~Hz}$, 1H, -ArH), $6.91(\mathrm{~d}, J=8.6 \mathrm{~Hz}, 2 \mathrm{H},-\mathrm{ArH}), 4.03\left(\mathrm{t}, J=5.7 \mathrm{~Hz}, 2 \mathrm{H},-\mathrm{OCH}_{2}\right), 3.25\left(\mathrm{~s}, 3 \mathrm{H},-\mathrm{NCH}_{3}\right), 3.03(\mathrm{~s}, 1 \mathrm{H}-\mathrm{NCH}), 2.39(\mathrm{~d}$, $\left.J=52.8 \mathrm{~Hz}, 2 \mathrm{H}-\mathrm{NCH}_{2}\right), 2.02\left(\mathrm{~s}, 2 \mathrm{H},-\mathrm{CH}_{2}\right), 1.85\left(\mathrm{~d}, J=51.5 \mathrm{~Hz}, 2 \mathrm{H},-\mathrm{CH}_{2}\right), 1.66\left(\mathrm{~d}, J=30.2 \mathrm{~Hz}, 2 \mathrm{H},-\mathrm{CH}_{2}\right), 1.44(\mathrm{~s}, 9 \mathrm{H},-$ $\left.\mathrm{CH}_{3}\right), 1.12\left(\mathrm{~d}, J=6.0 \mathrm{~Hz}, 3 \mathrm{H},-\mathrm{CH}_{3}\right)$.

${ }^{13}$ C NMR (101 MHz, CDCl $_{3}$ ) $\delta$ ppm 160.21, 159.21, 154.41, 144.53, 143.20, 138.61, 131.14, 129.97, 127.34, 126.81, 125.37, $114.84,80.54,77.54,66.29,60.75,53.79,50.52,37.16,32.48,28.31,27.98,21.58,18.47$

HRMS m/z (ESI) calcd for $\left[\mathrm{C}_{30} \mathrm{H}_{38} \mathrm{~N}_{4} \mathrm{O}_{4}\right]: 518.2893$, found: $519.2936(\mathrm{M}+\mathrm{H})^{+}$

Synthesis of 5a

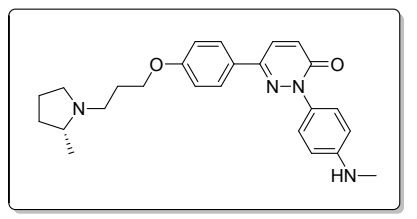

To a round bottomed flask equipped with a magnetic stir bar was placed $\mathbf{4 a}(267 \mathrm{mg}, 0.5 \mathrm{mmol})$ in DCM $(5 \mathrm{~mL})$. TFA $(1 \mathrm{~mL})$ was added to this compound and the reaction was allowed to stir at room temperature for $2 \mathrm{~h}$. The reaction was then poured into saturated sodium bicarbonate solution $(10 \mathrm{~mL})$ to $\mathrm{pH}=8$, and extracted into $\mathrm{DCM}(3 \times 25 \mathrm{~mL})$, the combined organic extracts were washed with brine ( $50 \mathrm{vol})$, dried by $\mathrm{Na}_{2} \mathrm{SO}_{4}$ and then concentrated in vacuo. The residue was purified over silica gel using DCM:MeOH=95:5 as the eluent. 5a (194 mg, 93\%) was obtained as yellow solid.

${ }^{1} \mathrm{H}$ NMR (400 MHz, CDCl 3 ) $\delta$ ppm $7.76(\mathrm{~d}, J=8.5 \mathrm{~Hz}, 2 \mathrm{H},-\mathrm{ArH}), 7.67(\mathrm{~d}, J=9.7 \mathrm{~Hz}, 1 \mathrm{H},-\mathrm{ArH}), 7.51(\mathrm{~d}, J=9.5 \mathrm{~Hz}, 2 \mathrm{H},-$ ArH), 7.07 (d, $J=9.6 \mathrm{~Hz}, 1 \mathrm{H},-\mathrm{ArH}), 6.96$ (d, $J=8.5 \mathrm{~Hz}, 2 \mathrm{H},-\mathrm{ArH}), 6.67$ (d, $J=8.5 \mathrm{~Hz}, 2 \mathrm{H},-\mathrm{ArH}), 4.08$ (t, $J=4.5 \mathrm{~Hz}, 2 \mathrm{H}$, $\left.-\mathrm{OCH}_{2}\right), 3.49-3.07\left(\mathrm{~m}, 2 \mathrm{H},-\mathrm{NCH}_{2}\right), 2.86\left(\mathrm{~s}, 3 \mathrm{H},-\mathrm{NCH}_{3}\right), 2.66(\mathrm{~s}, 1 \mathrm{H},-\mathrm{NCH}), 2.57-2.37\left(\mathrm{~m}, 2 \mathrm{H},-\mathrm{NCH}_{2}\right), 2.19-2.08(\mathrm{~m}$, $\left.2 \mathrm{H},-\mathrm{CH}_{2}\right), 2.06-1.88\left(\mathrm{~m}, 2 \mathrm{H},-\mathrm{CH}_{2}\right), 1.86-1.58\left(\mathrm{~m}, 2 \mathrm{H},-\mathrm{CH}_{2}\right), 1.25\left(\mathrm{~d}, J=6.0 \mathrm{~Hz}, 3 \mathrm{H},-\mathrm{CH}_{3}\right)$.

${ }^{13}$ C NMR (101 MHz, CDCl $_{3}$ ) $\delta$ ppm 159.90, 159.55, 149.13, 144.11, 131.76, 130.85, 129.51, 127.35, 126.30, 114.77, 111.76, $66.05,61.42,53.61,50.61,32.25,30.62,29.67,27.47,21.55,17.76$ 
HRMS m/z (ESI) calcd for $\left[\mathrm{C}_{26} \mathrm{H}_{32} \mathrm{~N}_{4} \mathrm{O}_{2}\right]: 418.2369$, found: $419.2410(\mathrm{M}+\mathrm{H})^{+}$

Synthesis of $\mathbf{5 b}$

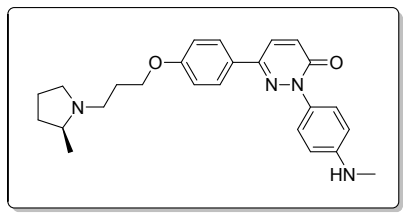

To a round bottomed flask equipped with a magnetic stir bar was placed $4 \mathbf{b}(267 \mathrm{mg}, 0.5 \mathrm{mmol})$ in DCM (5 mL). TFA (1 mL) was added to this compound and the reaction was allowed to stir at room temperature for $2 \mathrm{~h}$. The reaction was then poured into saturated sodium bicarbonate solution $(10 \mathrm{~mL})$ to $\mathrm{pH}=8$, and extracted into $\mathrm{DCM}(3 \times 25 \mathrm{~mL})$, The combined organic extracts were washed with brine $(50 \mathrm{vol})$, dried by $\mathrm{Na}_{2} \mathrm{SO}_{4}$ and then concentrated in vacuo. The residue was purified over silica gel using DCM:MeOH=95:5 as the eluent. $5 \mathbf{b}$ (180 mg, 86\%) was obtained as yellow solid.

${ }^{1} \mathbf{H}$ NMR (400 MHz, $\left.\mathbf{C D C l}_{3}\right) \delta \mathrm{ppm} 7.74(\mathrm{~d}, J=8.4 \mathrm{~Hz}, 2 \mathrm{H},-\mathrm{ArH}), 7.64(\mathrm{t}, J=9.9 \mathrm{~Hz}, 1 \mathrm{H},-\mathrm{ArH}), 7.49(\mathrm{t}, J=10.3 \mathrm{~Hz}, 2 \mathrm{H},-$ ArH), 7.06 (d, $J=9.6 \mathrm{~Hz}, 1 \mathrm{H},-\mathrm{ArH}), 6.92(\mathrm{~d}, J=8.4 \mathrm{~Hz}, 2 \mathrm{H},-\mathrm{ArH}), 6.67$ (d, $J=8.4 \mathrm{~Hz}, 2 \mathrm{H},-\mathrm{ArH}), 4.10-4.03(\mathrm{~m}, 2 \mathrm{H},-$ $\left.\mathrm{OCH}_{2}\right), 3.85-3.30\left(\mathrm{~m}, 2 \mathrm{H},-\mathrm{NCH}_{2}\right), 3.12(\mathrm{~m}, 1 \mathrm{H},-\mathrm{NCH}), 3.04-2.87\left(\mathrm{~m}, 2 \mathrm{H},-\mathrm{NCH}_{3}\right), 2.86\left(\mathrm{~s}, 3 \mathrm{H},-\mathrm{NCH}_{3}\right), 2.38-2.08(\mathrm{~m}$, $\left.4 \mathrm{H},-\mathrm{CH}_{2},-\mathrm{CH}_{2}\right), 2.03-1.81\left(\mathrm{~m}, 2 \mathrm{H},-\mathrm{CH}_{2}\right), 1.44\left(\mathrm{~d}, J=6.0 \mathrm{~Hz}, 3 \mathrm{H},-\mathrm{CH}_{3}\right)$.

${ }^{13}$ C NMR (101 MHz, $\left.\mathbf{C D C l}_{3}\right) \delta$ ppm 159.96, 159.54, 149.16, 144.13, 131.71, 130.82, 129.52, 127.34, 126.28, 114.79, 111.73, $66.15,61.17,53.67,50.60,32.35,30.59,29.67,27.67,21.58,18.01$

HRMS m/z (ESI) calcd for $\left[\mathrm{C}_{26} \mathrm{H}_{32} \mathrm{~N}_{4} \mathrm{O}_{2}\right]: 418.2369$, found: $419.2410(\mathrm{M}+\mathrm{H})^{+}$

Synthesis of 6a

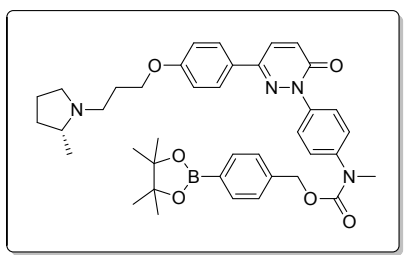

Under argon atmosphere, solution of $\mathbf{5 a}(109 \mathrm{mg}, 0.25 \mathrm{mmol})$ in DCM $(4 \mathrm{~mL})$ was added a solution of 4-(4,4,5,5-tetramethyl1,3,2-dioxaborolan-2-yl)benzyl carbonochloridate $(148 \mathrm{mg}, 0.5 \mathrm{mmol})$ in DCM $(4 \mathrm{~mL})$ dropwise at $0{ }^{\circ} \mathrm{C}$. After $30 \mathrm{~min}$, the mixture was allowed to stir at room temperature for $36 \mathrm{~h}$. Then the mixture was concentrated, and the residue was purified over silica gel using DCM:MeOH=40:1 as the eluent. $6 \mathbf{a}(81 \mathrm{mg}, 48 \%)$ was obtained as white solid.

${ }^{1}$ NMR (400 MHz, CDCl $) \delta$ ppm $7.82(\mathrm{dt}, J=35.2,10.7 \mathrm{~Hz}, 7 \mathrm{H},-\mathrm{ArH}), 7.40(\mathrm{t}, J=15.9 \mathrm{~Hz}, 4 \mathrm{H},-\mathrm{ArH}), 7.22-7.14(\mathrm{~m}, 1 \mathrm{H}$, -ArH), $7.03(\mathrm{t}, J=10.3 \mathrm{~Hz}, 2 \mathrm{H},-\mathrm{ArH}), 5.25\left(\mathrm{~s}, 2 \mathrm{H},-\mathrm{ArCH}_{2}\right), 4.23-4.12\left(\mathrm{~m}, 2 \mathrm{H},-\mathrm{OCH}_{2}\right), 3.84-3.69\left(\mathrm{~m}, 2 \mathrm{H},-\mathrm{NCH}_{2}\right), 3.47$ $-3.39\left(\mathrm{~m}, 3 \mathrm{H},-\mathrm{NCH}_{3}\right), 3.39(\mathrm{~s}, 1 \mathrm{H},-\mathrm{NCH}), 2.33-1.94\left(\mathrm{~m}, 6 \mathrm{H},-\mathrm{CH}_{2}\right), 1.43-1.37\left(\mathrm{~m}, 12 \mathrm{H},-\mathrm{CH}_{3}\right), 0.93\left(\mathrm{~s}, 3 \mathrm{H},-\mathrm{CH}_{3}\right)$. 
${ }^{13}$ C NMR (101 MHz, CDCl $_{3}$ ) $\delta$ ppm 159.81, 159.33, 155.25, 144.56, 142.68, 139.48, 139.31, 134.95, 131.38, 129.99, 127.52, $127.07,125.76,114.84,83.82,77.22,67.38,65.46,58.43,37.67,31.83,29.69,29.31,27.20,24.85,22.70,21.44,18.43,14.10$ HRMS m/z (ESI) calcd for $\left[\mathrm{C}_{39} \mathrm{H}_{47} \mathrm{BN}_{4} \mathrm{O}_{6}\right]: 678.3589$, found: $679.3672(\mathrm{M}+\mathrm{H})^{+}$

Synthesis of $\mathbf{6 b}$

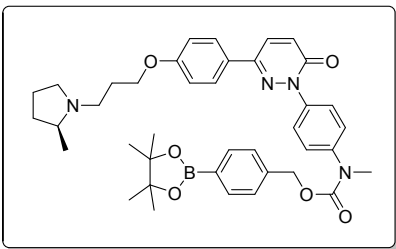

Under argon atmosphere, solution of $\mathbf{5 b}(109 \mathrm{mg}, 0.25 \mathrm{mmol})$ in DCM $(4 \mathrm{~mL})$ was added a solution of 4-(4,4,5,5-tetramethyl1,3,2-dioxaborolan-2-yl)benzyl carbonochloridate $(148 \mathrm{mg}, 0.5 \mathrm{mmol})$ in $\mathrm{DCM}(4 \mathrm{~mL})$ dropwise at $0{ }^{\circ} \mathrm{C}$. After $30 \mathrm{~min}$, the mixture was allowed to stir at room temperature for $36 \mathrm{~h}$. Then the mixture was concentrated, and the residue was purified over silica gel using DCM:MeOH=40:1 as the eluent. $6 \mathbf{b}(77 \mathrm{mg}, 45 \%)$ was obtained as white solid.

${ }^{1} \mathrm{H}$ NMR (400 MHz, CDCl 3 ) $\delta$ ppm $7.85(\mathrm{~d}, J=7.5 \mathrm{~Hz}, 2 \mathrm{H},-\mathrm{ArH}), 7.81$ (d, $\left.J=1.6 \mathrm{~Hz}, 2 \mathrm{H},-\mathrm{ArH}\right), 7.78$ (s, 1H, -ArH), 7.75 (s, 2H, -ArH), $7.41(\mathrm{t}, J=9.0 \mathrm{~Hz}, 4 \mathrm{H},-\mathrm{ArH}), 7.17(\mathrm{~d}, J=7.6 \mathrm{~Hz}, 1 \mathrm{H},-\mathrm{ArH}), 7.02(\mathrm{~d}, J=8.5 \mathrm{~Hz}, 2 \mathrm{H},-\mathrm{ArH}), 5.25(\mathrm{~s}, 2 \mathrm{H},-$ $\left.\mathrm{ArCH}_{2}\right), 4.18\left(\mathrm{t}, 2 \mathrm{H},-\mathrm{OCH}_{2}\right), 3.81-3.72\left(\mathrm{~m}, 2 \mathrm{H},-\mathrm{NCH}_{2}\right), 3.41\left(\mathrm{~s}, 3 \mathrm{H},-\mathrm{NCH}_{3}\right), 3.34(\mathrm{~s}, 1 \mathrm{H},-\mathrm{NCH}), 2.27\left(\mathrm{~s}, 4 \mathrm{H},-\mathrm{CH}_{2}\right), 1.66$ $\left(\mathrm{s}, 2 \mathrm{H},-\mathrm{CH}_{2}\right), 1.39\left(\mathrm{~s}, 12 \mathrm{H},-\mathrm{CH}_{3}\right), 0.98-0.90\left(\mathrm{~m}, 3 \mathrm{H},-\mathrm{CH}_{3}\right)$.

${ }^{13} \mathbf{C}$ NMR (101 MHz, $\left.\mathbf{C D C l}_{3}\right) \delta$ ppm 159.85, 159.33, 155.25, 144.58, 139.49, 139.32, 131.37, 130.00, 127.51, 127.33, 127.20, $127.07,125.76,114.84,83.81,77.22,68.16,67.39,58.44,38.73,37.67,31.90,29.69,29.32,28.92,24.85,21.47,18.43,14.04$ HRMS m/z (ESI) calcd for $\left[\mathrm{C}_{39} \mathrm{H}_{47} \mathrm{BN}_{4} \mathrm{O}_{6}\right]: 678.3589$, found: $679.3672(\mathrm{M}+\mathrm{H})^{+}$

Synthesis of 7

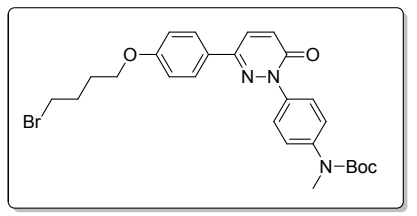

2 ( $786 \mathrm{mg}, 2 \mathrm{mmol})$, dibromobutane (1296 mg, $6 \mathrm{mmol}$ ), potassium carbonate ( $828 \mathrm{mg}, 6 \mathrm{mmol}$ ) were mixed in $10 \mathrm{~mL}$ acetonenitrile, and then refluxed for $18 \mathrm{~h}$. The mixture was concentrated by vacumm evaporatery and then $7(870 \mathrm{mg}, 82 \%)$ was obtained by column chromatography with eluent petroleum/ethyl acetate $=2: 1$.

${ }^{1}$ H NMR (400 MHz, CDCl $) \delta 7.80(\mathrm{~d}, J=8.8 \mathrm{~Hz}, 2 \mathrm{H},-\mathrm{ArH}), 7.74(\mathrm{dd}, J=10.9,9.3 \mathrm{~Hz}, 3 \mathrm{H},-\mathrm{ArH}), 7.41(\mathrm{~d}, J=8.8 \mathrm{~Hz}$, 2H, -ArH), $7.16(\mathrm{~d}, J=9.7 \mathrm{~Hz}, 1 \mathrm{H},-\mathrm{ArH}), 7.01(\mathrm{~d}, J=8.8 \mathrm{~Hz}, 2 \mathrm{H},-\mathrm{ArH}), 4.10\left(\mathrm{t}, J=6.0 \mathrm{~Hz}, 2 \mathrm{H},-\mathrm{OCH}_{2}\right), 3.54(\mathrm{t}, J=6.5$ $\left.\mathrm{Hz}, 2 \mathrm{H},-\mathrm{CH}_{2} \mathrm{Br}\right), 3.35\left(\mathrm{~s}, 3 \mathrm{H},-\mathrm{NCH}_{3}\right), 2.18-2.09\left(\mathrm{~m}, 2 \mathrm{H},-\mathrm{CH}_{2}\right), 2.06-2.00\left(\mathrm{~m}, 2 \mathrm{H},-\mathrm{CH}_{2}\right), 1.52\left(\mathrm{~s}, 9 \mathrm{H},-\mathrm{CH}_{3}\right)$. 
${ }^{13}$ C NMR (101 MHz, $\left.\mathbf{C D C l}_{3}\right) \delta$ 160.16, 159.36, 154.53, 144.59, 143.35, 138.64, 131.29, 129.94, 127.43, 127.09, 125.46,

$125.33,114.85,80.67,67.00,37.21,33.30,29.38,28.35,27.80$.

HRMS m/z (ESI) calcd for $\left[\mathrm{C}_{26} \mathrm{H}_{30} \mathrm{BrN}_{3} \mathrm{O}_{4}\right]: 528.4470$, found: $529.4344(\mathrm{M}+\mathrm{H})^{+}$

Synthesis of 8a

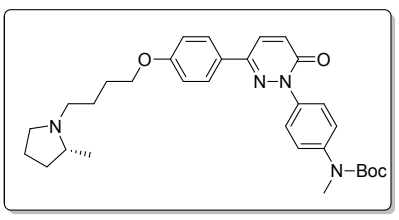

7 (264 mg, $0.5 \mathrm{mmol}),(R)-2$-methylpyrolidine $(125 \mathrm{mg}, 1.5 \mathrm{mmol})$, potassium carbonate $(207 \mathrm{mg}, 1.5 \mathrm{mmol})$, potassium iodide (94 mg, $0.5 \mathrm{mmol}$ ) were dissolved in $10 \mathrm{~mL}$ acetonenitrile, and then refluxed for $40 \mathrm{~h}$. The mixture was concentrated and 8a (227 mg, 85\%) was obtained as yellow oil by column chromatography with eluent dichloromethane/methanol = 40:1.

${ }^{1}$ H NMR (400 MHz, CDCl $\left.)_{3}\right) \delta$ ppm $7.74(\mathrm{~d}, J=8.5 \mathrm{~Hz}, 2 \mathrm{H},-\mathrm{ArH}), 7.72(\mathrm{~s}, 1 \mathrm{H},-\mathrm{ArH}), 7.68$ (d, $\left.J=9.0 \mathrm{~Hz}, 2 \mathrm{H},-\operatorname{ArH}\right), 7.36$ $(\mathrm{d}, J=8.6 \mathrm{~Hz}, 2 \mathrm{H},-\mathrm{ArH}), 7.08(\mathrm{~d}, J=9.7 \mathrm{~Hz}, 1 \mathrm{H},-\mathrm{ArH}), 6.95(\mathrm{~d}, J=8.5 \mathrm{~Hz}, 2 \mathrm{H},-\mathrm{ArH}), 4.03\left(\mathrm{~s}, 2 \mathrm{H},-\mathrm{OCH}_{2}\right), 3.42(\mathrm{~s}, 1 \mathrm{H},-$ $\mathrm{NCH}), 3.30\left(\mathrm{~s}, 3 \mathrm{H},-\mathrm{NCH}_{3}\right), 2.94\left(\mathrm{~d}, J=96.3 \mathrm{~Hz}, 2 \mathrm{H},-\mathrm{NCH}_{2}\right), 2.49\left(\mathrm{~s}, 2 \mathrm{H},-\mathrm{NCH}_{2}\right), 1.86\left(\mathrm{~s}, 8 \mathrm{H},-\mathrm{CH}_{2}\right), 1.48\left(\mathrm{~s}, 9 \mathrm{H},-\mathrm{CH}_{3}\right)$, $1.31\left(\mathrm{~d}, J=6.2 \mathrm{~Hz}, 3 \mathrm{H},-\mathrm{CH}_{3}\right)$.

${ }^{13}$ C NMR (101 MHz, CDCl $) \delta$ ppm 159.25, 158.33, 153.51, 143.61, 142.30, 137.66, 130.26, 128.98, 126.40, 125.92, 124.45, $124.29,113.87,79.64,66.70,60.15,52.59,52.47,36.21,31.32,27.35,26.20,23.52,20.51,17.02$

HRMS m/z (ESI) calcd for $\left[\mathrm{C}_{31} \mathrm{H}_{40} \mathrm{~N}_{4} \mathrm{O}_{4}\right]: 532.3050$, found: $533.3083(\mathrm{M}+\mathrm{H})^{+}$

Synthesis of $\mathbf{8 b}$

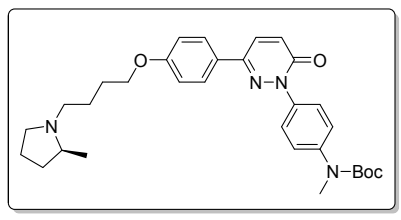

7 (264 mg, $0.5 \mathrm{mmol}),(S)-2$-methylpyrolidine $(125 \mathrm{mg}, 1.5 \mathrm{mmol})$, potassium carbonate $(207 \mathrm{mg}, 1.5 \mathrm{mmol})$, potassium iodide ( $94 \mathrm{mg}, 0.5 \mathrm{mmol}$ ) were dissolved in $10 \mathrm{~mL}$ acetonenitrile, and then refluxed for $40 \mathrm{~h}$. The mixture was concentrated and $\mathbf{8 b}(221 \mathrm{mg}, 83 \%)$ was obtained as yellow oil by column chromatography with eluent dichloromethane/methanol = 40:1.

${ }^{1} \mathrm{H}$ NMR (400 MHz, CDCl 3$) \delta \mathrm{ppm} 7.74(\mathrm{~d}, J=8.8 \mathrm{~Hz}, 2 \mathrm{H},-\mathrm{ArH}), 7.70(\mathrm{~d}, J=10.0 \mathrm{~Hz}, 1 \mathrm{H},-\mathrm{ArH}), 7.67(\mathrm{~d}, J=8.8 \mathrm{~Hz}, 2 \mathrm{H}$, -ArH), $7.35(\mathrm{~d}, J=8.7 \mathrm{~Hz}, 2 \mathrm{H},-\mathrm{ArH}), 7.07$ (d, $J=9.7 \mathrm{~Hz}, 1 \mathrm{H},-\mathrm{ArH}), 6.94(\mathrm{~d}, J=8.8 \mathrm{~Hz}, 2 \mathrm{H},-\mathrm{ArH}), 4.02(\mathrm{t}, J=5.6 \mathrm{~Hz}, 2 \mathrm{H}$, $\left.-\mathrm{OCH}_{2}\right), 3.41-3.33(\mathrm{~m}, 1 \mathrm{H},-\mathrm{NCH}), 3.29\left(\mathrm{~s}, 3 \mathrm{H},-\mathrm{NCH}_{3}\right), 3.07-2.65\left(\mathrm{~m}, 2 \mathrm{H},-\mathrm{NCH}_{2}\right), 2.43\left(\mathrm{q}, J=8.9 \mathrm{~Hz}, 2 \mathrm{H},-\mathrm{NCH}_{2}\right), 2.10$ $-1.62\left(\mathrm{~m}, 8 \mathrm{H},-\mathrm{CH}_{2}\right), 1.47\left(\mathrm{~s}, 9 \mathrm{H},-\mathrm{CH}_{3}\right), 1.26\left(\mathrm{~d}, J=6.2 \mathrm{~Hz}, 3 \mathrm{H},-\mathrm{CH}_{3}\right)$. 
${ }^{13}$ C NMR (101 MHz, $\left.\mathbf{C D C l}_{3}\right) \delta$ ppm 159.21, 158.33, 153.52, 143.61, 142.30, 137.66, 130.26, 129.00, 126.41, 125.95, 124.46,

$124.29,113.87,79.65,66.63,60.47,52.49,52.34,36.21,31.20,27.35,26.13,23.26,20.48,16.71$

HRMS m/z (ESI) calcd for $\left[\mathrm{C}_{31} \mathrm{H}_{40} \mathrm{~N}_{4} \mathrm{O}_{4}\right]: 532.3050$, found: $533.3083(\mathrm{M}+\mathrm{H})^{+}$

Synthesis of $\mathbf{8 c}$

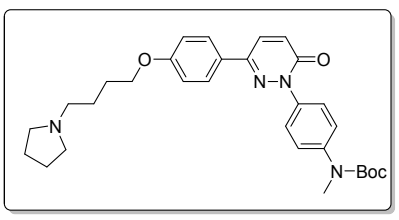

7 (264 mg, $0.5 \mathrm{mmol})$, pyrolidine (106 mg, $1.5 \mathrm{mmol})$, potassium carbonate (207 mg, $1.5 \mathrm{mmol})$, potassium iodide (9.4 mg, $0.05 \mathrm{mmol})$ were dissolved in $10 \mathrm{~mL}$ acetonenitrile, and then refluxed for $24 \mathrm{~h}$. The mixture was concentrated and $8 \mathbf{c}(202 \mathrm{mg}$, $76 \%$ ) was obtained as yellow solid by column chromatography with eluent dichloromethane/methanol $=40: 1$.

${ }^{1} \mathbf{H}$ NMR (400 MHz, $\left.\mathbf{C D C l}_{3}\right) \delta$ ppm $7.82(\mathrm{~d}, J=12.9 \mathrm{~Hz}, 2 \mathrm{H}, \mathrm{Ar}-\mathrm{H}), 7.77(\mathrm{~d}, J=8.0 \mathrm{~Hz}, 1 \mathrm{H}, \mathrm{Ar}-\mathrm{H}), 7.73$ (d, $J=8.5 \mathrm{~Hz}, 2 \mathrm{H}$, Ar-H), 7.44 (d, $J=8.5 \mathrm{~Hz}, 2 \mathrm{H}, \mathrm{Ar}-\mathrm{H}), 7.19$ (d, $J=9.7 \mathrm{~Hz}, 1 \mathrm{H}, \mathrm{Ar}-\mathrm{H}), 7.03$ (d, $J=8.8 \mathrm{~Hz}, 2 \mathrm{H}, \mathrm{Ar}-\mathrm{H}), 4.09$ (s, 2H, -OCH $)$, $3.38\left(\mathrm{~s}, 3 \mathrm{H},-\mathrm{NCH}_{3}\right), 2.81\left(\mathrm{~d}, J=20.7 \mathrm{~Hz}, 6 \mathrm{H},-\mathrm{NCH}_{2}\right), 1.95\left(\mathrm{~d}, J=13.1 \mathrm{~Hz}, 8 \mathrm{H},-\mathrm{CH}_{2}\right), 1.55\left(\mathrm{~s}, 9 \mathrm{H},-\mathrm{CH}_{3}\right)$.

${ }^{13}$ C NMR (101 MHz, $\mathbf{C D C l}_{3}$ ) $\delta$ ppm 160.19, 159.39, 144.66, 143.32, 138.59, 131.30, 130.03, 127.41, 126.93, 125.42, 114.83, $80.72,67.57,55.86,54.01,37.22,28.35,27.05,24.69,23.38$

HRMS m/z (ESI) calcd for $\left[\mathrm{C}_{30} \mathrm{H}_{38} \mathrm{~N}_{4} \mathrm{O}_{4}\right]: 518.2893$, found: $519.2936(\mathrm{M}+\mathrm{H})^{+}$

Synthesis of $\mathbf{8 d}$

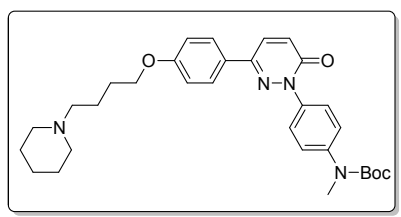

7 (264 mg, $0.5 \mathrm{mmol})$, piperidine (127 mg, $1.5 \mathrm{mmol})$, potassium carbonate (207 mg, $1.5 \mathrm{mmol})$, potassium iodide (9.4 mg, $0.05 \mathrm{mmol})$ were dissolved in $10 \mathrm{~mL}$ acetonenitrile, and then refluxed for $24 \mathrm{~h}$. The mixture was concentrated and $\mathbf{8 d}(217 \mathrm{mg}$, $82 \%$ ) was obtained as yellow solid by column chromatography with eluent dichloromethane/methanol $=40: 1$.

${ }^{1}$ H NMR (400 MHz, CDCl $) \delta$ ppm $7.80(\mathrm{~d}, J=8.8 \mathrm{~Hz}, 2 \mathrm{H}, \mathrm{Ar}-\mathrm{H}), 7.76(\mathrm{~d}, J=9.8 \mathrm{~Hz}, 1 \mathrm{H}, \mathrm{Ar}-\mathrm{H}), 7.72(\mathrm{~d}, J=8.8 \mathrm{~Hz}, 2 \mathrm{H}$, Ar-H), 7.40 (d, J=8.7 Hz, 2H, Ar-H), 7.15 (d, J=9.7 Hz, 1H, Ar-H), 6.99 (d, J=8.8 Hz, 2H, Ar-H), 4.08 (s, 2H, -OCH2), $3.35\left(\mathrm{~s}, 3 \mathrm{H},-\mathrm{NCH}_{3}\right), 2.64\left(\mathrm{~s}, 6 \mathrm{H},-\mathrm{NCH}_{2}\right), 1.89\left(\mathrm{~s}, 4 \mathrm{H},-\mathrm{NCH}_{2}\right), 1.81\left(\mathrm{~s}, 4 \mathrm{H},-\mathrm{CH}_{2}\right), 1.56\left(\mathrm{~s}, 2 \mathrm{H},-\mathrm{CH}_{2}\right), 1.52\left(\mathrm{~s}, 9 \mathrm{H},-\mathrm{CH}_{3}\right)$.

${ }^{13}$ C NMR (101 MHz, $\left.\mathbf{C D C l}_{3}\right) \delta 160.18,159.41,154.55,144.65,143.32,138.62,131.30,130.03,127.43,126.96,125.50$, $114.84,80.71,77.26,67.59,58.38,54.12,37.24,28.36,27.08,24.73,23.63,22.51$. 
HRMS m/z (ESI) calcd for $\left[\mathrm{C}_{31} \mathrm{H}_{40} \mathrm{~N}_{4} \mathrm{O}_{4}\right]: 532.3050$, found: $533.3083(\mathrm{M}+\mathrm{H})^{+}$

Synthesis of $\mathbf{8 e}$

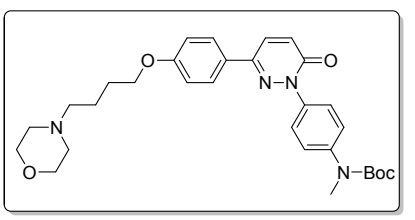

$7(264 \mathrm{mg}, 0.5 \mathrm{mmol})$, morpholine $(130 \mathrm{mg}, 1.5 \mathrm{mmol})$, potassium carbonate $(207 \mathrm{mg}, 1.5 \mathrm{mmol})$, potassium iodide $(9.4 \mathrm{mg}$, $0.05 \mathrm{mmol}$ ) were dissolved in $10 \mathrm{~mL}$ acetonenitrile, and then refluxed for $24 \mathrm{~h}$. The mixture was concentrated and $8 \mathrm{e}(245 \mathrm{mg}$, 92\%) was obtained as yellow solid by column chromatography with eluent dichloromethane/methanol $=40: 1$.

${ }^{1}$ H NMR (400 MHz, $\left.\mathbf{C D C l}_{3}\right) \delta \mathrm{ppm} 7.71(\mathrm{~m}, 8.7 \mathrm{~Hz}, 5 \mathrm{H}, \mathrm{Ar}-\mathrm{H}), 7.35(\mathrm{~d}, J=8.4 \mathrm{~Hz}, 2 \mathrm{H}, \mathrm{Ar}-\mathrm{H}), 7.07$ (d, $J=9.7 \mathrm{~Hz}, 1 \mathrm{H}, \mathrm{Ar}-$ H), $6.94(\mathrm{~d}, J=8.5 \mathrm{~Hz}, 2 \mathrm{H}, \mathrm{Ar}-\mathrm{H}), 4.02\left(\mathrm{t}, J=6.2 \mathrm{~Hz}, 2 \mathrm{H},-\mathrm{OCH}_{2}\right), 3.70\left(\mathrm{t}, J=4.3 \mathrm{~Hz}, 4 \mathrm{H},-\mathrm{OCH}_{2}\right), 3.29\left(\mathrm{~s}, 3 \mathrm{H},-\mathrm{NCH}_{3}\right), 2.43$ $\left(\mathrm{d}, J=8.6 \mathrm{~Hz}, 4 \mathrm{H},-\mathrm{NCH}_{2}\right), 2.39\left(\mathrm{~d}, J=7.4 \mathrm{~Hz}, 2 \mathrm{H},-\mathrm{NCH}_{2}\right), 1.87-1.77\left(\mathrm{~m}, 2 \mathrm{H},-\mathrm{CH}_{2}\right), 1.72-1.64\left(\mathrm{~m}, 2 \mathrm{H},-\mathrm{CH}_{2}\right), 1.48(\mathrm{~s}$, $\left.9 \mathrm{H},-\mathrm{NCH}_{3}\right)$.

${ }^{13}$ C NMR (101 MHz, CDCl $\mathbf{3}$ ) $\delta$ ppm 160.29, 159.27, 154.46, 144.55, 143.25, 138.63, 131.21, 129.93, 127.37, 126.83, 125.41, $125.24,114.82,80.58,67.78,66.93,58.52,53.68,37.18,28.34,27.07,23.00$

HRMS m/z (ESI) calcd for $\left[\mathrm{C}_{30} \mathrm{H}_{38} \mathrm{~N}_{4} \mathrm{O}_{5}\right]: 534.2842$, found: $535.2907(\mathrm{M}+\mathrm{H})^{+}$

Synthesis of $9 a$

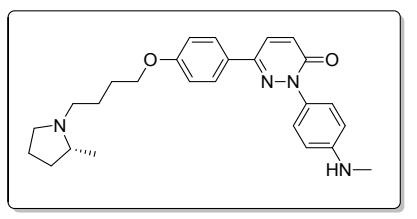

To a round bottomed flask equipped with a magnetic stir bar was placed $8 \mathbf{8 a}(267 \mathrm{mg}, 0.5 \mathrm{mmol})$ in DCM (5 mL). TFA (1 mL) was added to this compound and the reaction was allowed to stir at room temperature for $2 \mathrm{~h}$. The reaction mixture was then poured into saturated sodium bicarbonate solution $(10 \mathrm{~mL})$ to $\mathrm{pH}=8$, and extracted into $\mathrm{DCM}(3 \times 25 \mathrm{~mL})$. The combined organic extracts were washed with brine $(50 \mathrm{vol})$, dried by $\mathrm{Na}_{2} \mathrm{SO}_{4}$ and then concentrated in vacuo. The residue was purified over silica gel using DCM:MeOH=95:5 as the eluent. 9a (185 mg, 86\%) was obtained as yellow solid.

${ }^{1} \mathbf{H}$ NMR (400 MHz, $\left.\mathbf{C D C l}_{3}\right) \delta \mathrm{ppm} 7.78(\mathrm{~d}, J=8.2 \mathrm{~Hz}, 2 \mathrm{H},-\mathrm{ArH}), 7.70(\mathrm{~d}, J=9.7 \mathrm{~Hz}, 1 \mathrm{H},-\mathrm{ArH}), 7.52(\mathrm{~d}, J=8.2 \mathrm{~Hz}, 2 \mathrm{H},-$ ArH), $7.11(\mathrm{~d}, J=9.6 \mathrm{~Hz}, 1 \mathrm{H},-\mathrm{ArH}), 6.98(\mathrm{~d}, J=8.3 \mathrm{~Hz}, 2 \mathrm{H},-\mathrm{ArH}), 6.70(\mathrm{~d}, J=8.3 \mathrm{~Hz}, 2 \mathrm{H},-\mathrm{ArH}), 4.06(\mathrm{t}, J=5.7 \mathrm{~Hz}, 2 \mathrm{H}$, $\left.-\mathrm{OCH}_{2}\right), 3.32(\mathrm{~s}, 1 \mathrm{H},-\mathrm{NH}), 3.01-2.93(\mathrm{~m}, 1 \mathrm{H},-\mathrm{NCH}), 2.90\left(\mathrm{~s}, 3 \mathrm{H},-\mathrm{NCH}_{3}\right), 2.28\left(\mathrm{~s}, 2 \mathrm{H},-\mathrm{NCH}_{2}\right), 2.02\left(\mathrm{~s}, 2 \mathrm{H},-\mathrm{NCH}_{2}\right), 1.86$ $-1.74\left(\mathrm{~m}, 4 \mathrm{H},-\mathrm{CH}_{2}\right), 1.30\left(\mathrm{~s}, 4 \mathrm{H},-\mathrm{CH}_{2}\right), 1.22\left(\mathrm{~d}, J=5.8 \mathrm{~Hz}, 3 \mathrm{H},-\mathrm{CH}_{3}\right)$. 
${ }^{13}$ C NMR (101 MHz, $\left.\mathbf{C D C l}_{3}\right) \delta$ ppm 160.10, 159.59, 149.08, 144.19, 131.88, 130.92, 129.52, 127.35, 126.34, 114.81, 111.84, $77.28,67.76,53.69,53.59,32.44,30.69,29.69,27.28,24.74,21.56,18.30$

HRMS m/z (ESI) calcd for $\left[\mathrm{C}_{26} \mathrm{H}_{32} \mathrm{~N}_{4} \mathrm{O}_{2}\right]: 432.2525$, found: $433.2564(\mathrm{M}+\mathrm{H})^{+}$

Synthesis of $\mathbf{9 b}$

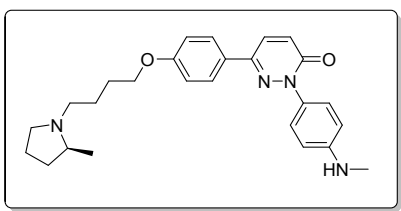

To a round bottomed flask equipped with a magnetic stir bar was placed $\mathbf{8 b}(267 \mathrm{mg}, 0.5 \mathrm{mmol})$ in DCM (5 mL). TFA (1 mL) was added to this compound and the reaction was allowed to stir at room temperature for $2 \mathrm{~h}$. The reaction mixture was then poured into saturated sodium bicarbonate solution $(10 \mathrm{~mL})$ to $\mathrm{pH}=8$, and extracted into $\mathrm{DCM}(3 \times 25 \mathrm{~mL})$. The combined organic extracts were washed with brine $(50 \mathrm{vol})$, dried by $\mathrm{Na}_{2} \mathrm{SO}_{4}$ and then concentrated in vacuo. The residue was purified over silica gel using DCM:MeOH=95:5 as the eluent. 9b (167 mg, 77\%) was obtained as yellow solid.

${ }^{1}$ H NMR (400 MHz, $\left.\mathbf{C D C l}_{3}\right) \delta$ ppm $7.78(\mathrm{~d}, J=8.4 \mathrm{~Hz}, 2 \mathrm{H},-\mathrm{ArH}), 7.70$ (d, $\left.J=9.7 \mathrm{~Hz}, 1 \mathrm{H},-\mathrm{ArH}\right), 7.52(\mathrm{~d}, J=8.4 \mathrm{~Hz}, 2 \mathrm{H},-$ ArH), $7.10(\mathrm{~d}, J=9.7 \mathrm{~Hz}, 1 \mathrm{H},-\mathrm{ArH}), 6.97(\mathrm{~d}, J=8.4 \mathrm{~Hz}, 2 \mathrm{H},-\mathrm{ArH}), 6.69(\mathrm{~d}, J=8.5 \mathrm{~Hz}, 2 \mathrm{H},-\mathrm{ArH}), 4.05(\mathrm{~d}, J=5.6 \mathrm{~Hz}, 2 \mathrm{H}$, $\left.-\mathrm{OCH}_{2}\right), 3.36(\mathrm{~s}, 1 \mathrm{H},-\mathrm{NH}), 2.99(\mathrm{~m}, 1 \mathrm{H},-\mathrm{NCH}), 2.89\left(\mathrm{~s}, 3 \mathrm{H},-\mathrm{NCH}_{3}\right), 2.34\left(\mathrm{~s}, 2 \mathrm{H},-\mathrm{NCH}_{2}\right), 2.03(\mathrm{t}, J=16.1 \mathrm{~Hz}, 2 \mathrm{H},-\mathrm{NCH})$, $1.84\left(\mathrm{~s}, 4 \mathrm{H},-\mathrm{CH}_{2}\right), 1.60\left(\mathrm{~s}, 2 \mathrm{H},-\mathrm{CH}_{2}\right), 1.29\left(\mathrm{~s}, 2 \mathrm{H},-\mathrm{CH}_{2}\right), 1.24\left(\mathrm{~s}, 3 \mathrm{H},-\mathrm{CH}_{3}\right)$.

${ }^{13}$ C NMR (101 MHz, CDCl $\left.\mathbf{3}\right) \delta$ ppm 160.07, 159.60, 149.11, 144.19, 131.87, 130.92, 129.54, 127.37, 126.35, 114.81, 111.85, $77.30,67.70,61.15,53.59,32.34,30.69,29.70,27.22,24.52,21.54,18.01$

HRMS m/z (ESI) calcd for $\left[\mathrm{C}_{26} \mathrm{H}_{32} \mathrm{~N}_{4} \mathrm{O}_{2}\right]: 432.2525$, found: $433.2564(\mathrm{M}+\mathrm{H})^{+}$

Synthesis of 9c

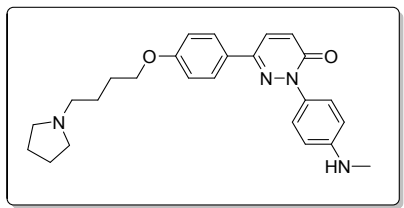

To a round bottomed flask equipped with a magnetic stir bar was placed $8 \mathbf{c}(261 \mathrm{mg}, 0.5 \mathrm{mmol})$ in DCM (5 mL). TFA (1 mL) was added to this compound and the reaction was allowed to stir at room temperature for $2 \mathrm{~h}$. The reaction mixture was then poured into saturated sodium bicarbonate solution $(10 \mathrm{~mL})$ to $\mathrm{pH}=8$, and extracted into $\mathrm{DCM}(3 \times 25 \mathrm{~mL})$. The combined organic extracts were washed with brine ( $50 \mathrm{vol})$, dried by $\mathrm{Na}_{2} \mathrm{SO}_{4}$ and then concentrated in vacuo. The residue was purified over silica gel using DCM:MeOH=95:5 as the eluent. 9c (186 mg, 89\%) was obtained as yellow solid. 
${ }^{1}$ H NMR (400 MHz, CDCl $) \delta$ ppm $7.80(\mathrm{~d}, J=8.8 \mathrm{~Hz}, 2 \mathrm{H},-\mathrm{ArH}), 7.74(\mathrm{~d}, J=9.7 \mathrm{~Hz}, 1 \mathrm{H},-\mathrm{ArH}), 7.57(\mathrm{~d}, J=8.7 \mathrm{~Hz}, 2 \mathrm{H},-$ ArH), $7.15(\mathrm{~d}, J=9.7 \mathrm{~Hz}, 1 \mathrm{H},-\mathrm{ArH}), 6.97(\mathrm{~d}, J=8.8 \mathrm{~Hz}, 2 \mathrm{H},-\mathrm{ArH}), 6.87(\mathrm{~d}, J=8.8 \mathrm{~Hz}, 2 \mathrm{H},-\mathrm{ArH}), 4.08(\mathrm{t}, J=5.8 \mathrm{~Hz}, 2 \mathrm{H}$, $\left.-\mathrm{OCH}_{2}\right), 3.91\left(\mathrm{~d}, J=5.1 \mathrm{~Hz}, 2 \mathrm{H},-\mathrm{NCH}_{2}\right), 3.24-3.20\left(\mathrm{~m}, 2 \mathrm{H},-\mathrm{NCH}_{2}\right), 2.96\left(\mathrm{~s}, 3 \mathrm{H},-\mathrm{NCH}_{3}\right), 2.86(\mathrm{dd}, J=10.7,7.4 \mathrm{~Hz}, 2 \mathrm{H},-$ $\left.\mathrm{NCH}_{2}\right), 2.25\left(\mathrm{dd}, J=7.4,4.9 \mathrm{~Hz}, 2 \mathrm{H},-\mathrm{CH}_{2}\right), 2.12\left(\mathrm{dd}, J=15.4,7.3 \mathrm{~Hz}, 4 \mathrm{H},-\mathrm{CH}_{2}\right), 1.95\left(\mathrm{dd}, J=13.7,6.1 \mathrm{~Hz}, 2 \mathrm{H},-\mathrm{CH}_{2}\right)$.

${ }^{13}$ C NMR (101 MHz, CDCl $) \delta$ ppm 159.70, 159.64, 147.59, 144.28, 131.01, 129.70, 127.45, 126.48, 114.72, 113.33, 77.26, $66.87,55.23,53.65,31.67,29.81,26.40,23.32,22.90$

HRMS m/z (ESI) calcd for $\left[\mathrm{C}_{26} \mathrm{H}_{32} \mathrm{~N}_{4} \mathrm{O}_{2}\right]: 418.2369$, found: $419.2410(\mathrm{M}+\mathrm{H})^{+}$

\section{Synthesis of 9d}

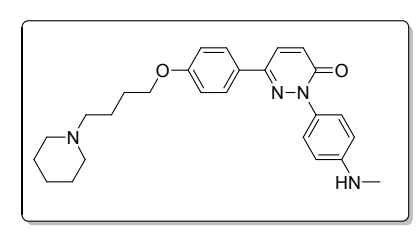

To a round bottomed flask equipped with a magnetic stir bar was placed $8 \mathbf{d}(267 \mathrm{mg}, 0.5 \mathrm{mmol})$ in DCM (5 mL). TFA (1 mL) was added to this compound and the reaction was allowed to stir at room temperature for $2 \mathrm{~h}$. The reaction mixture was then poured into saturated sodium bicarbonate solution $(10 \mathrm{~mL})$ to $\mathrm{pH}=8$, and extracted into $\mathrm{DCM}(3 \times 25 \mathrm{~mL})$. The combined organic extracts were washed with brine ( $50 \mathrm{vol})$, dried by $\mathrm{Na}_{2} \mathrm{SO}_{4}$ and then concentrated in vacuo. The residue was purified over silica gel using DCM:MeOH=95:5 as the eluent. 9d (194 mg, 90\%) was obtained as yellow solid.

${ }^{1} \mathrm{H}$ NMR (400 MHz, $\left.\mathbf{C D C l}_{3}\right) \delta \mathrm{ppm} 7.72(\mathrm{~d}, J=8.9 \mathrm{~Hz}, 2 \mathrm{H},-\mathrm{ArH}), 7.65(\mathrm{~d}, J=9.7 \mathrm{~Hz}, 1 \mathrm{H},-\mathrm{ArH}), 7.46(\mathrm{~d}, J=8.9 \mathrm{~Hz}, 2 \mathrm{H},-$ ArH), 7.06 (d, $J=9.7 \mathrm{~Hz}, 1 \mathrm{H},-\mathrm{ArH}), 6.90(\mathrm{~d}, J=8.9 \mathrm{~Hz}, 2 \mathrm{H},-\mathrm{ArH}), 6.66(\mathrm{~d}, J=8.9 \mathrm{~Hz}, 2 \mathrm{H},-\mathrm{ArH}), 3.98(\mathrm{t}, J=5.8 \mathrm{~Hz}, 2 \mathrm{H}$, $\left.-\mathrm{OCH}_{2}\right), 3.04-2.98\left(\mathrm{~m}, 2 \mathrm{H},-\mathrm{NCH}_{2}\right), 2.84\left(\mathrm{~s}, 3 \mathrm{H},-\mathrm{NCH}_{3}\right), 2.66\left(\mathrm{~s}, 2 \mathrm{H},-\mathrm{NCH}_{2}\right), 1.96\left(\mathrm{~s}, 6 \mathrm{H},-\mathrm{CH}_{2}\right), 1.82\left(\mathrm{~s}, 4 \mathrm{H},-\mathrm{CH}_{2}\right)$.

${ }^{13}$ C NMR (101 MHz, CDCl $)$ ) $\delta$ ppm 159.70, 159.64, 149.21, 144.21, 131.60, 130.82, 129.63, 127.39, 126.33, 114.67, 111.73, $77.39,66.88,56.85,53.00,30.61,26.38,22.73,22.00,20.78$

HRMS m/z (ESI) calcd for $\left[\mathrm{C}_{26} \mathrm{H}_{32} \mathrm{~N}_{4} \mathrm{O}_{2}\right]: 432.2525$, found: $433.2562(\mathrm{M}+\mathrm{H})^{+}$

Synthesis of $9 \mathbf{e}$

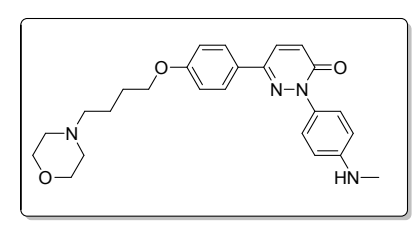

To a round bottomed flask equipped with a magnetic stir bar was placed $8 \mathrm{e}(267 \mathrm{mg}, 0.5 \mathrm{mmol})$ in DCM $(5 \mathrm{~mL})$. TFA (1 mL) was added to this compound and the reaction was allowed to stir at room temperature for $2 \mathrm{~h}$. The reaction mixture was then 
poured into saturated sodium bicarbonate solution $(10 \mathrm{~mL})$ to $\mathrm{pH}=8$, and extracted into $\mathrm{DCM}(3 \times 25 \mathrm{~mL})$. The combined organic extracts were washed with brine $(50 \mathrm{vol})$, dried by $\mathrm{Na}_{2} \mathrm{SO}_{4}$ and then concentrated in vacuo. The residue was purified over silica gel using DCM:MeOH=95:5 as the eluent. 9e (193 mg, 89\%) was obtained as yellow solid.

${ }^{1} \mathbf{H}$ NMR (400 MHz, CDCl $\left.)_{3}\right) \delta$ ppm $7.78(\mathrm{~d}, J=7.9 \mathrm{~Hz}, 2 \mathrm{H},-\mathrm{ArH}), 7.69(\mathrm{~d}, J=9.7 \mathrm{~Hz}, 1 \mathrm{H},-\mathrm{ArH}), 7.52(\mathrm{~d}, J=7.8 \mathrm{~Hz}, 2 \mathrm{H},-$ ArH), 7.10 (d, $J=9.7 \mathrm{~Hz}, 1 \mathrm{H},-\mathrm{ArH}), 6.98(\mathrm{~d}, J=7.9 \mathrm{~Hz}, 2 \mathrm{H},-\mathrm{ArH}), 6.69$ (d, $J=7.8 \mathrm{~Hz}, 2 \mathrm{H},-\mathrm{ArH}), 4.06(\mathrm{t}, J=6.0 \mathrm{~Hz}, 2 \mathrm{H}$, $\left.-\mathrm{OCH}_{2}\right), 3.76\left(\mathrm{~s}, 4 \mathrm{H},-\mathrm{OCH}_{2}\right), 2.88\left(\mathrm{~s}, 3 \mathrm{H},-\mathrm{NCH}_{3}\right), 2.49\left(\mathrm{~s}, 4 \mathrm{H},-\mathrm{NCH}_{2}\right), 2.47-2.41\left(\mathrm{~m}, 2 \mathrm{H},-\mathrm{NCH}_{2}\right), 1.91-1.83(\mathrm{~m}, 2 \mathrm{H},-$ $\left.\mathrm{CH}_{2}\right), 1.76-1.68\left(\mathrm{~m}, 2 \mathrm{H},-\mathrm{CH}_{2}\right)$.

${ }^{13}$ C NMR (101 MHz, CDCl $)$ ) $\delta$ ppm 160.12, 159.57, 149.11, 144.15, 131.81, 130.88, 129.50, 127.34, 127.23, 126.30, 114.77, $111.80,67.79,66.97,58.56,53.71,30.65,27.12,23.04$

HRMS m/z (ESI) calcd for $\left[\mathrm{C}_{25} \mathrm{H}_{30} \mathrm{~N}_{4} \mathrm{O}_{3}\right]: 434.2318$, found: $435.2642(\mathrm{M}+\mathrm{H})^{+}$

\section{Synthesis of 10a (PCAB)}

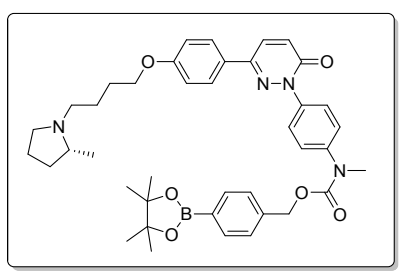

Under argon atmosphere, solution of $\mathbf{9 a}(108 \mathrm{mg}, 0.25 \mathrm{mmol})$ in DCM $(4 \mathrm{~mL})$ was added a solution of 4-(4,4,5,5-tetramethyl1,3,2-dioxaborolan-2-yl)benzyl carbonochloridate $(148 \mathrm{mg}, 0.5 \mathrm{mmol})$ in DCM $(4 \mathrm{~mL})$ dropwise at $0{ }^{\circ} \mathrm{C}$. After $30 \mathrm{~min}$, the mixture was allowed to stir at room temperature for $36 \mathrm{~h}$. Then the mixture was concentrated, and the residue was purified over silica gel using DCM:MeOH=40:1 as the eluent. 10a (PCAB, 86 mg, 49\%) was obtained as yellow solid.

${ }^{1}$ H NMR (400 MHz, CDCl $\left.)_{3}\right) \delta$ ppm $7.85-7.74$ (m, 7H, -ArH), 7.40 (t, 4H, -ArH), 7.16 (d, $J=9.3$ Hz, 1H, -ArH), 7.00 (d, $J$ $=8.1 \mathrm{~Hz}, 2 \mathrm{H},-\mathrm{ArH}), 5.32\left(\mathrm{~s}, 2 \mathrm{H},-\mathrm{ArCH}_{2}\right), 4.10\left(\mathrm{t}, 2 \mathrm{H},-\mathrm{OCH}_{2}\right), 3.40\left(\mathrm{~s}, 3 \mathrm{H},-\mathrm{NCH}_{3}\right), 2.86\left(\mathrm{t}, J=47.4 \mathrm{~Hz}, 2 \mathrm{H},-\mathrm{NCH}_{2}\right), 2.31$ $-2.16\left(\mathrm{~m}, 2 \mathrm{H},-\mathrm{NCH}_{2}\right), 2.08-1.90\left(\mathrm{~m}, 6 \mathrm{H},-\mathrm{CH}_{2}\right), 1.38\left(\mathrm{~s}, 12 \mathrm{H},-\mathrm{CH}_{3}\right), 1.30\left(\mathrm{~s}, 3 \mathrm{H},-\mathrm{CH}_{3}\right)$.

${ }^{13}$ C NMR (101 MHz, CDCl $_{3}$ ) $\delta$ ppm 160.03, 159.31, 155.23, 144.62, 142.65, 139.48, 139.33, 136.25, 134.94, 131.34, 130.02, $127.49,127.14,127.06,125.76,114.86,83.81,78.59,77.24,67.37,56.87,53.02,37.65,37.47,31.70,29.68,27.08,26.90$, $24.85,21.33$

HRMS m/z (ESI) calcd for $\left[\mathrm{C}_{40} \mathrm{H}_{49} \mathrm{BN}_{4} \mathrm{O}_{6}\right]: 692.3745$, found: $693.3841(\mathrm{M}+\mathrm{H})^{+}$ 


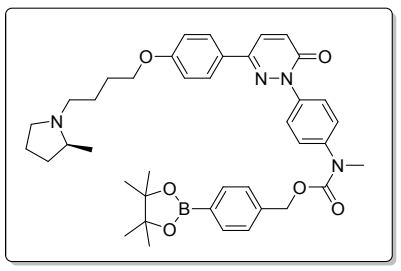

Under argon atmosphere, solution of $\mathbf{9 b}(108 \mathrm{mg}, 0.25 \mathrm{mmol})$ in DCM $(4 \mathrm{~mL})$ was added a solution of 4-(4,4,5,5-tetramethyl1,3,2-dioxaborolan-2-yl)benzyl carbonochloridate $(148 \mathrm{mg}, 0.5 \mathrm{mmol})$ in $\mathrm{DCM}(4 \mathrm{~mL})$ dropwise at $0{ }^{\circ} \mathrm{C}$. After $30 \mathrm{~min}$, the mixture was allowed to stir at room temperature for $36 \mathrm{~h}$. Then the mixture was concentrated, and the residue was purified over silica gel using DCM:MeOH=40:1 as the eluent. 10b ( $85 \mathrm{mg}, 49 \%)$ was obtained as yellow solid.

${ }^{1}$ H NMR (400 MHz, CDCl $) \delta$ ppm 7.85 (d, $J=7.5$ Hz, 2H, -ArH), 7.81 (d, $J=1.6$ Hz, 2H, -ArH), 7.78 (s, 1H, -ArH), 7.75 (s, 2H, -ArH), 7.41 (t, $J=9.0 \mathrm{~Hz}, 4 \mathrm{H},-\mathrm{ArH}), 7.17$ (d, $J=7.6 \mathrm{~Hz}, 1 \mathrm{H},-\mathrm{ArH}), 7.02(\mathrm{~d}, J=8.5 \mathrm{~Hz}, 2 \mathrm{H},-\mathrm{ArH}), 5.25$ (s, 2H, $\left.\mathrm{ArCH}_{2}\right), 4.18\left(\mathrm{t}, 2 \mathrm{H},-\mathrm{OCH}_{2}\right), 3.81-3.72\left(\mathrm{~m}, 2 \mathrm{H},-\mathrm{NCH}_{2}\right), 3.41\left(\mathrm{~s}, 3 \mathrm{H},-\mathrm{NCH}_{3}\right), 3.34(\mathrm{~s}, 1 \mathrm{H},-\mathrm{NCH}), 2.43-2.17(\mathrm{~m}, 4 \mathrm{H}), 1.77$ $-1.62(\mathrm{~m}, 2 \mathrm{H}), 1.39(\mathrm{~s}, 12 \mathrm{H}), 0.95(\mathrm{t}, 3 \mathrm{H})$.

${ }^{13}$ C NMR (101 MHz, CDCl$\left._{3}\right) \delta$ ppm 159.93, 159.32, 144.59, 142.67, 139.49, 134.95, 131.38, 130.00, 127.55, 127.26, 127.07, $126.46,126.00,125.77,114.90,114.85,83.81,77.22,67.38,67.17,53.18,37.69,31.56,29.69,29.34,26.77,24.85,22.68$, $21.33,14.11$

HRMS m/z (ESI) calcd for $\left[\mathrm{C}_{40} \mathrm{H}_{49} \mathrm{BN}_{4} \mathrm{O}_{6}\right]: 692.3745$, found: $693.3826(\mathrm{M}+\mathrm{H})^{+}$

Synthesis of 10c

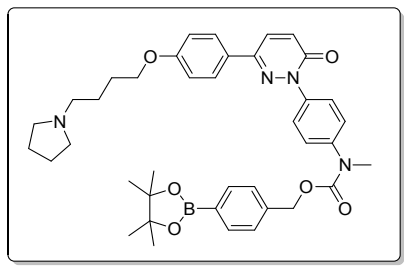

Under argon atmosphere, solution of $\mathbf{9 c}(104 \mathrm{mg}, 0.25 \mathrm{mmol})$ in DCM $(4 \mathrm{~mL})$ was added a solution of 4-(4,4,5,5-tetramethyl1,3,2-dioxaborolan-2-yl)benzyl carbonochloridate $(148 \mathrm{mg}, 0.5 \mathrm{mmol})$ in DCM $(4 \mathrm{~mL})$ dropwise at $0{ }^{\circ} \mathrm{C}$. After $30 \mathrm{~min}$, the mixture was allowed to stir at room temperature for $36 \mathrm{~h}$. Then the mixture was concentrated, and the residue was purified over silica gel using DCM:MeOH=40:1 as the eluent. 10c (40 mg, 24\%) was obtained as white solid.

${ }^{1}$ H NMR (400 MHz, $\left.\mathbf{C D C l}_{3}\right) \delta$ ppm 7.86 - $7.81(\mathrm{~m}, 2 \mathrm{H},-\mathrm{ArH}), 7.81-7.77(\mathrm{~m}, 2 \mathrm{H},-\mathrm{ArH}), 7.75(\mathrm{~d}, J=2.1 \mathrm{~Hz}, 1 \mathrm{H},-\mathrm{ArH})$, $7.73(\mathrm{~d}, J=2.0 \mathrm{~Hz}, 2 \mathrm{H},-\mathrm{ArH}), 7.39$ (t, $J=9.0 \mathrm{~Hz}, 4 \mathrm{H},-\mathrm{ArH}), 7.15$ (d, $J=9.7 \mathrm{~Hz}, 1 \mathrm{H},-\mathrm{ArH}), 6.98$ (d, $J=7.4 \mathrm{~Hz}, 2 \mathrm{H},-\mathrm{ArH})$, $5.23\left(\mathrm{~s}, 2 \mathrm{H},-\mathrm{ArCH}_{2}\right), 4.05\left(\mathrm{t}, J=5.7 \mathrm{~Hz}, 2 \mathrm{H},-\mathrm{OCH}_{2}\right), 3.94-3.74\left(\mathrm{~m}, 2 \mathrm{H},-\mathrm{NCH}_{2}\right), 3.39\left(\mathrm{~d}, J=2.0 \mathrm{~Hz}, 3 \mathrm{H},-\mathrm{NCH}_{3}\right), 3.16(\mathrm{~s}$, $\left.2 \mathrm{H},-\mathrm{NCH}_{2}\right), 2.83\left(\mathrm{~s}, 2 \mathrm{H},-\mathrm{NCH}_{2}\right), 2.27\left(\mathrm{~s}, 2 \mathrm{H},-\mathrm{CH}_{2}\right), 2.12\left(\mathrm{~d}, J=24.0 \mathrm{~Hz}, 4 \mathrm{H},-\mathrm{CH}_{2}\right), 1.95\left(\mathrm{~s}, 2 \mathrm{H},-\mathrm{CH}_{2}\right), 1.37(\mathrm{~d}, J=2.0 \mathrm{~Hz}$, $\left.12 \mathrm{H},-\mathrm{CH}_{3}\right)$. 
${ }^{13}$ C NMR (101 MHz, CDCl $)$ ) $\delta$ ppm 160.03, 159.88, 159.35, 155.24, 144.63, 142.67, 139.47, 139.30, 134.94, 131.34, 130.06, $127.52,127.15(\mathrm{~d}, J=18.1 \mathrm{~Hz}), 125.77,114.84,83.82,77.26,67.37,66.98,55.28,53.65,37.64,29.68,26.49,24.85,23.36$, 22.87

HRMS m/z (ESI) calcd for $\left[\mathrm{C}_{39} \mathrm{H}_{47} \mathrm{BN}_{4} \mathrm{O}_{6}\right]: 678.3589$, found: $679.3670(\mathrm{M}+\mathrm{H})^{+}$

Synthesis of 10d

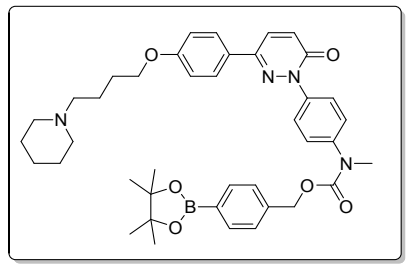

Under argon atmosphere, solution of $\mathbf{9 d}(108 \mathrm{mg}, 0.25 \mathrm{mmol})$ in DCM $(4 \mathrm{~mL})$ was added a solution of 4-(4,4,5,5-tetramethyl1,3,2-dioxaborolan-2-yl)benzyl carbonochloridate $(148 \mathrm{mg}, 0.5 \mathrm{mmol})$ in $\mathrm{DCM}(4 \mathrm{~mL})$ dropwise at $0{ }^{\circ} \mathrm{C}$. After $30 \mathrm{~min}$, the mixture was allowed to stir at room temperature for $36 \mathrm{~h}$. Then the mixture was concentrated, and the residue was purified over silica gel using DCM:MeOH=40:1 as the eluent. 10d (63 mg, 36\%) was obtained as white solid.

${ }^{1} \mathrm{H}$ NMR $\left(400 \mathrm{MHz}, \mathbf{C D C l}_{3}\right) \delta \mathrm{ppm} 7.80(\mathrm{~d}, J=7.7 \mathrm{~Hz}, 2 \mathrm{H},-\mathrm{ArH}), 7.75(\mathrm{~d}, J=8.7 \mathrm{~Hz}, 2 \mathrm{H},-\mathrm{ArH}), 7.73(\mathrm{~d}, J=2.1 \mathrm{~Hz}, 1 \mathrm{H},-$ ArH), $7.70(\mathrm{~d}, J=3.5 \mathrm{~Hz}, 2 \mathrm{H},-\mathrm{ArH}), 7.37$ (t, $J=8.8 \mathrm{~Hz}, 4 \mathrm{H},-\mathrm{ArH}), 7.13(\mathrm{~d}, J=9.1 \mathrm{~Hz}, 1 \mathrm{H},-\mathrm{ArH}), 6.94(\mathrm{~d}, J=8.7 \mathrm{~Hz}, 2 \mathrm{H}$, -ArH), $5.20\left(\mathrm{~s}, 2 \mathrm{H},-\mathrm{ArCH}_{2}\right), 4.01\left(\mathrm{t}, J=5.7 \mathrm{~Hz}, 2 \mathrm{H},-\mathrm{OCH}_{2}\right), 3.58\left(\mathrm{~d}, J=11.2 \mathrm{~Hz}, 2 \mathrm{H},-\mathrm{NCH}_{2}\right), 3.36\left(\mathrm{~s}, 3 \mathrm{H},-\mathrm{NCH}_{3}\right), 3.03(\mathrm{~d}$, $\left.J=4.6 \mathrm{~Hz}, 2 \mathrm{H},-\mathrm{NCH}_{2}\right), 2.63\left(\mathrm{q}, J=10.0 \mathrm{~Hz}, 2 \mathrm{H},-\mathrm{NCH}_{2}\right), 2.04\left(\mathrm{dd}, J=13.6,11.2 \mathrm{~Hz}, 4 \mathrm{H},-\mathrm{CH}_{2}\right), 1.85\left(\mathrm{~s}, 6 \mathrm{H},-\mathrm{CH}_{2}\right), 1.34(\mathrm{~s}$, $\left.12 \mathrm{H},-\mathrm{CH}_{3}\right)$.

${ }^{13}$ C NMR (101 MHz, CDCl 3 ) $\delta$ ppm 159.94, 159.42, 155.21, 144.80, 142.65, 139.46, 139.25, 134.94, 131.28, 130.14, 127.51, $127.02,126.48,125.78,125.62,114.80,83.82,77.39,67.35,66.93,56.85,53.03,37.62,26.39,24.84,22.67,22.00,20.76$ HRMS m/z (ESI) calcd for $\left[\mathrm{C}_{39} \mathrm{H}_{47} \mathrm{BN}_{4} \mathrm{O}_{7}\right]: 692.3745$, found: $693.3829(\mathrm{M}+\mathrm{H})^{+}$

Synthesis of 10e

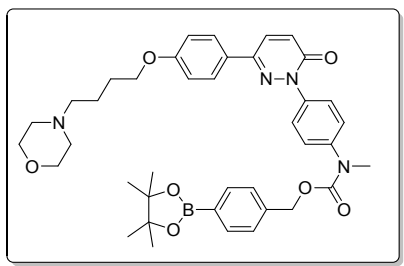

Under argon atmosphere, solution of $9 \mathrm{e}(109 \mathrm{mg}, 0.25 \mathrm{mmol})$ in DCM $(4 \mathrm{~mL})$ was added a solution of 4-(4,4,5,5-tetramethyl1,3,2-dioxaborolan-2-yl)benzyl carbonochloridate $(148 \mathrm{mg}, 0.5 \mathrm{mmol})$ in $\mathrm{DCM}(4 \mathrm{~mL})$ dropwise at $0{ }^{\circ} \mathrm{C}$. After $30 \mathrm{~min}$, the 
mixture was allowed to stir at room temperature for $36 \mathrm{~h}$. Then the mixture was concentrated, and the residue was purified over silica gel using DCM:MeOH=40:1 as the eluent. 10e $(62 \mathrm{mg}, 36 \%)$ was obtained as white solid.

${ }^{1}$ H NMR (400 MHz, $\mathbf{C D C l}_{3}$ ) $\delta$ ppm $7.83(\mathrm{~d}, J=7.9 \mathrm{~Hz}, 2 \mathrm{H},-\mathrm{ArH}), 7.80$ (d, $\left.J=8.7 \mathrm{~Hz}, 2 \mathrm{H},-\mathrm{ArH}\right), 7.76$ (s, 1H, -ArH), 7.74 (s, 2H, -ArH), 7.45 - 7.35 (m, 4H, -ArH), $7.16-7.13$ (m, 1H, -ArH), 7.00 (d, J=8.3 Hz, 2H, -ArH), 5.24 (s, 2H, - $\mathrm{ArCH}_{2}$ ), $4.08\left(\mathrm{t}, J=6.0 \mathrm{~Hz}, 2 \mathrm{H},-\mathrm{OCH}_{2}\right), 3.81\left(\mathrm{~s}, 4 \mathrm{H},-\mathrm{OCH}_{2}\right), 3.39\left(\mathrm{~s}, 3 \mathrm{H},-\mathrm{NCH}_{3}\right), 2.58\left(\mathrm{~s}, 6 \mathrm{H},-\mathrm{NCH}_{2}\right), 1.92-1.87\left(\mathrm{~m}, 2 \mathrm{H},-\mathrm{CH}_{2}\right)$, $1.79\left(\mathrm{~s}, 2 \mathrm{H},-\mathrm{CH}_{2}\right), 1.37\left(\mathrm{~s}, 12 \mathrm{H},-\mathrm{CH}_{3}\right)$.

${ }^{13}$ C NMR (101 MHz, CDCl $)$ ) $\delta$ ppm 160.29, 159.32, 155.23, 144.68, 142.65, 139.49, 134.95, 131.34, 130.02, 127.44, 127.06, $126.93,126.46,125.77,114.87,83.81,77.26,67.72,67.37,66.54,58.46,53.50,37.66,29.69,27.04,24.86,22.71$

HRMS m/z (ESI) calcd for $\left[\mathrm{C}_{39} \mathrm{H}_{47} \mathrm{BN}_{4} \mathrm{O}_{7}\right]:$ : 694.3538, found: $695.3629(\mathrm{M}+\mathrm{H})^{+}$ 


\section{Pharmacokinetic and metabolic properties}

The $\mathrm{H}_{3} \mathrm{R}$ in vitro binding assays of pyridazinone compounds $5 \mathbf{a}, \mathbf{6 a}, \mathbf{6 b}, \mathbf{9 a}, \mathbf{1 0 a}(\mathbf{P C A B}), \mathbf{1 0 b}, \mathbf{1 0 c}, \mathbf{1 0 d}, \mathbf{1 0 e}$ were measured by displacement of $\left[{ }^{3} \mathrm{H}\right] \mathrm{N}-\alpha$-methylhistamine $\left(\left[{ }^{3} \mathrm{H}\right] \mathrm{NAMH}\right)$ in membranes isolated from $\mathrm{CHO}$ cells transfected with cloned human $\mathrm{H}_{3}$ or rat $\mathrm{H}_{3}$ receptors. ${ }^{[1]}$

The pharmacokinetics experiments were performed as literature described. ${ }^{[2]}$ All Sprague-Dawley (SD) rats (male, $210 \pm 10$ g) were provided by the Laboratory Animal Science Center of Peking University Health Science Center. They were maintained in a controlled environment under a $12 \mathrm{~h}$ light or dark cycle, at $24 \pm 1{ }^{\circ} \mathrm{C}, 70 \pm 5 \%$ relative humidity, for three days, with free access to water and standard food. All animals were fasted for $12 \mathrm{~h}$ prior to administration of the solution of probe, but water was freely accessible during the experiment. All experimental protocols were carried out according to the Care and Use of Laboratory Animals in Beijing, authorised by the Institutional Animal Care and Use Committee of Peking University (Approval No. LA 2020114).

For tissue distribution study, 25 male Sprague-Dawley rats $(200 \pm 20 \mathrm{~g})$ were divided into five groups $(\mathrm{n}=5$ per group). The rats were anesthetized with chloral hydrate $(0.35 \mathrm{~g} / \mathrm{kg}$ rat $)$ at 2, 30, 60, 120 and 180 min after injection of $\mathbf{P C A B}$. Then heart perfusion was conducted with normal saline to obliterate blood in the tissues of heart, liver, spleen, lung, kidney, stomach and brain. Each tissue sample was weighted, homogenized and stored at $-80{ }^{\circ} \mathrm{C}$ until analysis. The UPLC-MS/MS data processing was performed with Analyst 1.6 software (Applied Biosystems Inc., Toronto, Ontario, Canada). All of the statistical analysis was dealt with Microsoft Excel 2003 (Microsoft, Redmond, WA, USA). 
Table S1. The in vitro $\mathrm{H}_{3} \mathrm{R}$ binding affinities of pyridazinone compounds.

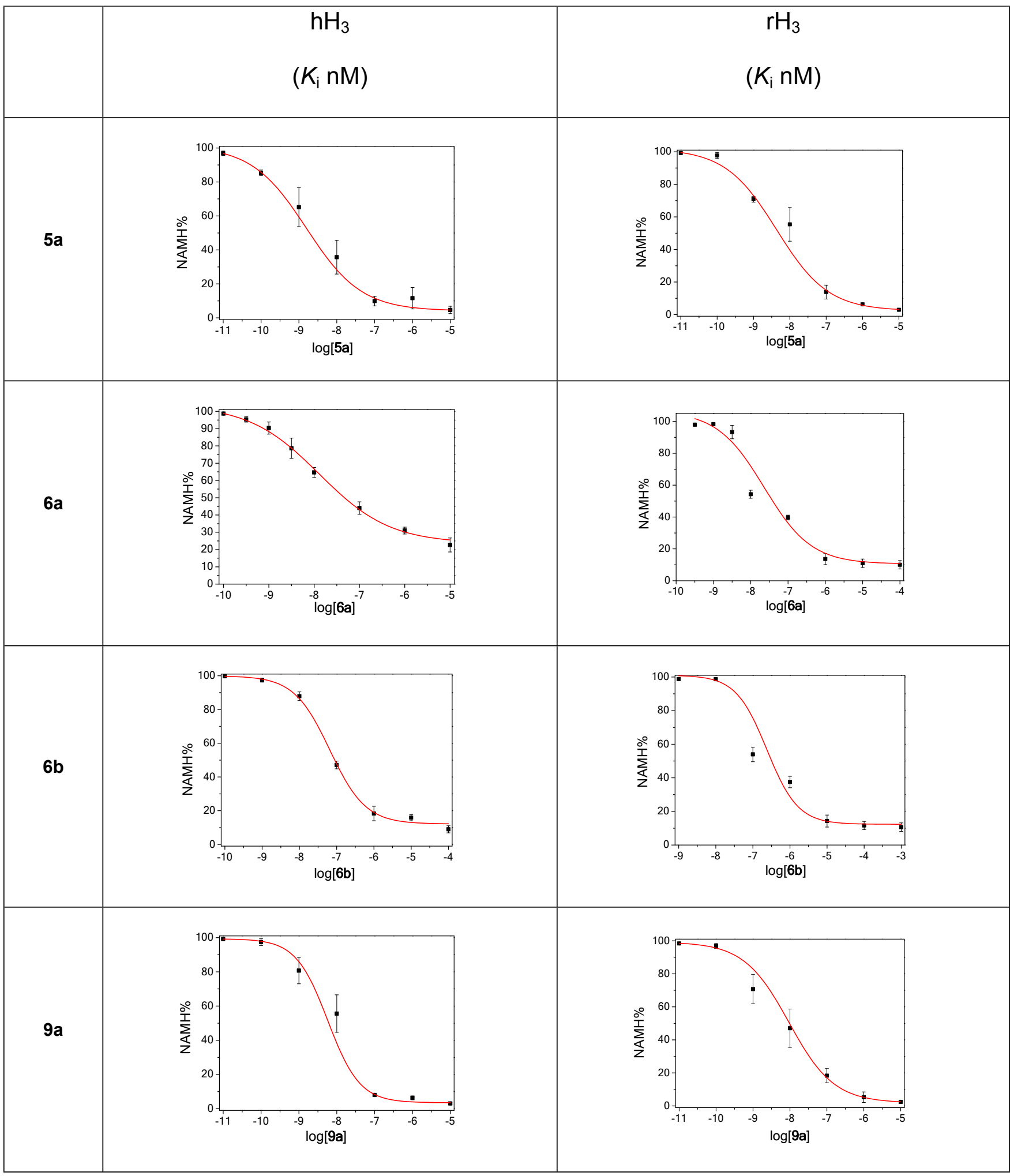




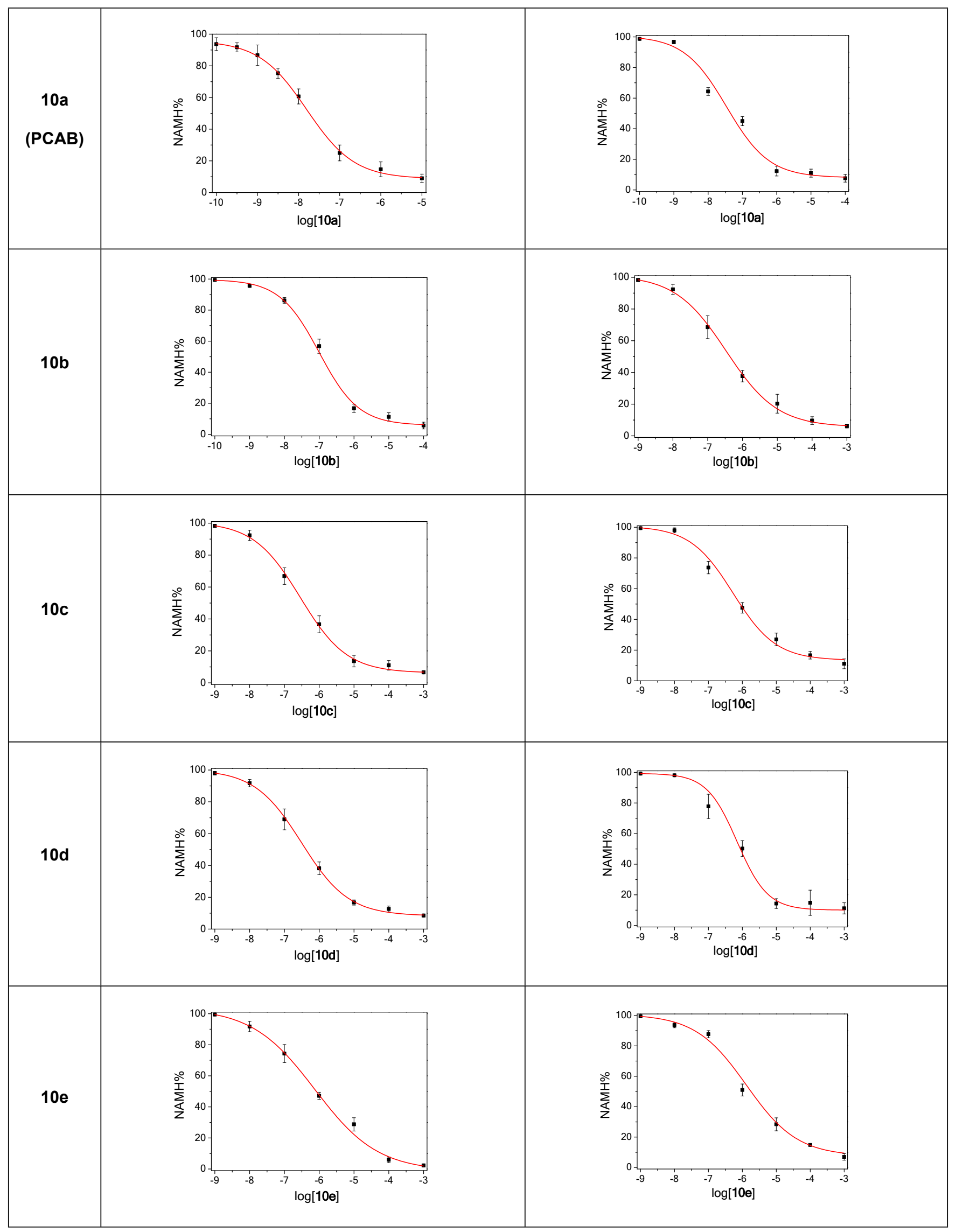


Table S2. The in vitro binding affinities of PCAB with different human histamine receptors.

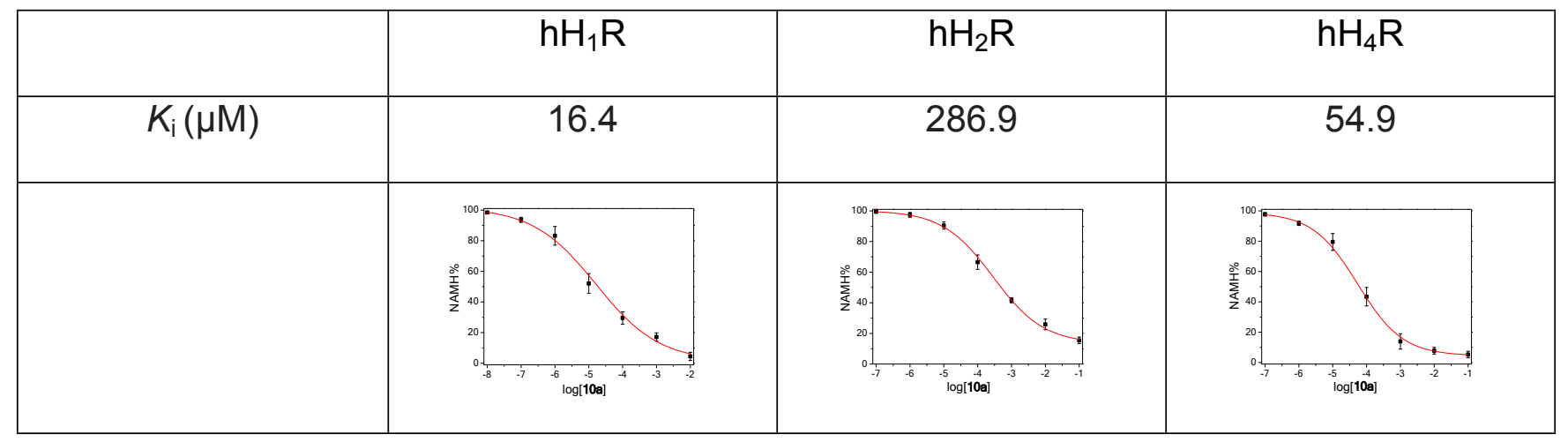




\section{Photophysical properties}

\section{Determination of the fluorescence quantum yield of PCAB}

Quantum yields of one-photon emission of synthesized PCAB was measured with fluorescein (FLS, dissolved in $0.1 \mathrm{M}$ NaOH aqueous solution) as reference. The one- photon fluorescence measurements were performed in $1 \mathrm{~cm}$ quartz cells with $1 \mu \mathrm{M}$ compound in DMSO or DCM on a fluorescence lifetime and steady state spectrophotometer (Edinburgh Instrument FLS920) equipped $450 \mathrm{~W}$ Xenon light, slits $2.5 \times 2.5$. The values of fluorescence quantum yield, $\Phi$ (sample), were calculated according to equation as following: [3]

$$
\Phi_{\text {sample }}=\Phi_{\text {ref }} \cdot \frac{O D_{\text {ref }} \cdot I_{\text {sample }} \cdot d_{\text {sample }}^{2}}{O D_{\text {sample }} \cdot I_{\text {ref }} \cdot d_{\text {ref }}^{2}}(\mathbf{1})
$$

$\Phi_{\text {ref }}$ : The values of fluorescence quantum yield of the reference.

$\Phi_{F L S}=0.92 .{ }^{[4]}$

I: integrated emission intensity.

OD: optical density at the excitation wavelength.

$\mathrm{d}$ : the refractive index of solvents

$d_{\mathrm{DMSO}}=1.478, d_{\mathrm{DCM}}=1.444, d_{\mathrm{H} 2 \mathrm{O}}=1.333, d_{\mathrm{MeOH}}=1.329$ 
Table S3. Photophysical properties of PCAB before and after the treatment of $\mathrm{H}_{2} \mathrm{O}_{2} \cdot{ }^{\text {a }}$

\begin{tabular}{|c|c|c|c|c|}
\hline & $\varepsilon\left(\mathrm{cm}^{2} / \mathrm{mol}\right)^{\mathrm{b}}$ & $\operatorname{UV}\left(\lambda_{\max }\right)$ & $\operatorname{Ex/Em}\left(\lambda_{\max }\right)$ & $\Phi^{c}$ \\
\hline before & 0.74 & 318 & $300 / 427$ & $0.015 / 0.006$ \\
\hline after & 0.92 & 360 & $340 / 515$ & $0.12 / 0.138$ \\
\hline
\end{tabular}

a All data were measured in DMSO at $298 \mathrm{~K} .{ }^{\mathrm{b}}$ Extinction coefficient in $1 \times 10^{4} \mathrm{M}^{-1} \mathrm{~cm}^{-1}$. ${ }^{\mathrm{c}}$ Quantum yields in DMSO and PBS buffer, respectively.
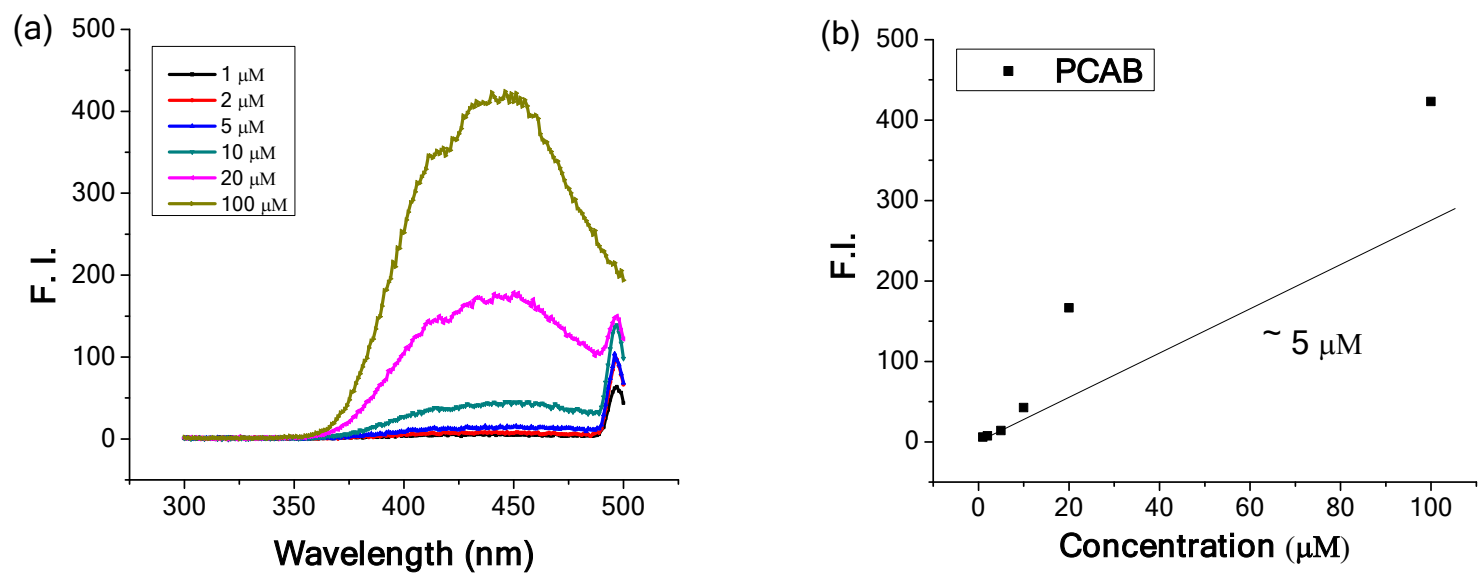

Figure S1. Plot of fluorescence intensity against PCAB concentration in PBS buffer (3 mM PBS, pH 7.4) 


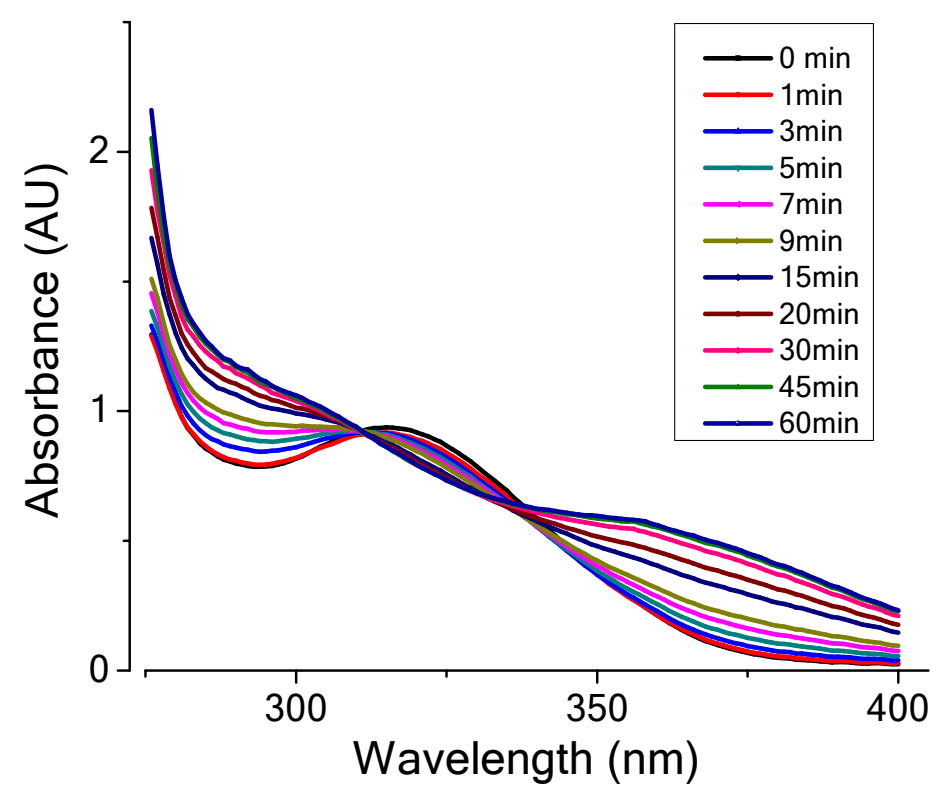

Figure S2. Time-dependent UV spectra of PCAB with addition of $\mathrm{H}_{2} \mathrm{O}_{2}$.
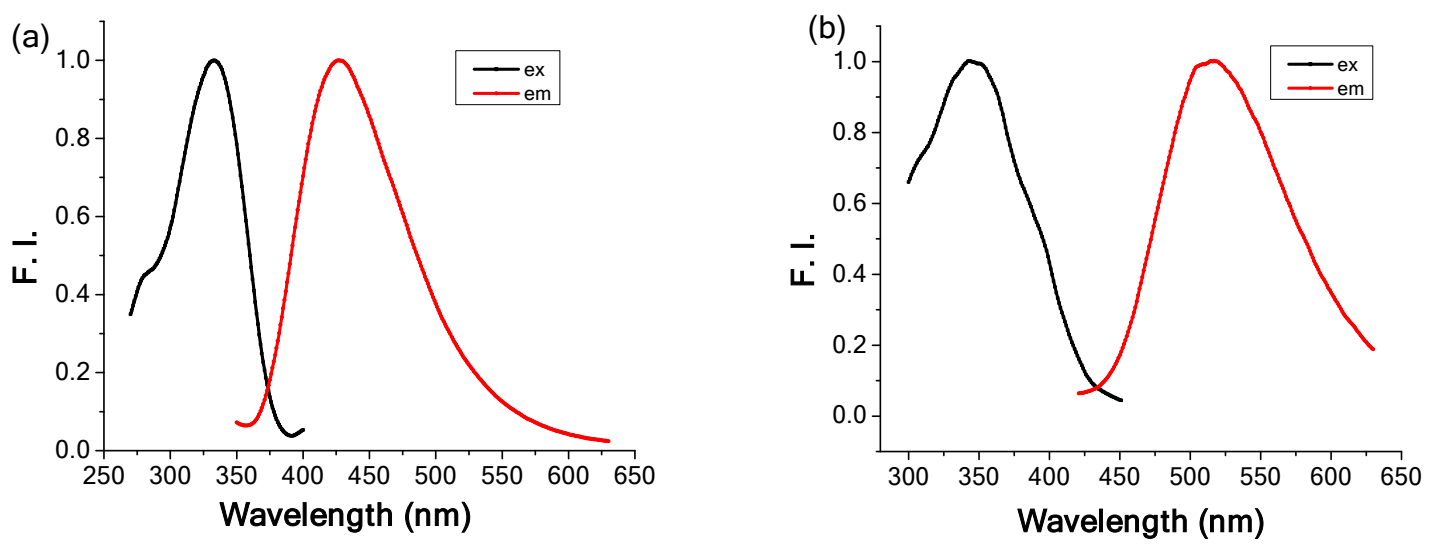

Figure S3. Normalized excitation and emission spectra for (a) PCAB and (b) 9a in PBS buffer. 


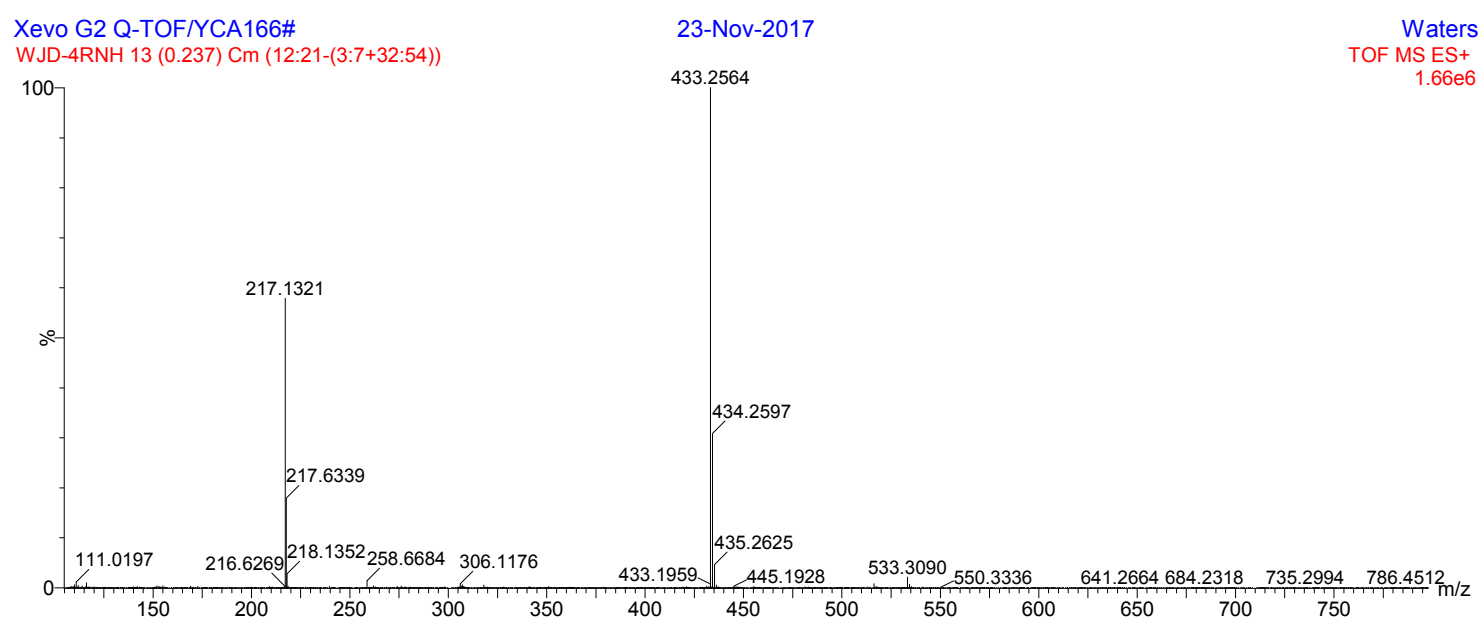

Figure S4. MS spectrum of PCAB after the treatment of $\mathrm{H}_{2} \mathrm{O}_{2}$.
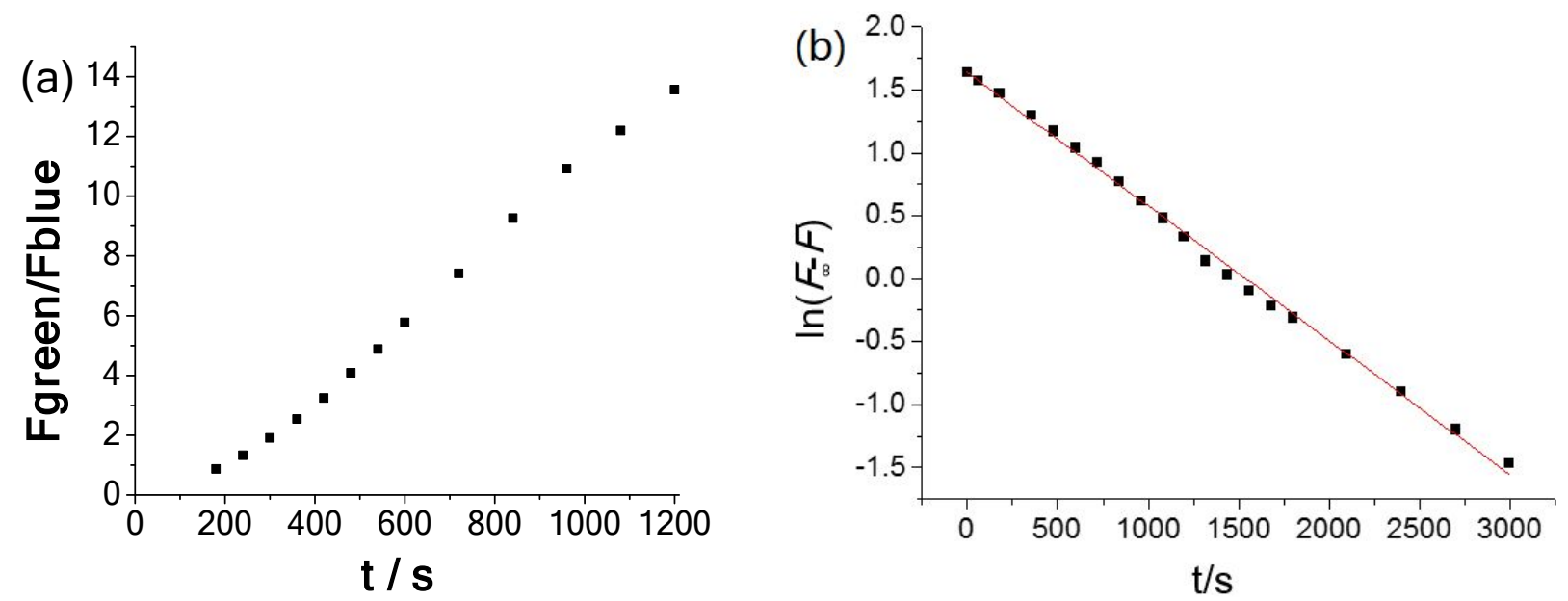

Figure S5. Fluorescenece responses of PCAB $(10 \mu \mathrm{M})$ to $1 \mathrm{mM} \mathrm{H}_{2} \mathrm{O}_{2}$ with excitation at $320 \mathrm{~nm}$. The $k_{\text {obs }}$ was obtained from plot using excitation wavelength at $320 \mathrm{~nm}$. 


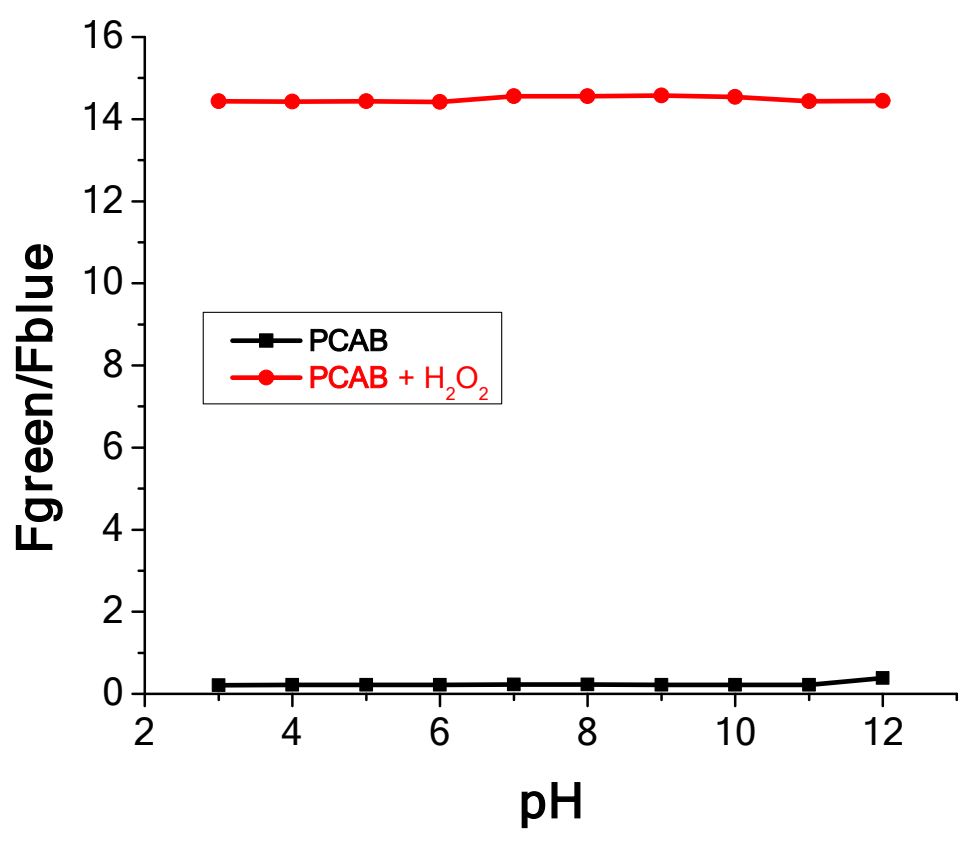

Figure S6. Ratio changes of $\mathrm{pH}$-dependent fluorescent intensity of PCAB $(5 \mu \mathrm{M})$ toward $\mathrm{H}_{2} \mathrm{O}_{2}(5 \mu \mathrm{M})$, in PBS buffer $(25$ $\mathrm{mM}, \mathrm{pH}=3-12):$ glycerol $(4: 6, \mathrm{v} / \mathrm{v}), \lambda_{\mathrm{ex}}: 320 \mathrm{~nm}$. 
Determination of the two-photon absorption cross section of PCAB.

The two-photon absorption spectra of PCAB was determined over a broad spectral region (700 $\mathrm{nm}$ to $900 \mathrm{~nm})$ by the typical two-photon induced fluorescence method relative to fluorescein as standard. The two-photon fluorescence data were acquired using a Tsunami femtosecond Ti: Sapphire laser (pulse width $\leq 100 \mathrm{fs}, 80 \mathrm{MHz}$ repetition rate, tuning range $700-900 \mathrm{~nm}$ Spectra Physics Inc., USA). The two-photon fluorescence measurements were performed in a $1 \mathrm{~cm}$ quartz cell with $1 \times 10^{-4}$ mol/L sample dissolved in DMSO and the excitation power density is set to be $100 \mathrm{~mW}$. The two-photon absorption cross section of PCAB $\left(\delta_{\text {sample }}\right)$ was calculated at every $10 \mathrm{~nm}$ wavelength from $700 \mathrm{~nm}$ to $900 \mathrm{~nm}$ according to equation as following:

$$
\delta_{\text {sample }}=\delta_{\text {ref }} \cdot \frac{\Phi_{\text {ref }} \cdot C_{r e f} \cdot I_{\text {sample }} \cdot d_{\text {sample }}}{\Phi_{\text {sample }} \cdot C_{\text {sample }} \cdot I_{\text {ref }} \cdot d_{\text {ref }}}(\mathbf{2})
$$

$\delta_{\text {ref: }}$ Two-photon absorption cross section of fluorescein from the previous literature. ${ }^{[5]}$

$\Phi$ : Quantum yield of sample and reference.

I: Integrated emission intensity.

C: Concentration of each sample.

$\mathrm{d}$ : The refractive index of solvents. 


\section{Photostability of PCAB}

PCAB was dissolved in DMSO/ $\mathrm{H}_{2} \mathrm{O}(\mathrm{v} / \mathrm{v}=5: 95)$ solution for longer than 3 days. The electron spectra were obtained with an Agilent $8453 \mathrm{UV} /$ vis spectrophotometer in $10 \mathrm{~mm}$ path length quartz cuvettes.

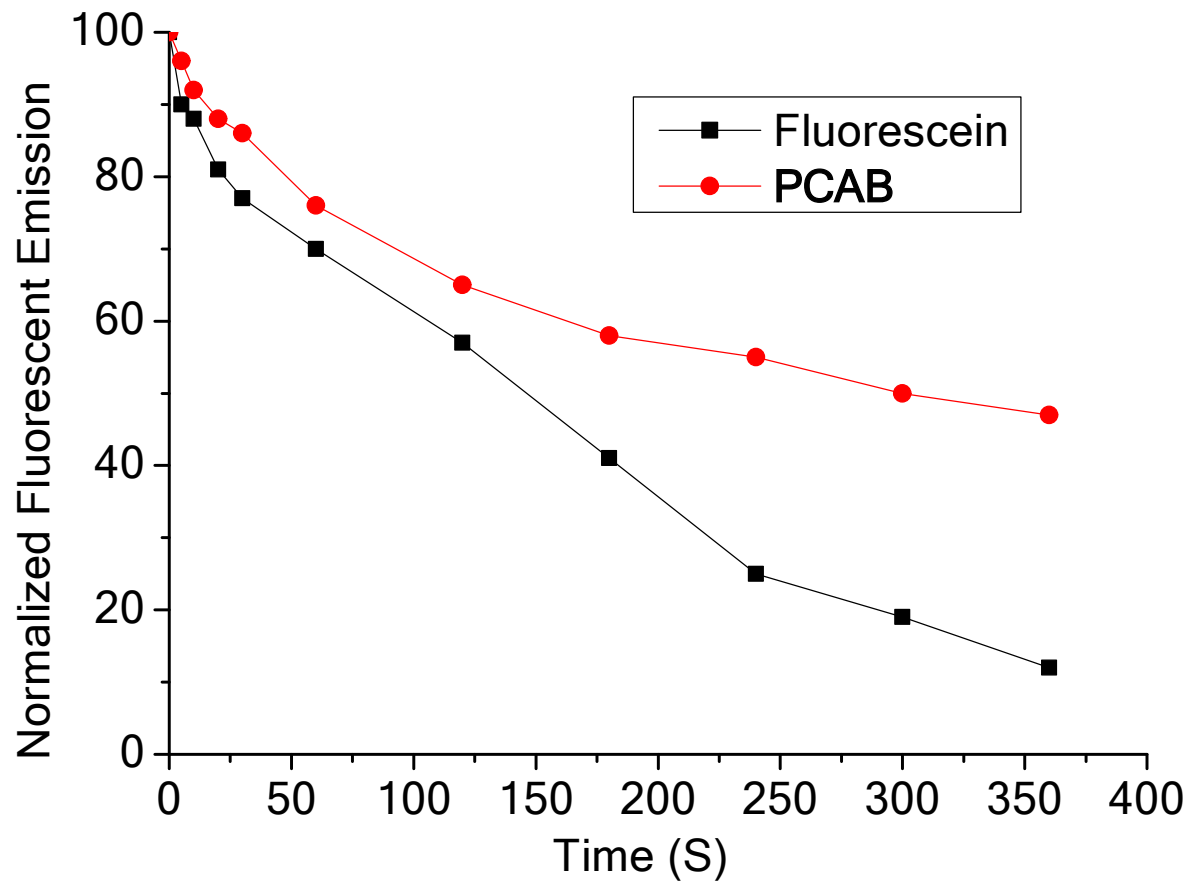

Figure S7. Emission spectra of PCAB and fluorescein after 0, 5, 10, 20, 30, 60, 120, 180, 240, 300, and 360 seconds of UV-light exposure. 


\section{Biosafety of PCAB}

\subsection{Cell viability.}

The cytotoxicity assays were conducted according to the literature. ${ }^{[6]}$ SH-SY5Y cells were seeded in flatbottomed 96-well plates, 104 cells per well, with $200 \mu \mathrm{L}$ complete culture media in the dark for $24 \mathrm{~h}$. After washed with PBS for three times (200 $\mu \mathrm{L} * 3)$, the cells were incubated with appropriate concentrations of PCAB. All stock solutions were prepared in DMSO and diluted with complete media, and the final DMSO concentrations were less than $0.1 \%$. After cultured for $24 \mathrm{~h}$, the cells were washed with PBS $(200 \mu \mathrm{L} * 3) .10 \mu \mathrm{L}$ Cell Counting Kit-8 (CCK8) solution and $90 \mu \mathrm{L}$ PBS were added per well simultaneously. After 2 hours, the absorbance at $450 \mathrm{~nm}$ was read by $96-$-well plate reader. The viability of cells was calculated by the following equation:

$$
\mathrm{CV}=(\mathrm{As}-\mathrm{Ab}) /(\mathrm{Ac}-\mathrm{Ab}) \times 100 \%
$$

where CV stands for the viability of cells, As, Ac and Ab stand for the absorbance of cells containing PCAB, cell control (0 $\mu$ M PCAB) and blank control (wells containing no cells or PCAB).

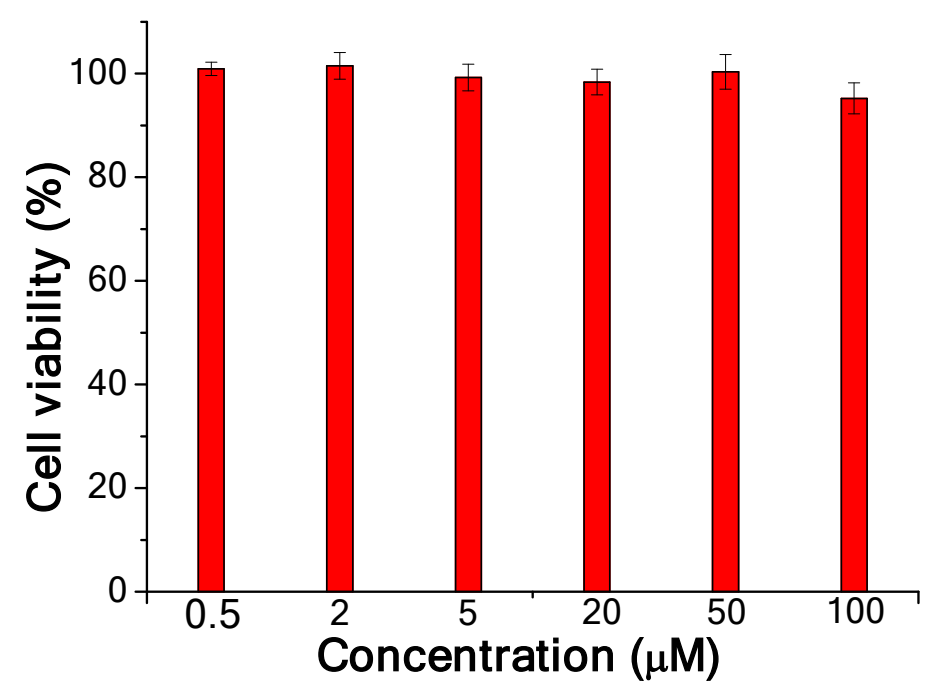

Figure S8. CCK-8 assays of PCAB. 


\subsection{Erythrocyte hemolysis.}

The erythrocyte toxicity assay was conducted as described by Wang et al. with modifications. ${ }^{[7]}$ In brief, $25 \mu \mathrm{L}$ of the erythrocyte stock dispersion was added to $450 \mu \mathrm{L}$ of saline containing different concentrations of PCAB ( 0.8/ 4/ 20/100 $\mu \mathrm{M}, 25 \mu \mathrm{L}$ ) and incubated in an Eppendorf Thermomixer (Hamburg, Germany) at a mixing frequency of $450 \mathrm{rpm}$ and a temperature of $37^{\circ} \mathrm{C}$ for $1 \mathrm{~h}$. Intact erythrocytes were removed by centrifugation at $10000 \mathrm{rpm}$ for $5 \mathrm{~min}$. Then, the absorbance of the resulting supernatant was measured at $540 \mathrm{~nm}$. Saline solution $(0.9 \% \mathrm{NaCl})$ was employed as a negative control ( $0 \%$ lysis) and $0.1 \%$ triton as a positive control $(100 \%$ lysis $)$. The hemolysis rate was calculated according to the following equation:

$$
\text { Hemolysis rate }(\%)=\frac{D_{t}-D_{n c}}{D_{p c}-D_{n c}} \times 100 \text { (4) }
$$

where $D_{t}, D_{n c}$, and $D_{p c}$ are the absorbance of the tested sample, negative control, and positive control, respectively. The experiments were performed in triplicate.
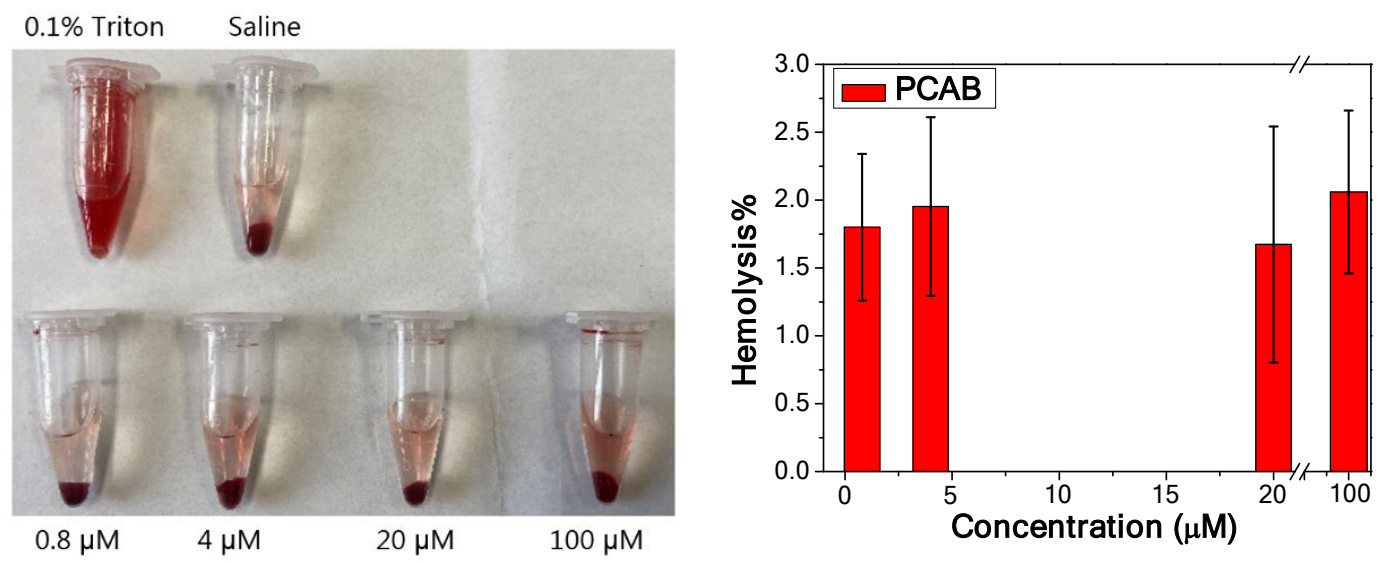

Figure S9. Hemolysis test of PCAB. 
6. Cell imaging
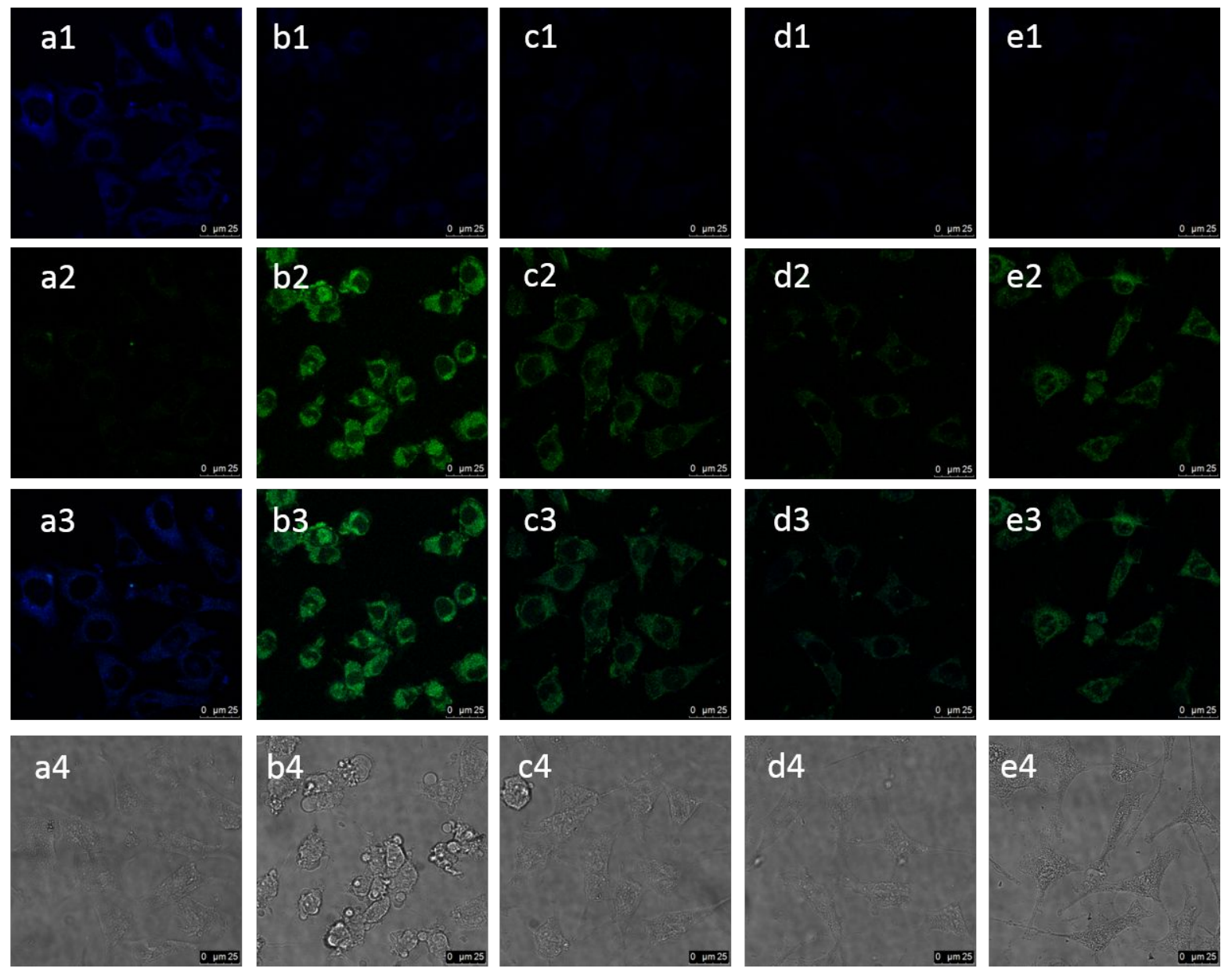

Figure S10. Detection of extracellular $\mathrm{H}_{2} \mathrm{O}_{2}$ by PCAB. Images captured in two channels. (1) Fluorescence captured from blue channel. (2) Fluorescence captured from green channel. (3) Overlap of two channels. (4) Bright fields. (a) SH-SY5Y cells incubated with PCAB. (b) PCAB $+\mathrm{H}_{2} \mathrm{O}_{2}$. (c) PCAB $+\mathrm{H}_{2} \mathrm{O}_{2}+$ melatonin. (d) PCAB $+\mathrm{H}_{2} \mathrm{O}_{2}+$ BAPTA. (e) PCAB $+\mathrm{H}_{2} \mathrm{O}_{2}+\mathrm{NAC}$. 


\section{OGD and OGD/R cellular model}

SH-SY5Y cells were subjected to OGD/R treatment. ${ }^{[8]}$ The regular medium Dulbecco's modified Eagle's Medium (DMEM) with 10\% fetal bovine serum (FBS, Gibco, Australia) was replaced with Earle's balanced saline solution (EBSS) without glucose. Cells were cultured in an anoxia chamber (Billups-Rothenberg, San Diego, USA) for 0$12 \mathrm{~h}$, and then re-cultured in DMEM (with 2\% FBS) at normal condition for 0-12 h. Melatonin, BAPTA and NAC were used as inhibitors to block the cellular $\mathrm{H}_{2} \mathrm{O}_{2}$ generation, respectively. The in vitro experiments were divided into 4 groups: OGD/R, OGD/R+melatonin, $\mathrm{OGD} / \mathrm{R}+\mathrm{BAPTA}$, and $\mathrm{OGD} / \mathrm{R}+\mathrm{NAC}$. Cells were pre-treated with indicated concentration of PCAB 10 min before anoxia.
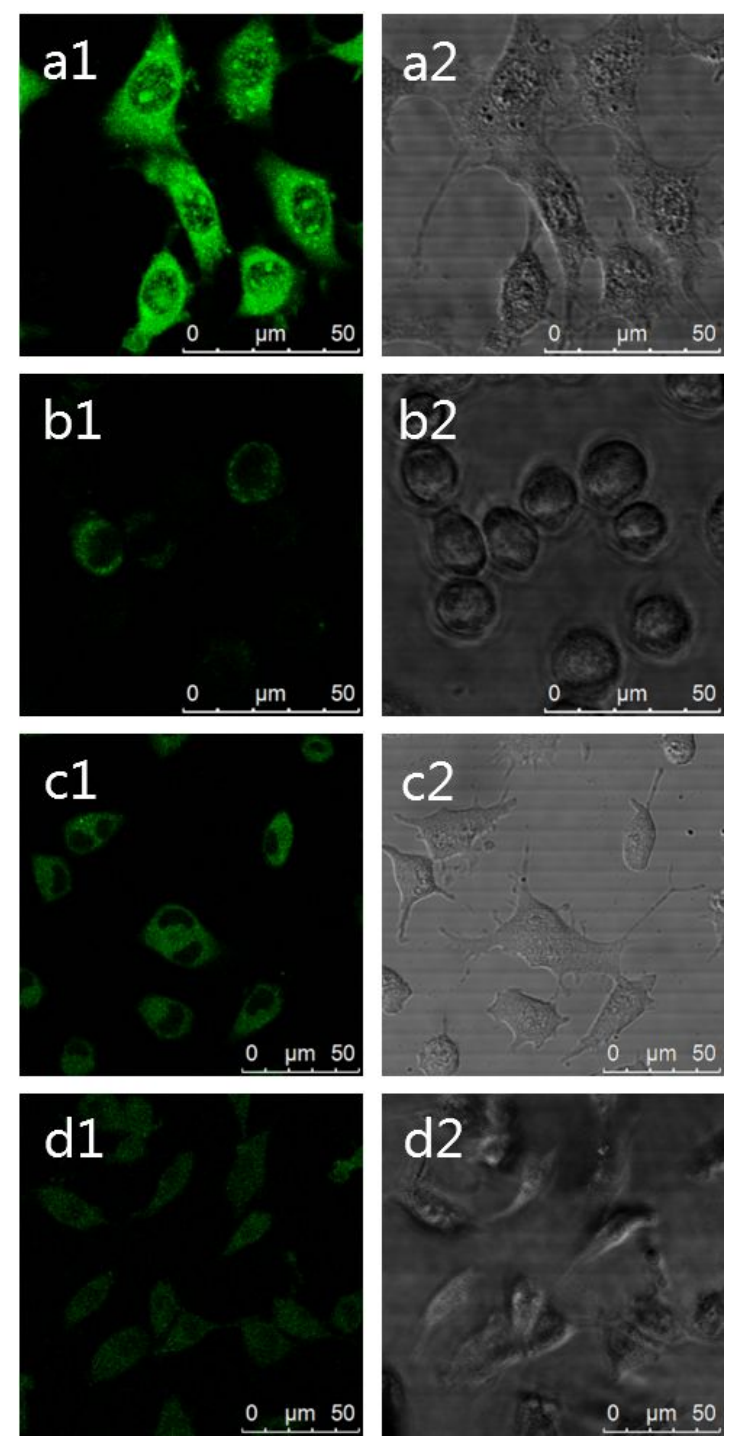

Figure S11. Fluorescent imaging of SH-SY5Y cells incubated by PCAB with/without different $\mathrm{H}_{2} \mathrm{O}_{2}$ scanvengers in OGD/R conditions. (a) PCAB. (b) PCAB+melatonin. (c) PCAB+BAPTA. (d) PCAB+NAC. 


\section{Animals for in vivo imaging}

Adult male BALB/c nude and KM mice (weighing 22-25 g) were purchased from the Laboratory Animal Center, Peking University Health Science Center. The experimental procedures and animal care administration were performed following the guidelines of Care and Use of Laboratory Animals by the Beijing Committee on Animal Care and Use in accordance with the Guide for the Care and Use of Laboratory Animals (1996, published by National Academy Press, 2101 Constitution Ave. NW, Washington, DC 20055, USA). The experiments were approved by the Committee on the Ethics of Animal Experiments of the Peking University Health Science Center (Approval No. LA 2020114).

\section{MCAO model in mice}

Cerebral Ischemia Reperfusion Injury was induced by middle cerebral artery occlusion (MCAO) in mice as described previously. ${ }^{[9]}$ Briefly, mice was anesthetized with chloral hydrate (500 mg/kg, ip), and a monofilament nylon suture was introduced into the internal carotid artery until its rounded tip reached the entrance of the MCA. After $1.5 \mathrm{~h}$, the monofilament was removed and the blood supply was restored. The cerebral blood flow was monitored using Doppler flow-probe (PeriFlux System 5000, Perimed AB, Jarfalla, Sweden) to indicate ischemia or reperfusion. After $0.5,1.0,1.5,2.0,3.0 \mathrm{~h}$ reperfusion, mouse were subjected to in vivo imaging, ex vivo fluorescent staining, and ex vivo TTC staining.

\section{In vivo imaging of MCAO mouse brain}

For in vivo imaging, mouse (weighing 22-25 g) were shaved before background imaging and were iv injected with PCAB $(0.4 \mathrm{mg} / \mathrm{kg}, 20 \%$ DMSO, 80\% propylene glycol, $50 \mu \mathrm{L})$. Fluorescent signals from the brain were recorded at different I/R time points after iv injection of PCAB. For the measurement, a filter set was used, and optical images were acquired using an exposure time of $1 \mathrm{~s}$. During the imaging process, the mice were kept on the imaging stage under anesthesia with $2.5 \%$ isoflurane gas in an oxygen flow $(1.5 \mathrm{~L} / \mathrm{min})$. Imaging data was analyzed by Living Image software, and an ROI was drawn around the brain region. Intensity of brain fluorescence was calculated from the photon counts. The data were analyzed by normalizing the fluorescence intensity to the background fluorescence of each mouse [i.e., $\mathrm{F}(\mathrm{t}) / \mathrm{F}(\mathrm{pre})]$, where $\mathrm{F}(\mathrm{t})$ is the fluorescence intensity of the time point of interest and $\mathrm{F}$ (pre) is the background fluorescence signal. 


\section{Ex vivo imaging of brain tissues}

After in vivo imaging, mouse of different reperfusion time point were anesthetized with chloral hydrate $(500 \mathrm{mg} / \mathrm{kg}$, i.p.) and transcardially perfused with cold normal saline. The brains were dissected rapidly, cut into five coronal slices, and stained with 2,3,5-triphenyte-tetrazolium chloride (TTC, 2\%) for $30 \mathrm{~min}$. The slices were then fixed in 4\% paraformaldehyde (PFA) overnight and photo-graphed with a digital camera (Power-Shot G12, Cannon). The white regions were defined as infarct regions. The infarct volume was calculated with ImageJ software by measuring the white regions of each slice across the thickness of every slice. Subsequently, two-photon fluorescence microscopy images of those brain slices were performed on a modified Olympus Fluoview FV1000MPE microscope system equipped with excitation light laser provided by a modelocked Ti: sapphire laser, (Mai Tai, Spectra-Physics Inc., USA). The microscopy settings were as follows: $16 \times$ immersion lens objective, a resolution of $512 \times 512,720 \mathrm{~nm}$ excitation wavelength, $30 \%$ laser power $(10 \mathrm{~mW})$.

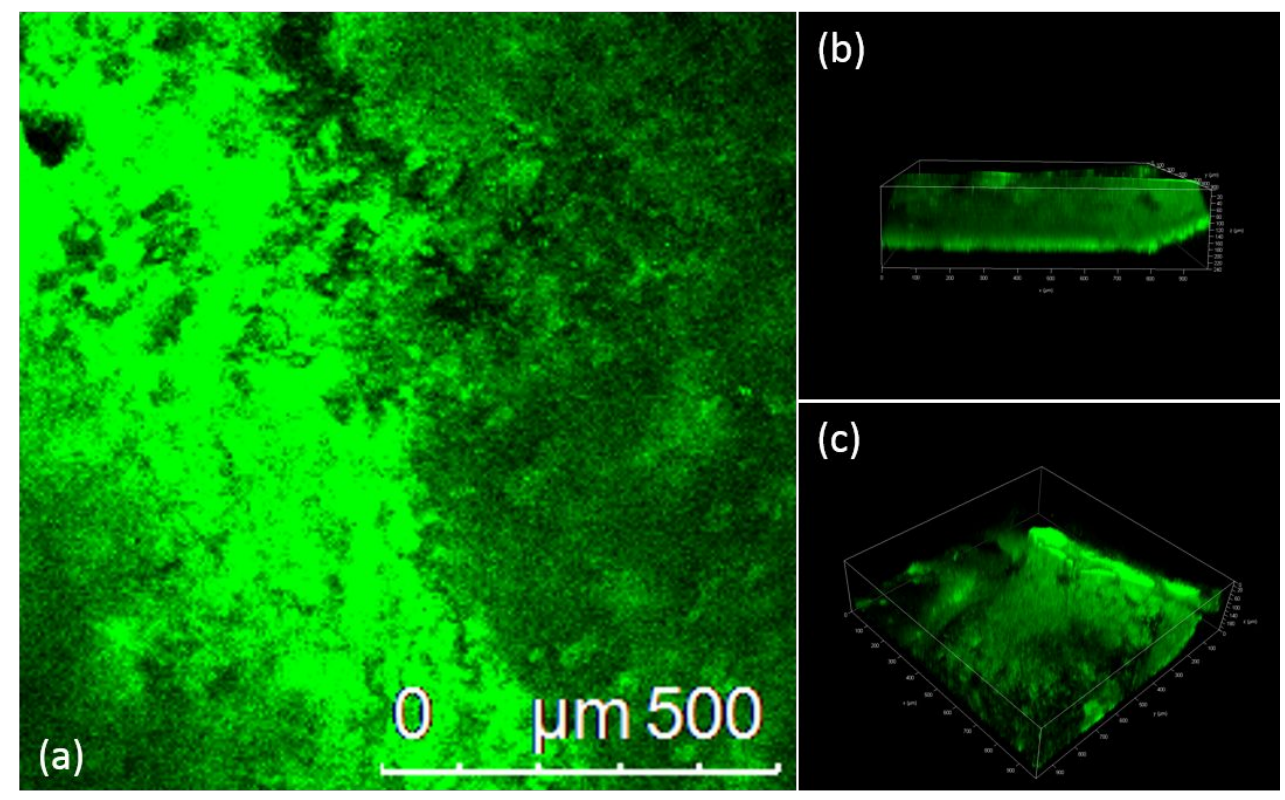

Figure S12. Fluorescent imaging of brain slice with PCAB captured by TPM. (a) Detailed fluorescent image of the brain slice. (b) and (c) Depth of the TPM fluorescent imaging of brain slice by PCAB.

\section{Western Bolt}

Protein samples were separated by SDS-PAGE (for $\beta$-actin) or Tricine-SDS-PAGE (for LC3), blotted onto PVDF membrane. The blots were blocked and incubated with primary and secondary antibodies. Anti-LC3 antibody (PM036-PN) was from MBL (Nagoya, Japan), and anti- $\beta$-actin antibody (sc-47,778) from Santa Cruz 
Biotechnology (Santa Cruz, USA). Immunoreactive bands were visualized using Chemiluminescent HRP Substrate (Millipore) and quantified using the Imagelab software.

\section{Transmission electron microscopy (TEM)}

Ultrastructural change was observed using TEM as described before. ${ }^{[10]}$ Briefly, the cerebral cortex of mice were fixed, dehydrated, stained and examined with a transmission electron microscope (JEM-1400, JEOL, Japan) and photographed. 


\section{NMR Spectra of isolated compounds}

tert-butyl(4-(3-(4-(3-bromopropoxy)phenyl)-6-oxopyridazin-1(6H)-yl)phenyl)(methyl)carbamate (3)

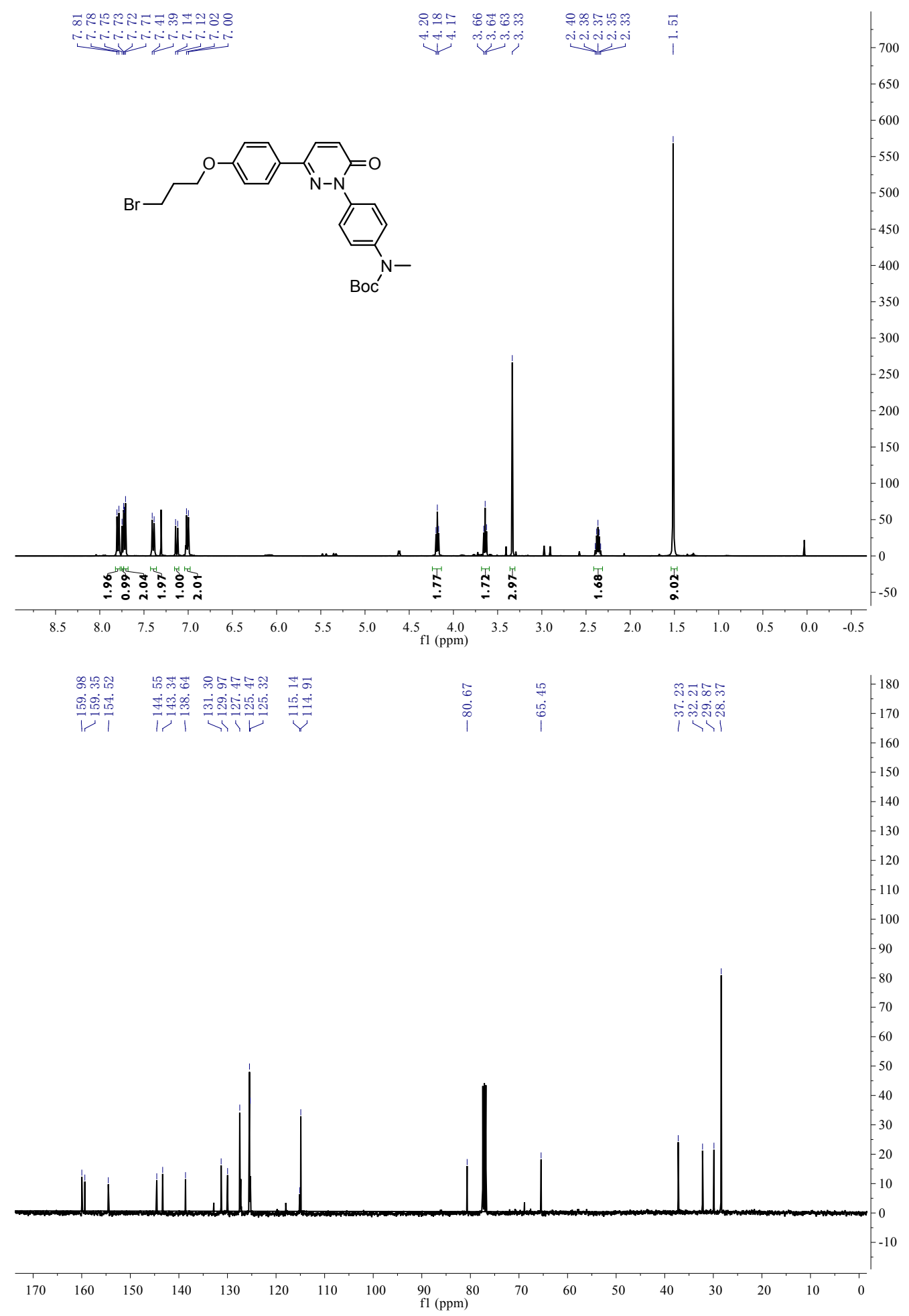


(R)-tert-butylmethyl(4-(3-(4-(3-(2-methylpyrrolidin-1-yl)propoxy)phenyl)-6-oxopyridazin-1(6H)-

yl)phenyl)carbamate (4a)

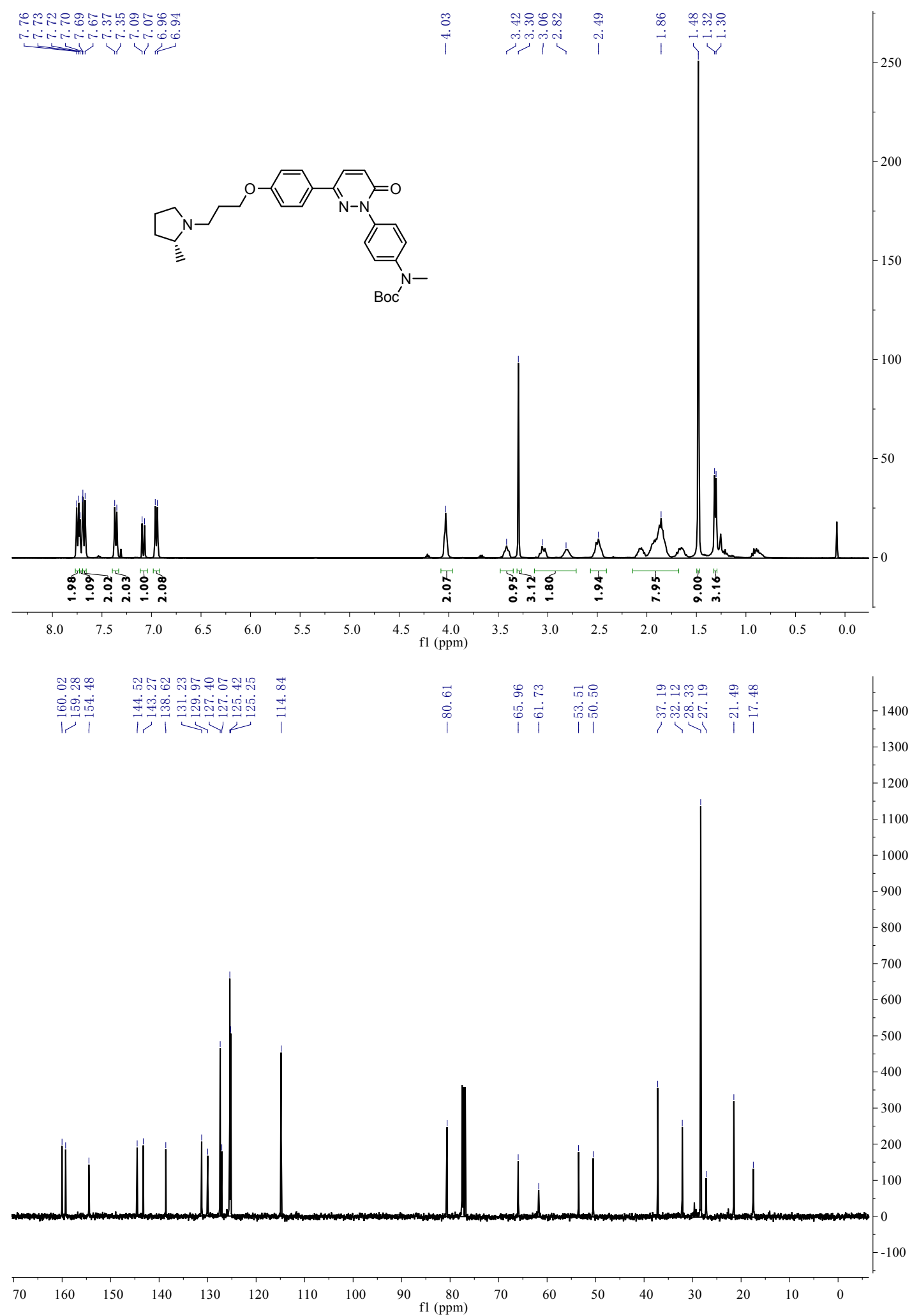


(S)-tert-butylmethyl(4-(3-(4-(3-(2-methylpyrrolidin-1-yl)propoxy)phenyl)-6-oxopyridazin-1(6H)-

yl)phenyl)carbamate (4b)

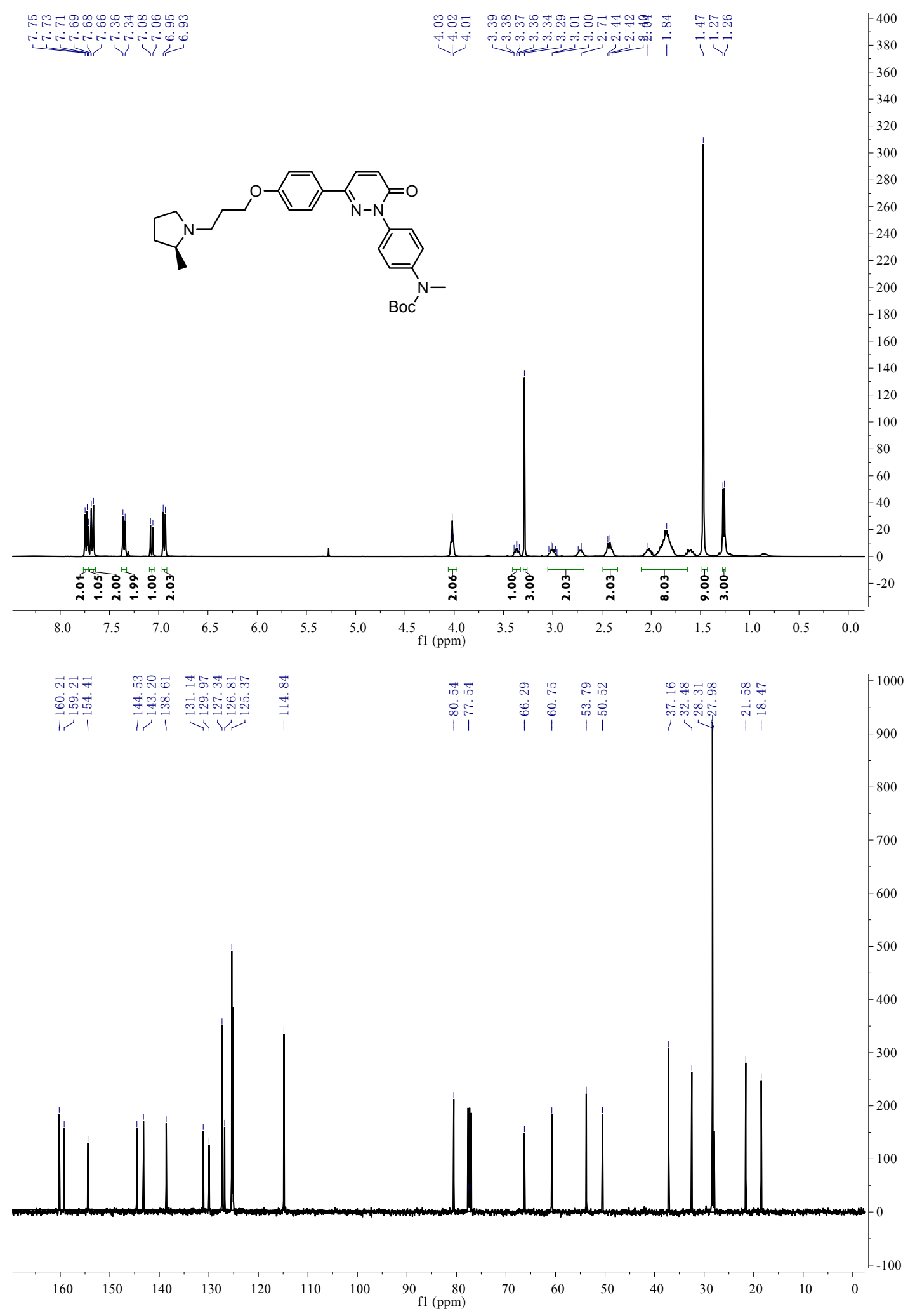


(R)-2-(4-(methylamino)phenyl)-6-(4-(3-(2-methylpyrrolidin-1-yl)propoxy)phenyl)pyridazin-3(2H)-one (5a)

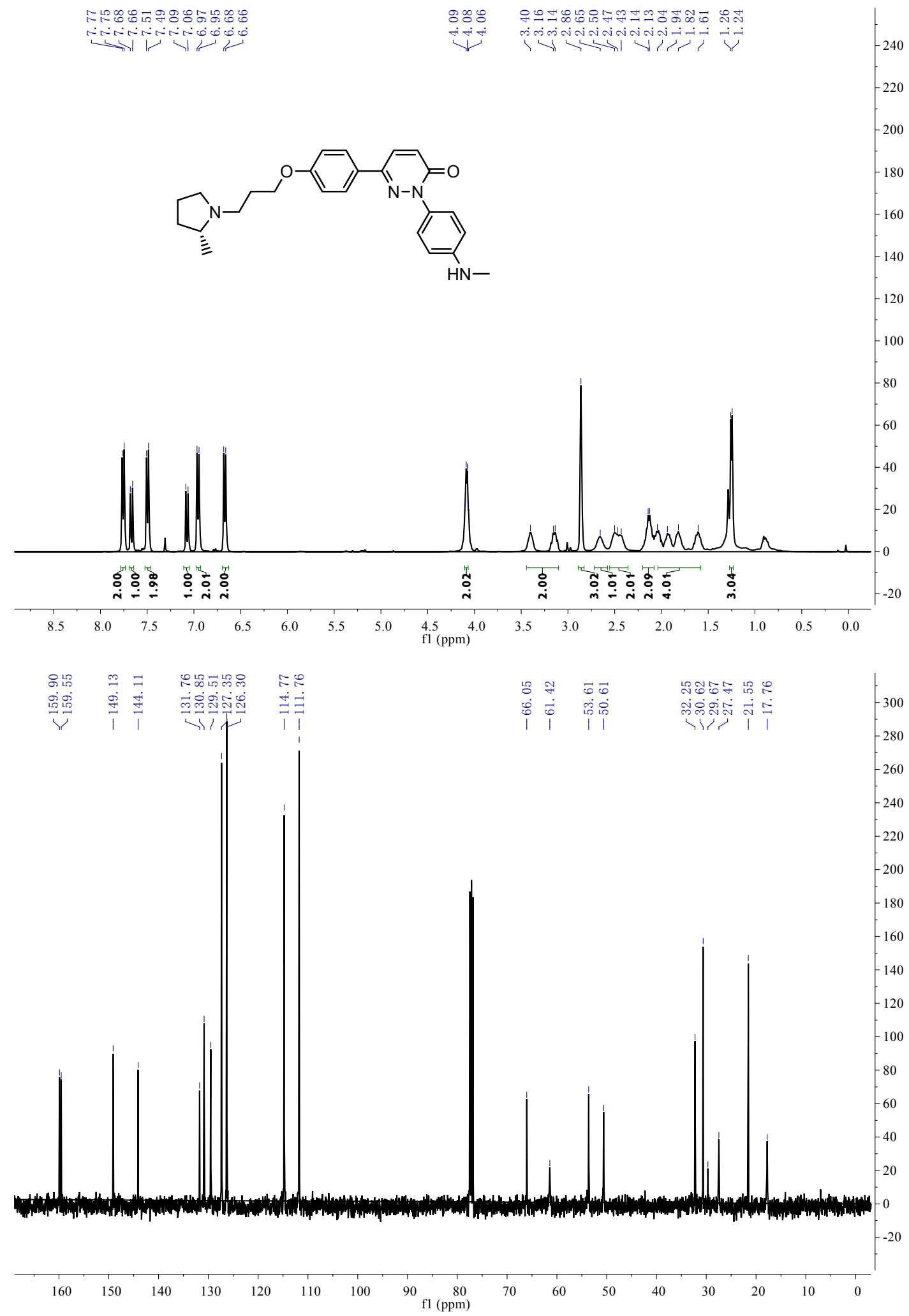


(S)-2-(4-(methylamino)phenyl)-6-(4-(3-(2-methylpyrrolidin-1-yl)propoxy)phenyl)pyridazin-3(2H)-one (5b)

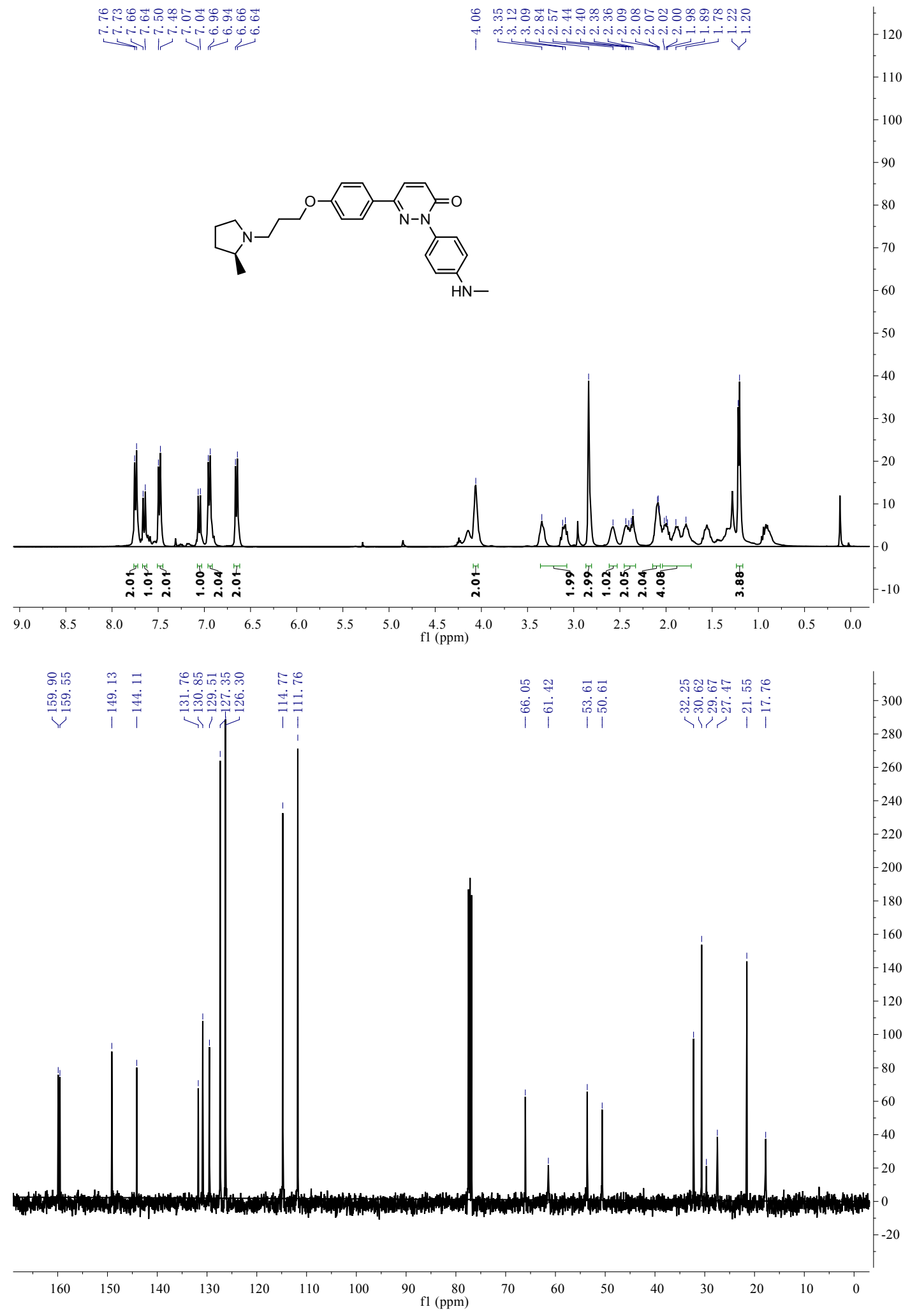


(R)-4-(4,4,5,5-tetramethyl-1,3,2-dioxaborolan-2-yl)benzylmethyl(4-(3-(4-(3-(2-methylpyrrolidin-1yl)propoxy)phenyl)-6-oxopyridazin-1(6H)-yl)phenyl)carbamate (6a)

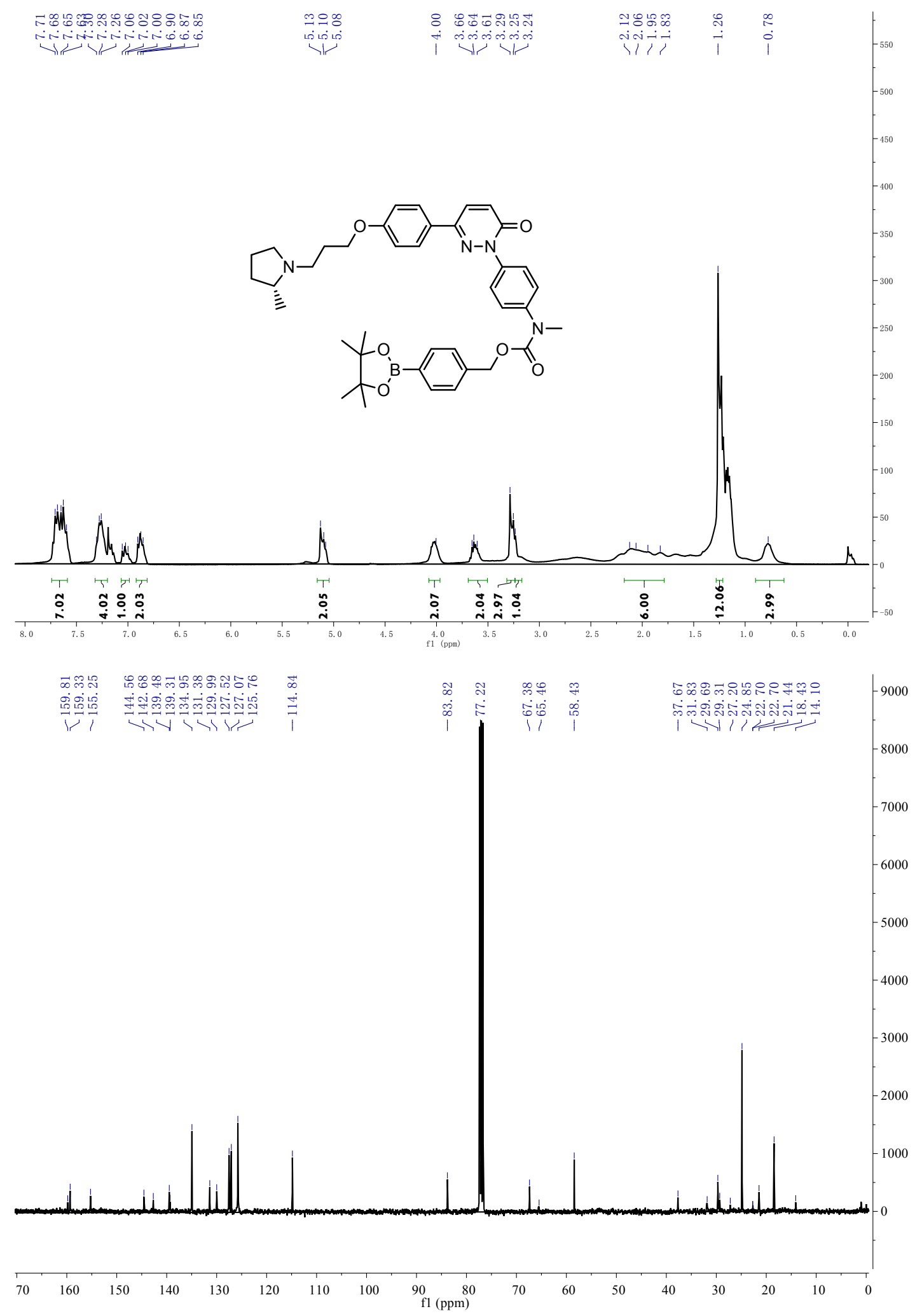


(S)-4-(4,4,5,5-tetramethyl-1,3,2-dioxaborolan-2-yl)benzylmethyl(4-(3-(4-(3-(2-methylpyrrolidin-1yl)propoxy)phenyl)-6-oxopyridazin-1(6H)-yl)phenyl)carbamate (6b)

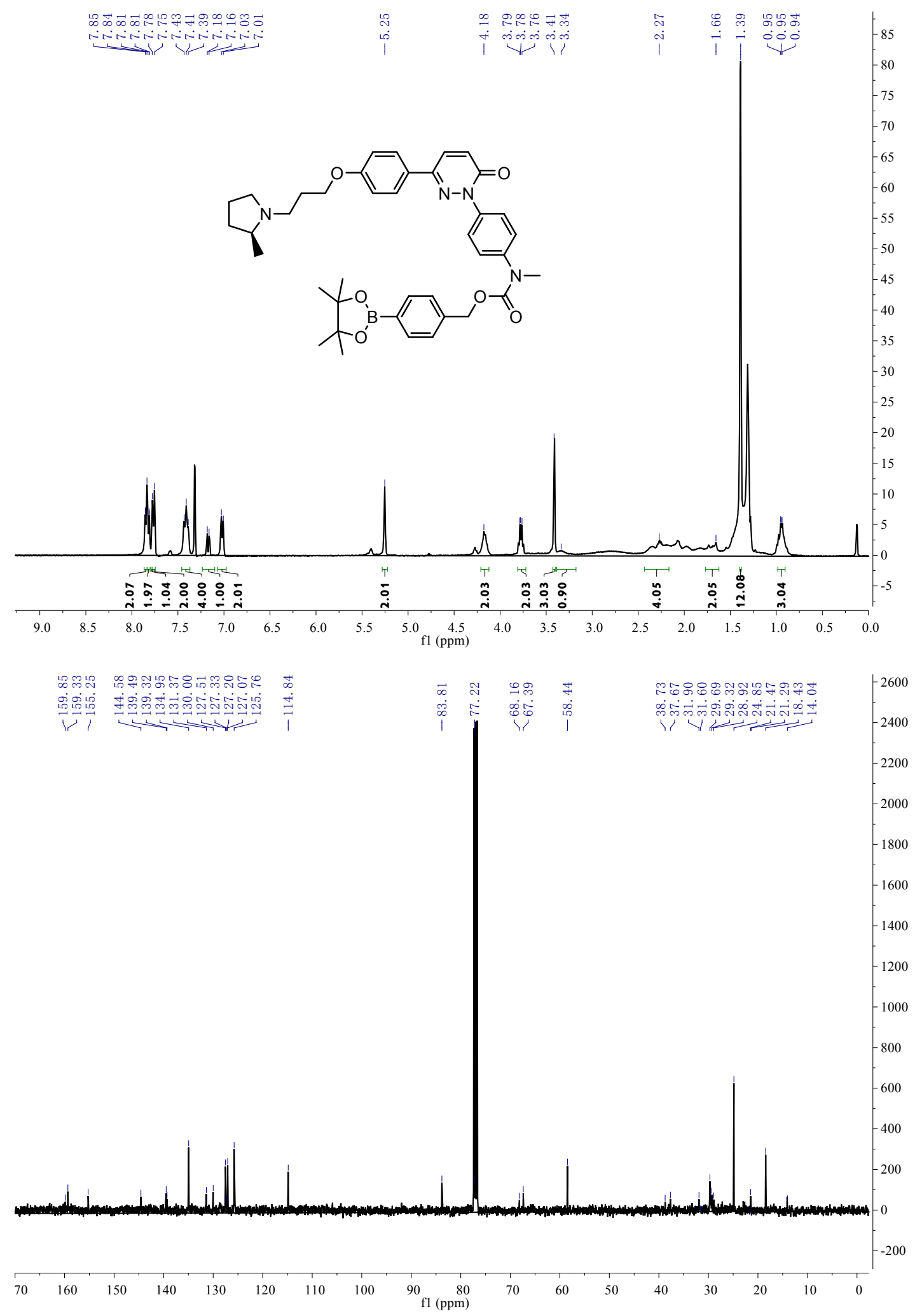

tert-butyl(4-(3-(4-(4-bromobutoxy)phenyl)-6-oxopyridazin-1(6H)-yl)phenyl)(methyl)carbamate (7) 


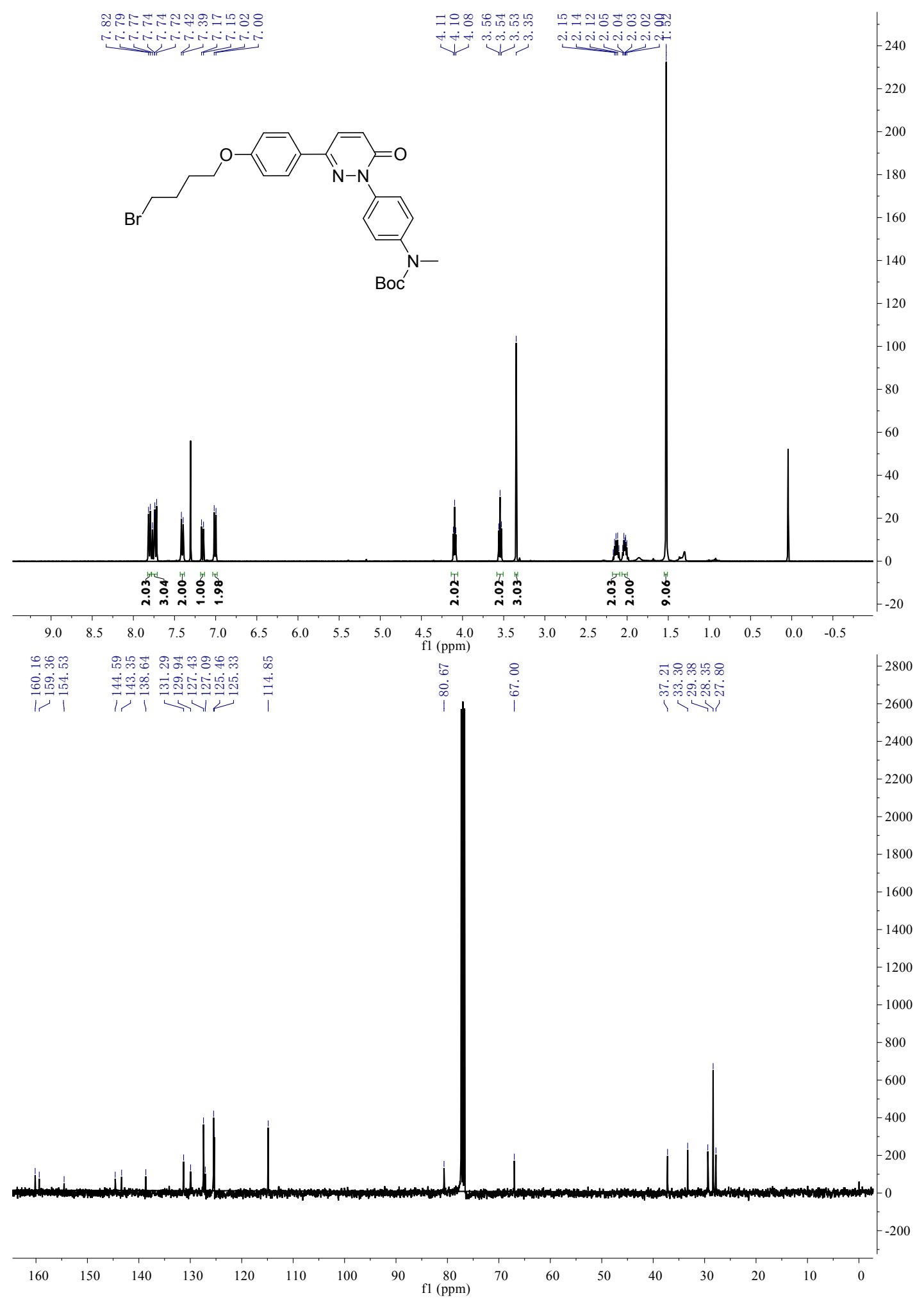


(R)-tert-butylmethyl(4-(3-(4-(4-(2-methylpyrrolidin-1-yl)butoxy)phenyl)-6-oxopyridazin-1(6H)yl)phenyl)carbamate (8a)

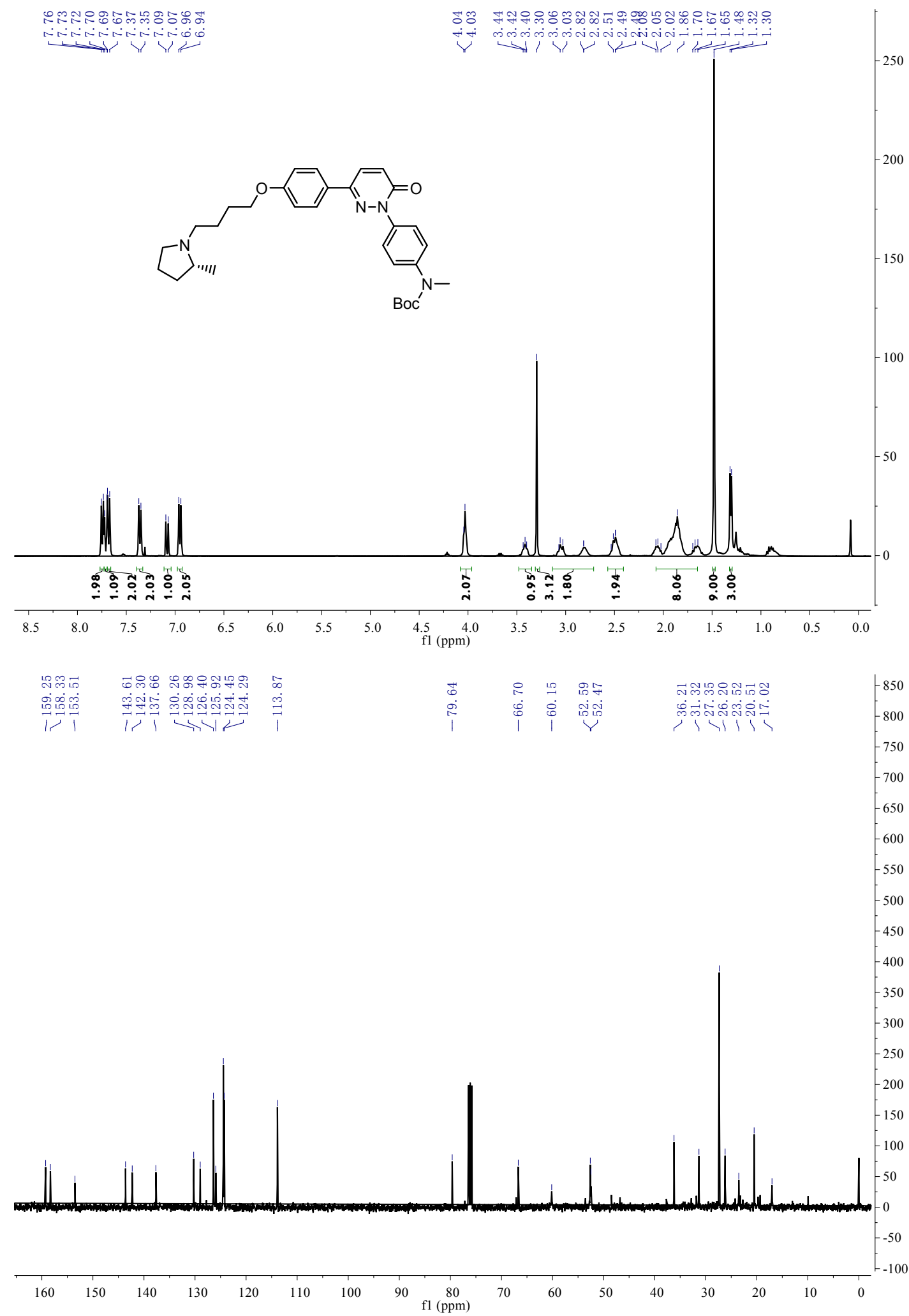


(S)-tert-butylmethyl(4-(3-(4-(4-(2-methylpyrrolidin-1-yl)butoxy)phenyl)-6-oxopyridazin-1(6H)yl)phenyl)carbamate (8b)

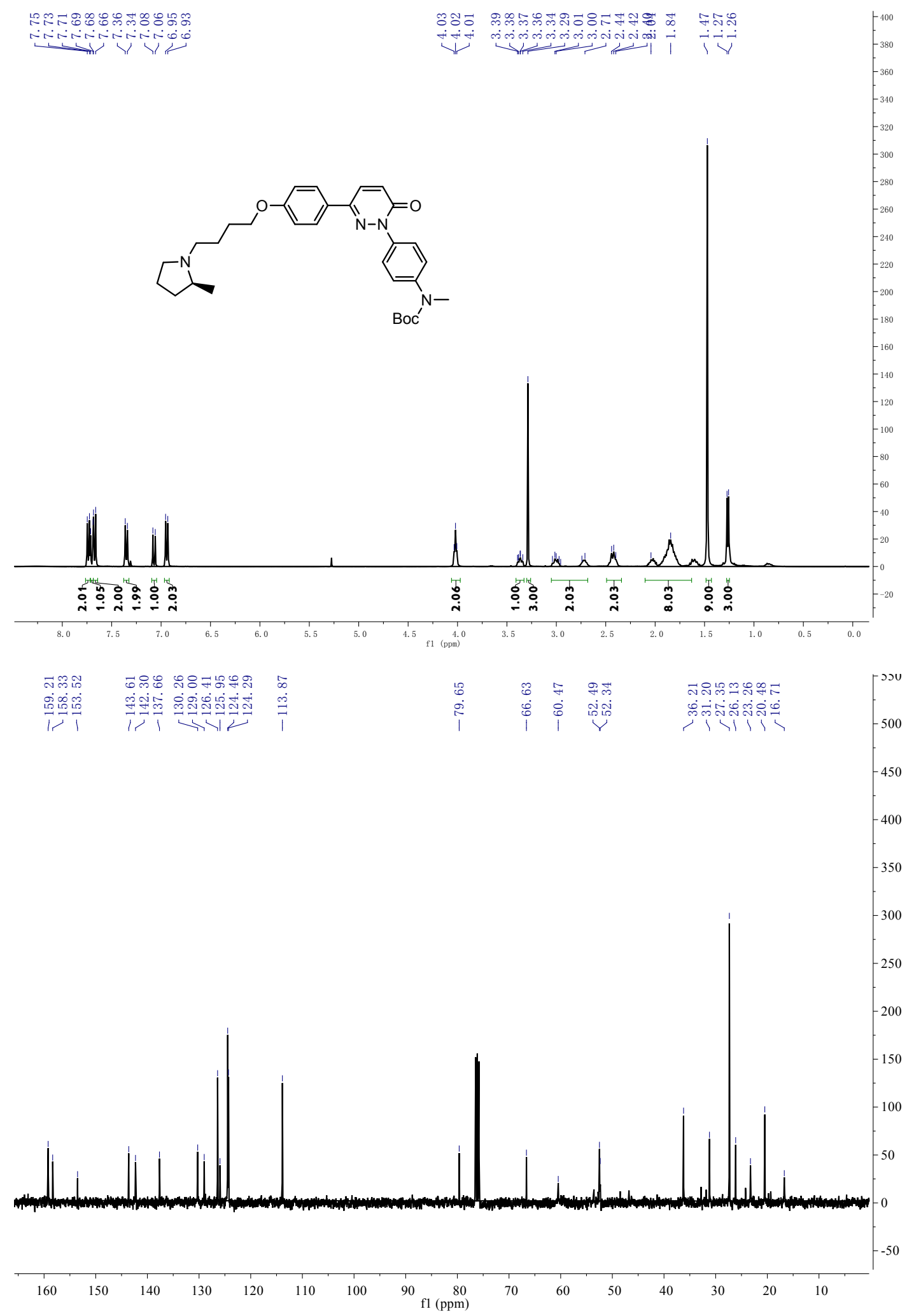


tert-butylmethyl(4-(6-oxo-3-(4-(4-(pyrrolidin-1-yl)butoxy)phenyl)pyridazin-1(6H)-yl)phenyl)carbamate

(8c)

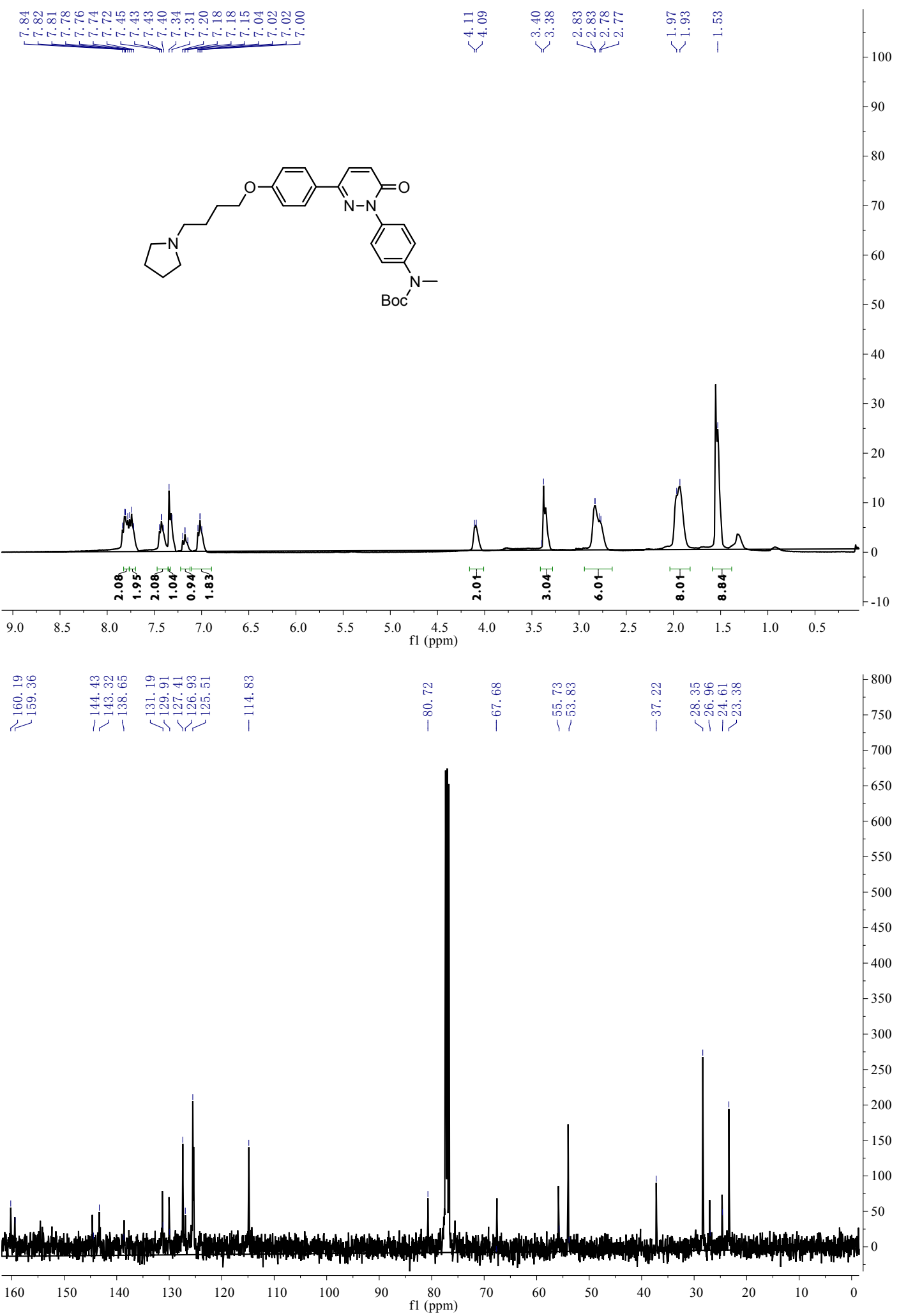


tert-butylmethyl(4-(6-oxo-3-(4-(4-(piperidin-1-yl)butoxy)phenyl)pyridazin-1(6H)-yl)phenyl)carbamate (8d)

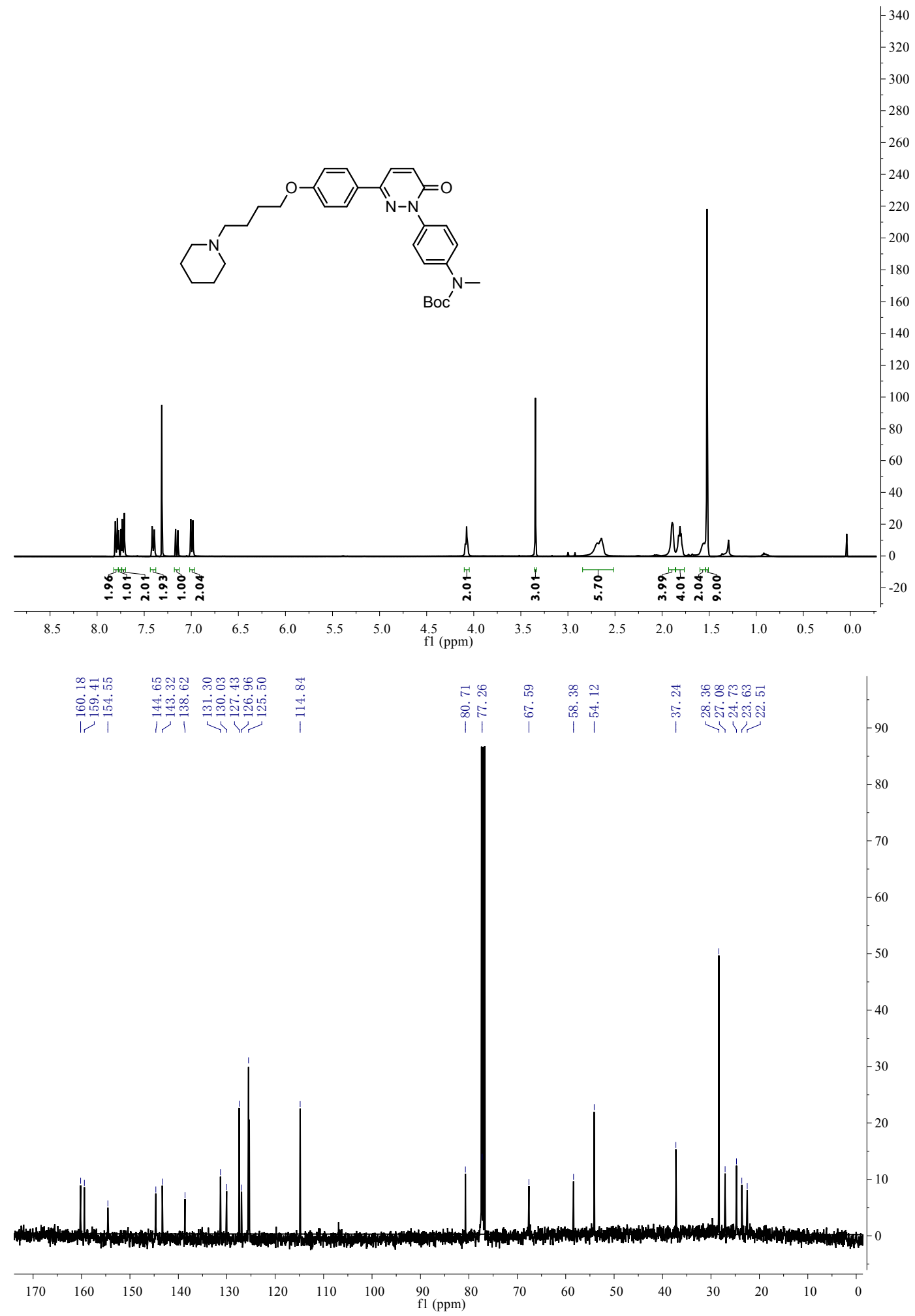


tert-butylmethyl(4-(3-(4-(4-morpholinobutoxy)phenyl)-6-oxopyridazin-1(6H)-yl)phenyl)carbamate (8e)

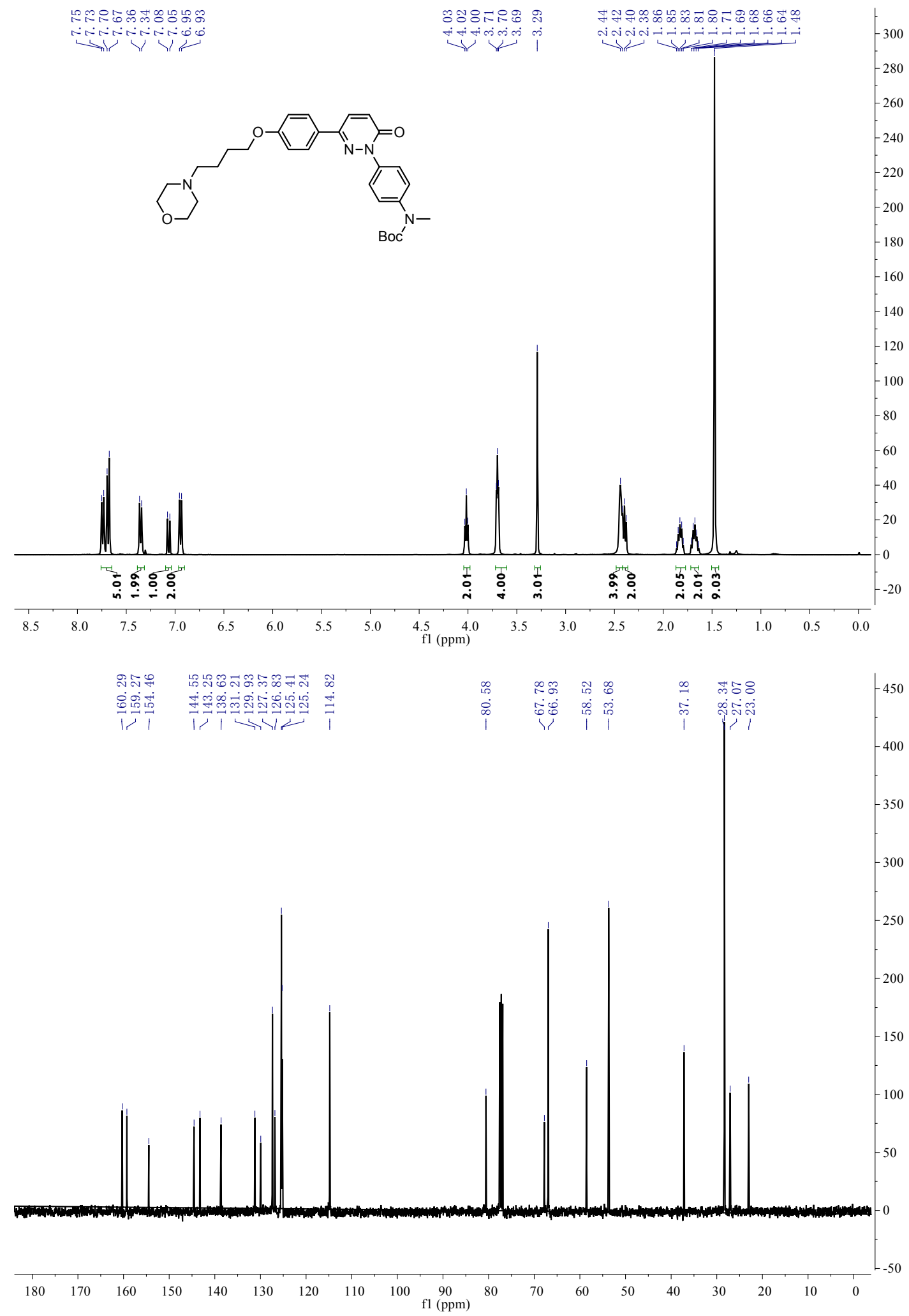


(R)-2-(4-(methylamino)phenyl)-6-(4-(4-(2-methylpyrrolidin-1-yl)butoxy)phenyl)pyridazin-3(2H)-one (9a)

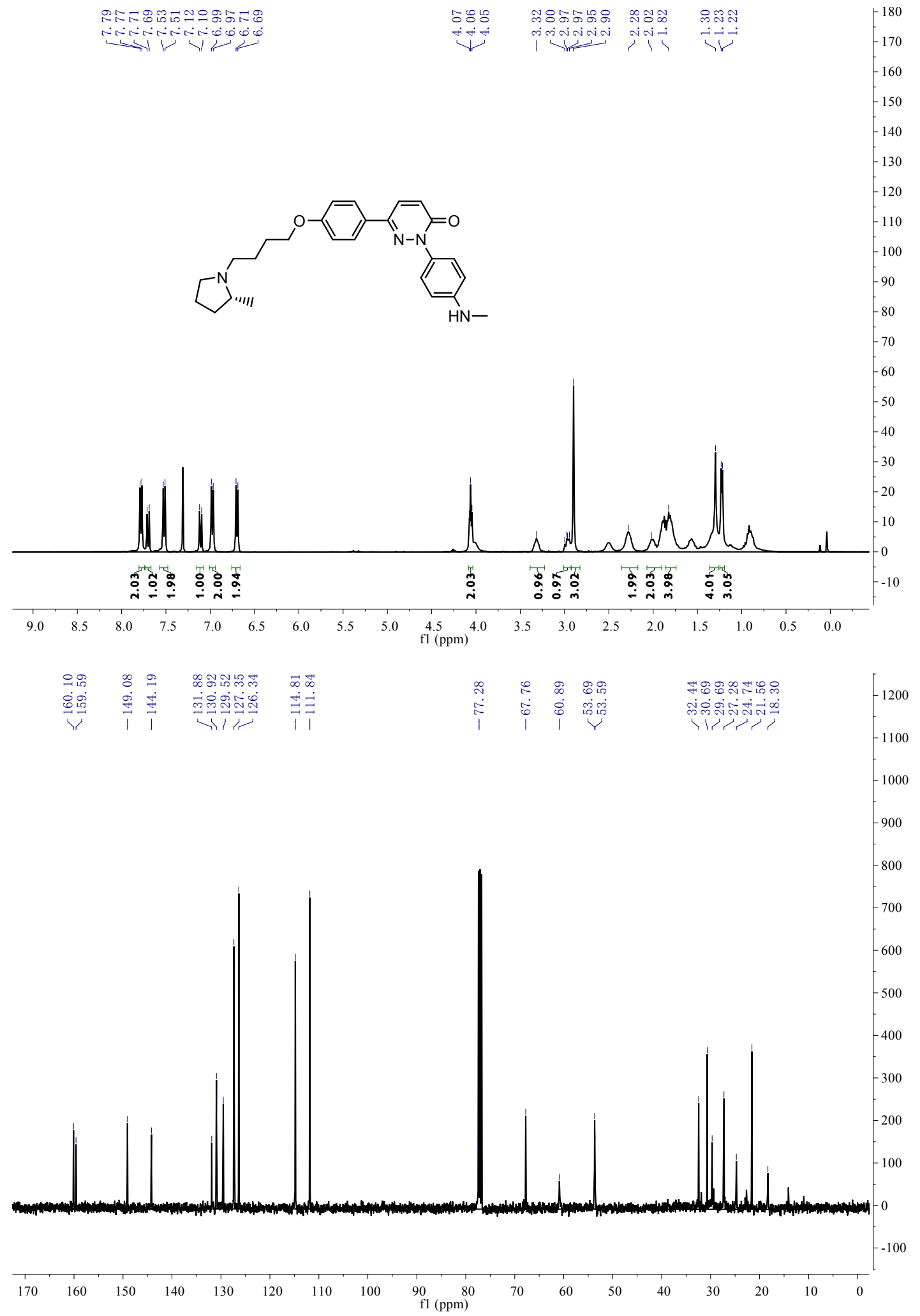


(S)-2-(4-(methylamino)phenyl)-6-(4-(4-(2-methylpyrrolidin-1-yl)butoxy)phenyl)pyridazin-3(2H)-one (9b)

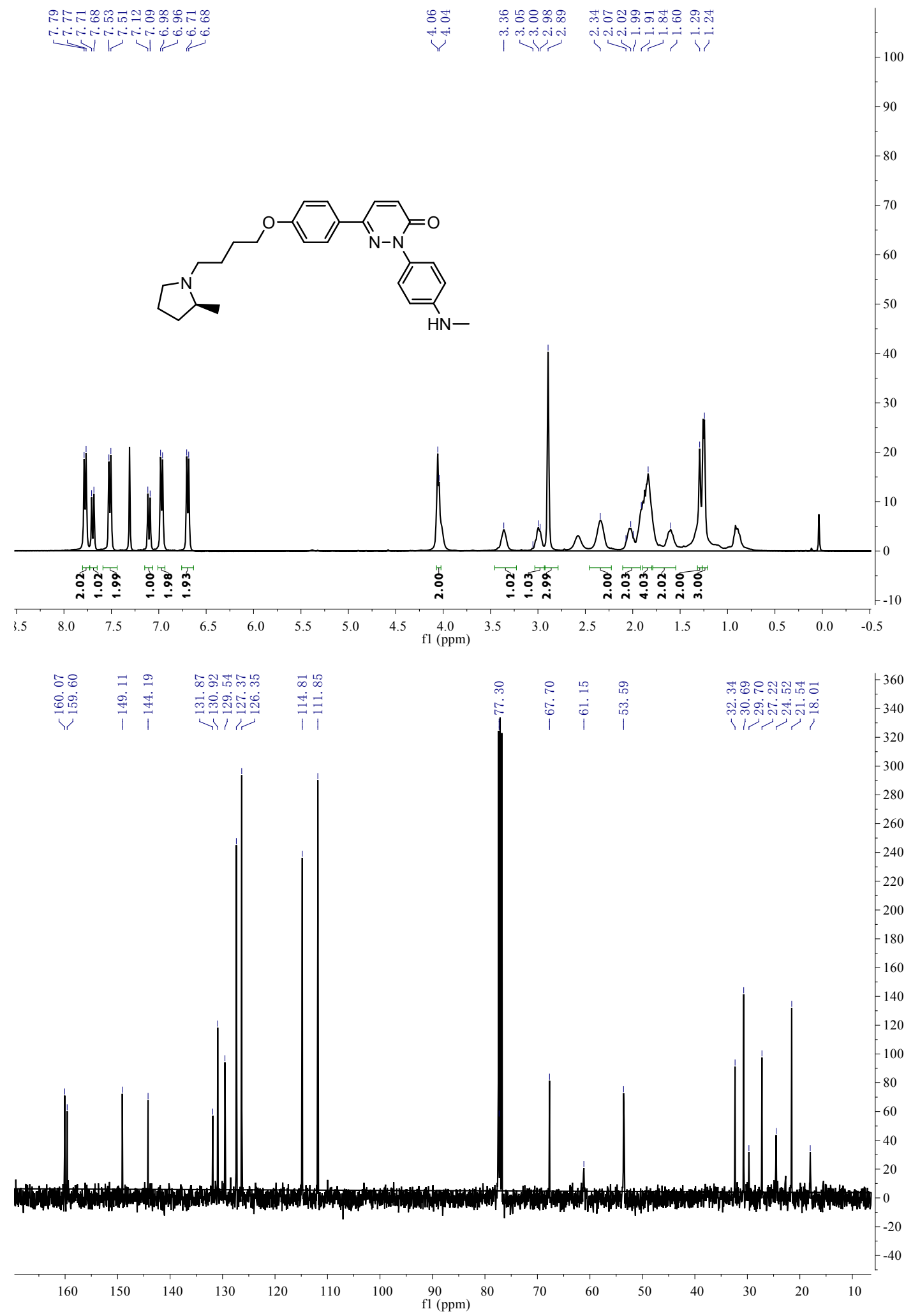


2-(4-(methylamino)phenyl)-6-(4-(4-(pyrrolidin-1-yl)butoxy)phenyl)pyridazin-3(2H)-one (9c)

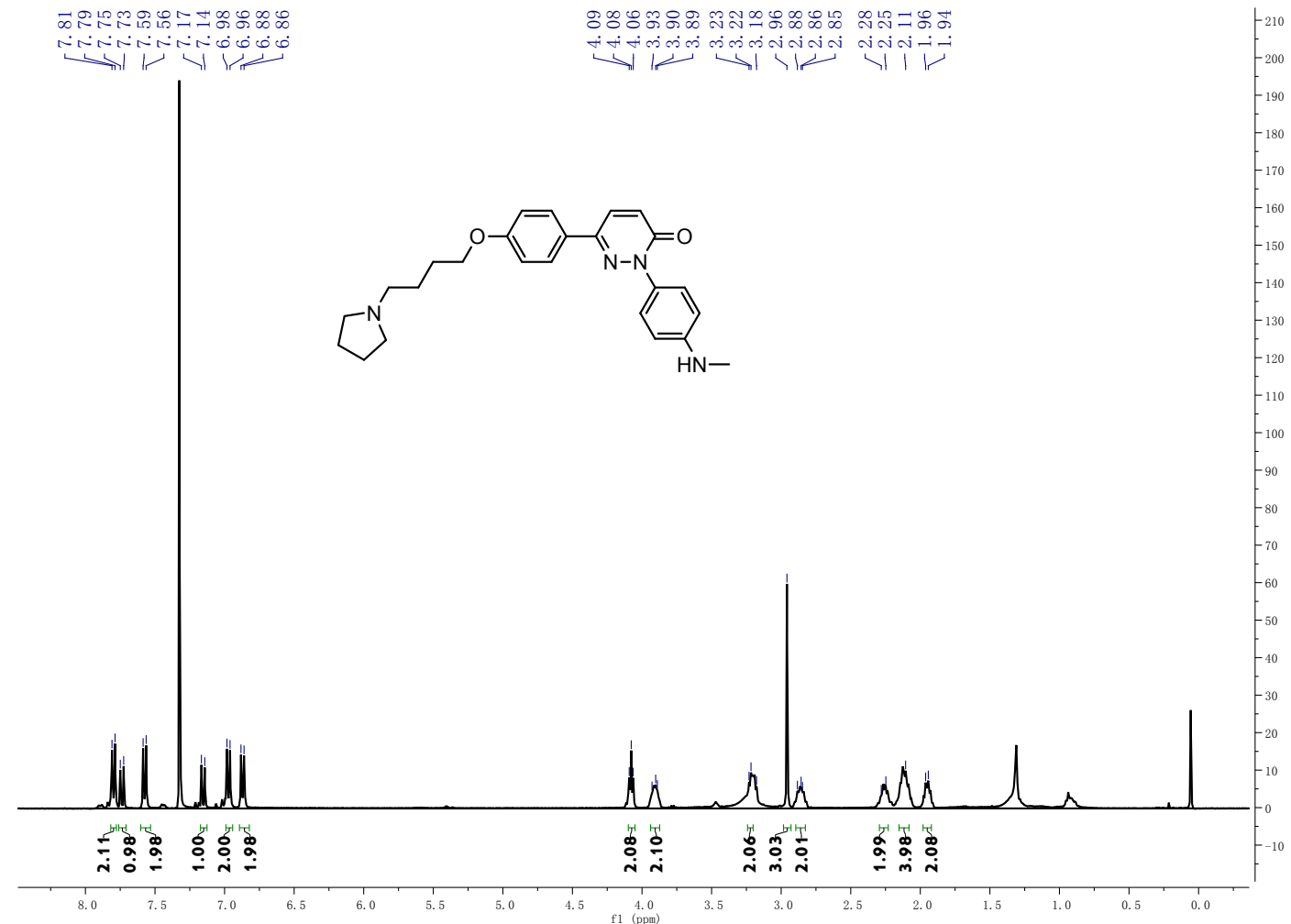

\begin{tabular}{|c|c|c|}
\hline 4 & is $\stackrel{\infty}{\sim}$ & 겅오낭 워 \\
\hline : & 焉导 & ت่) \\
\hline
\end{tabular}

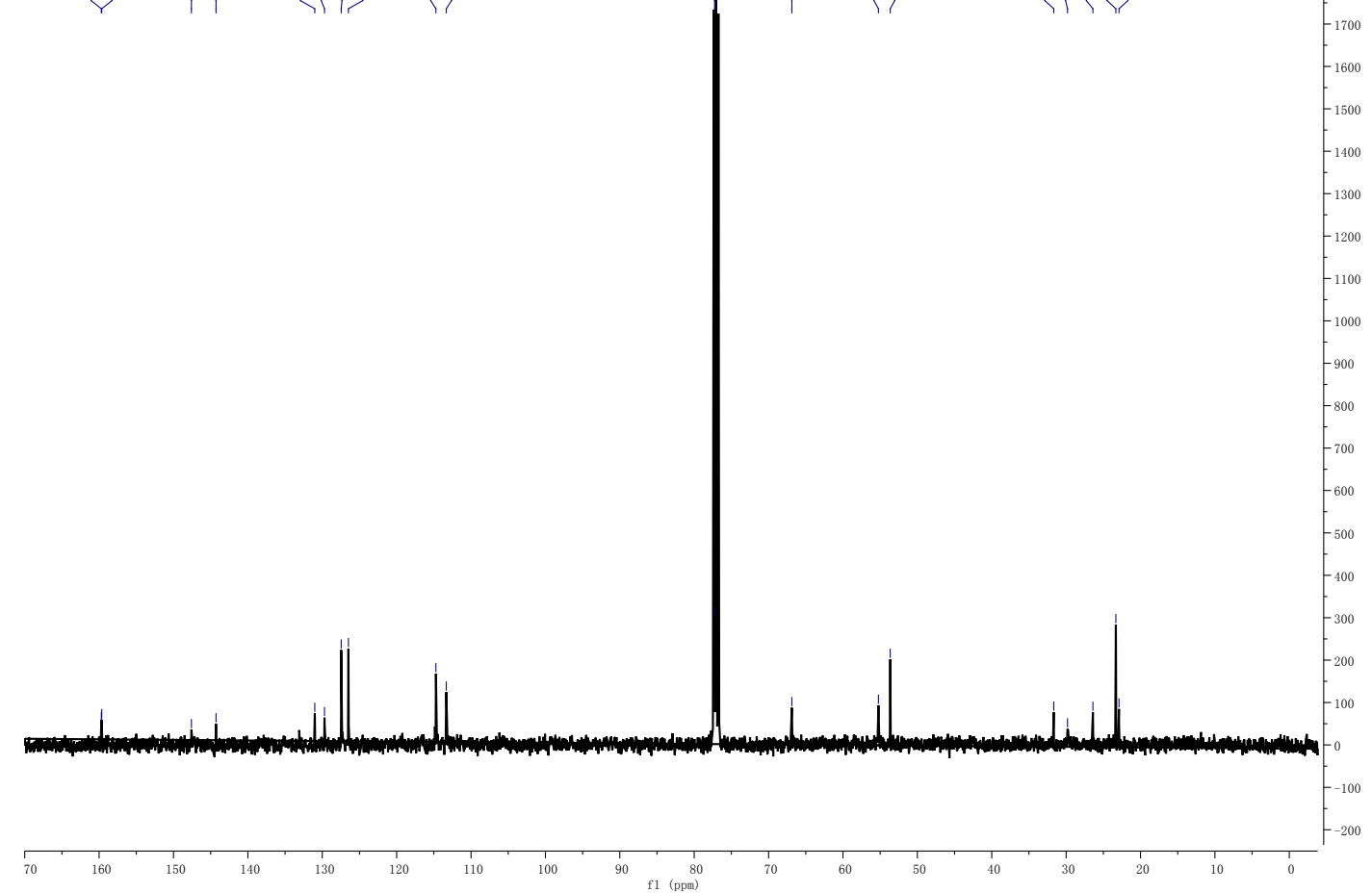


2-(4-(methylamino)phenyl)-6-(4-(4-(piperidin-1-yl)butoxy)phenyl)pyridazin-3(2H)-one (9d)

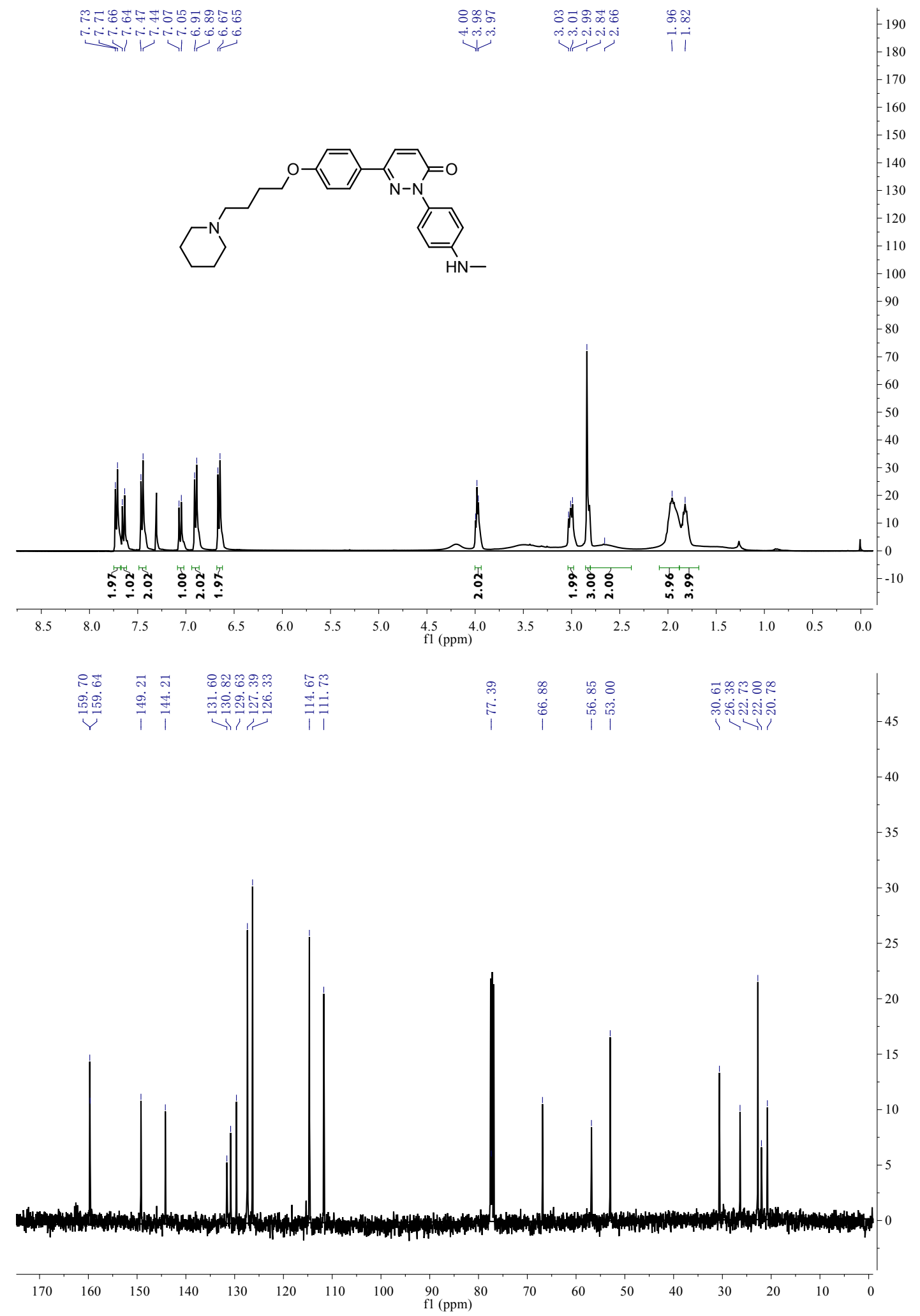


2-(4-(methylamino)phenyl)-6-(4-(4-morpholinobutoxy)phenyl)pyridazin-3(2H)-one (9e)

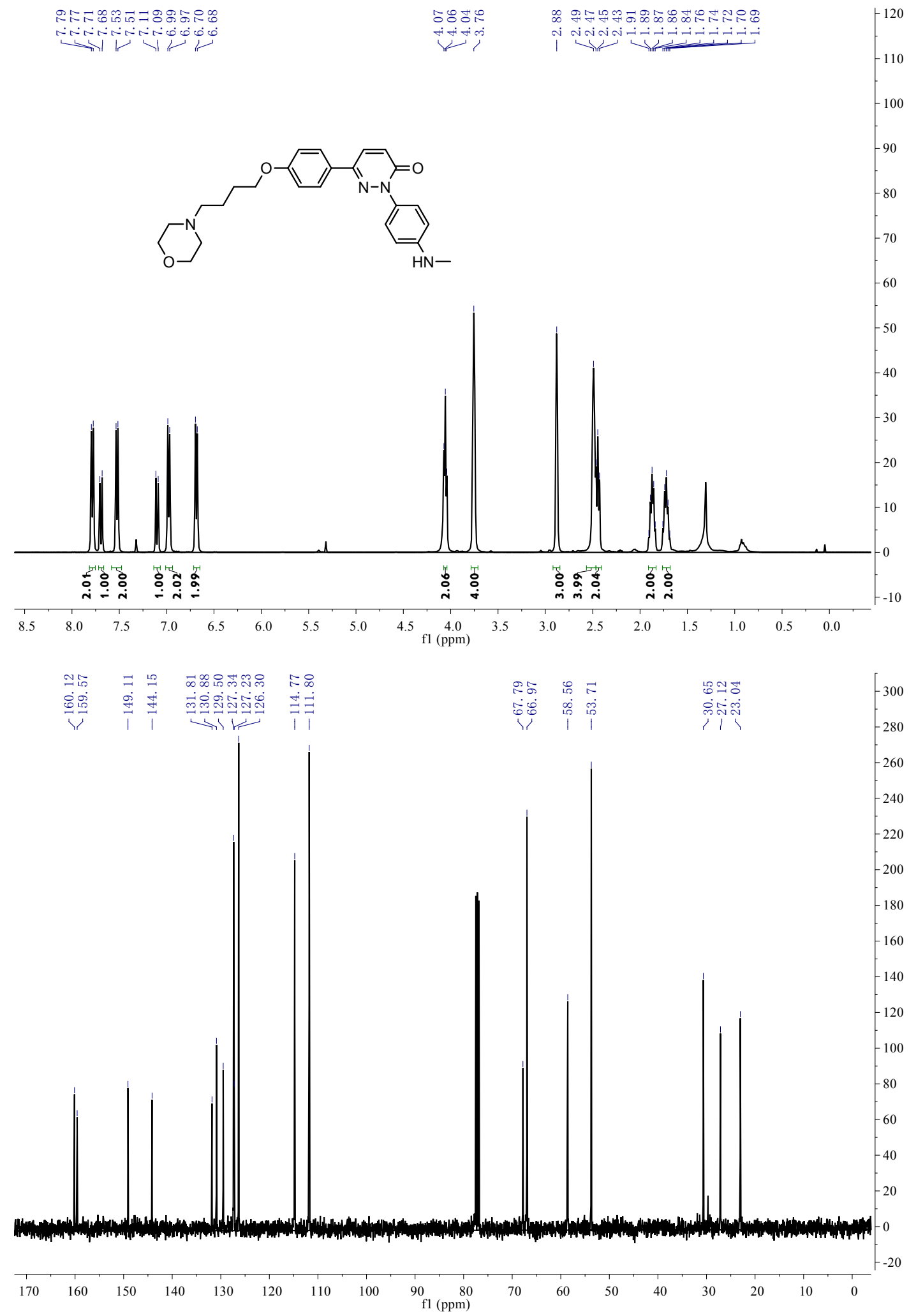


(R)-4-(4,4,5,5-tetramethyl-1,3,2-dioxaborolan-2-yl)benzylmethyl(4-(3-(4-(4-(2-methylpyrrolidin-1yl)butoxy)phenyl)-6-oxopyridazin-1(6H)-yl)phenyl)carbamate (PCAB)

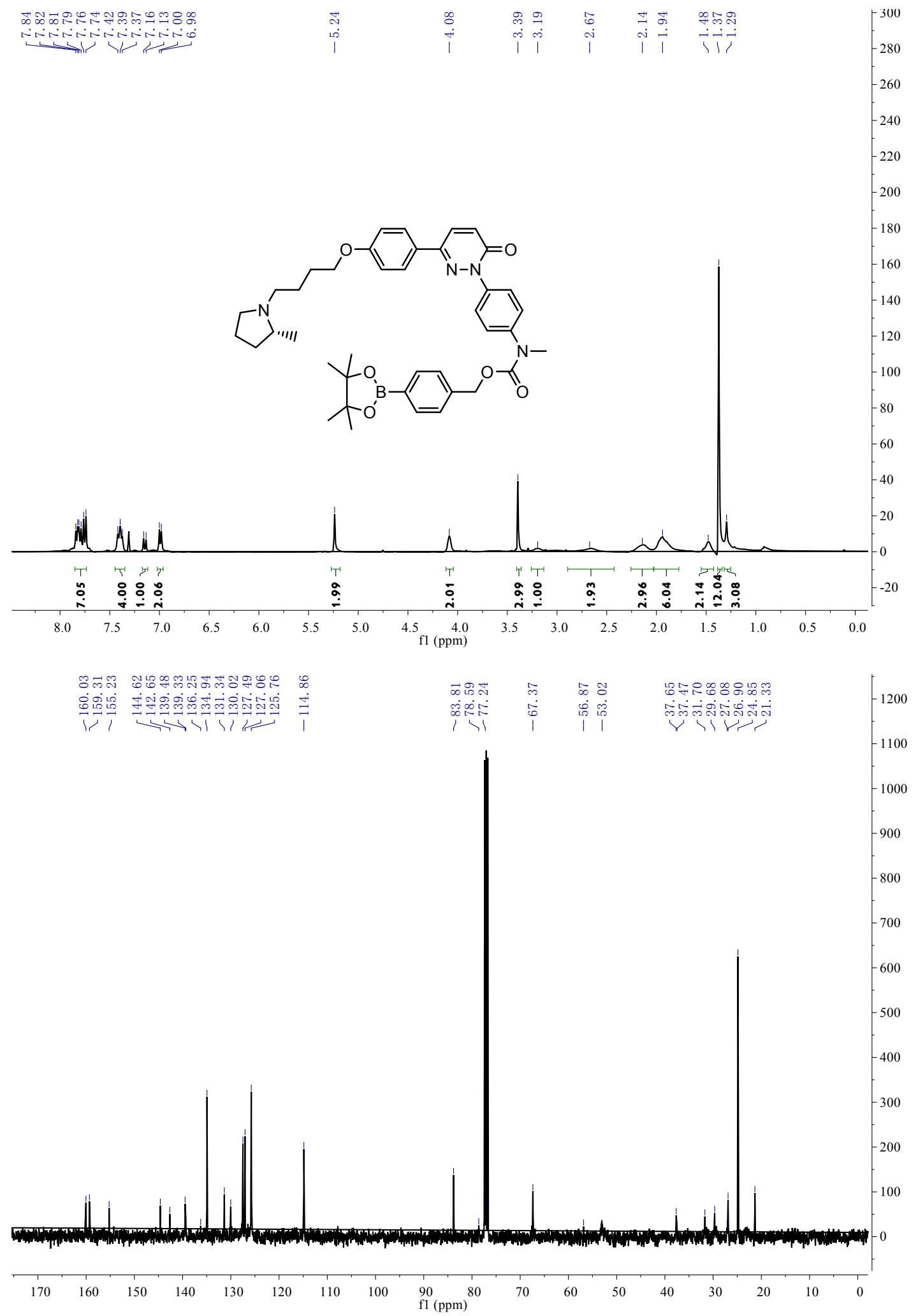

(S)-4-(4,4,5,5-tetramethyl-1,3,2-dioxaborolan-2-yl)benzylmethyl(4-(3-(4-(4-(2-methylpyrrolidin-1yl)butoxy)phenyl)-6-oxopyridazin-1(6H)-yl)phenyl)carbamate (10b) 


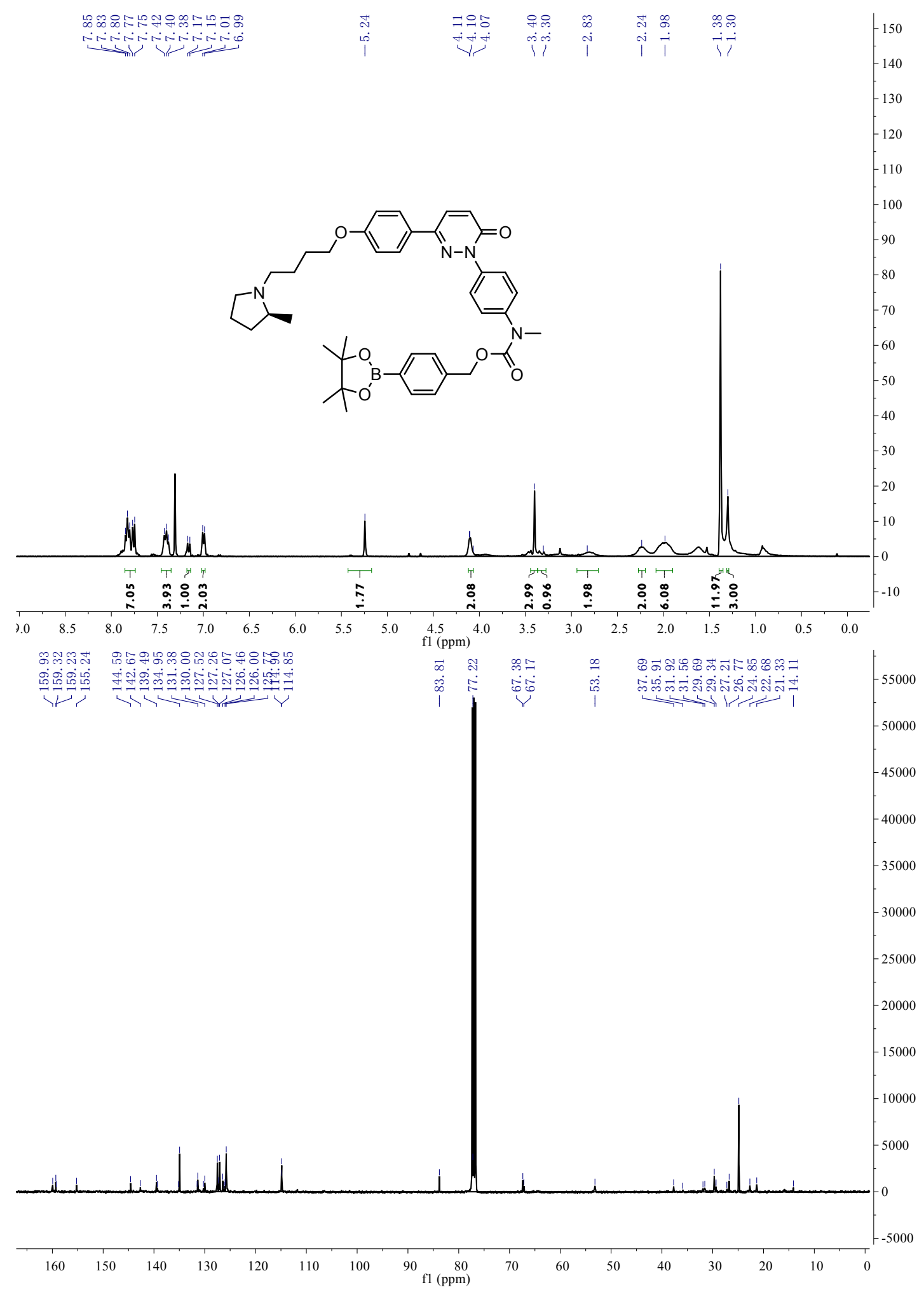


4-(4,4,5,5-tetramethyl-1,3,2-dioxaborolan-2-yl)benzylmethyl(4-(6-oxo-3-(4-(4-(pyrrolidin-1-

yl)butoxy)phenyl)pyridazin-1(6H)-yl)phenyl)carbamate (10c)

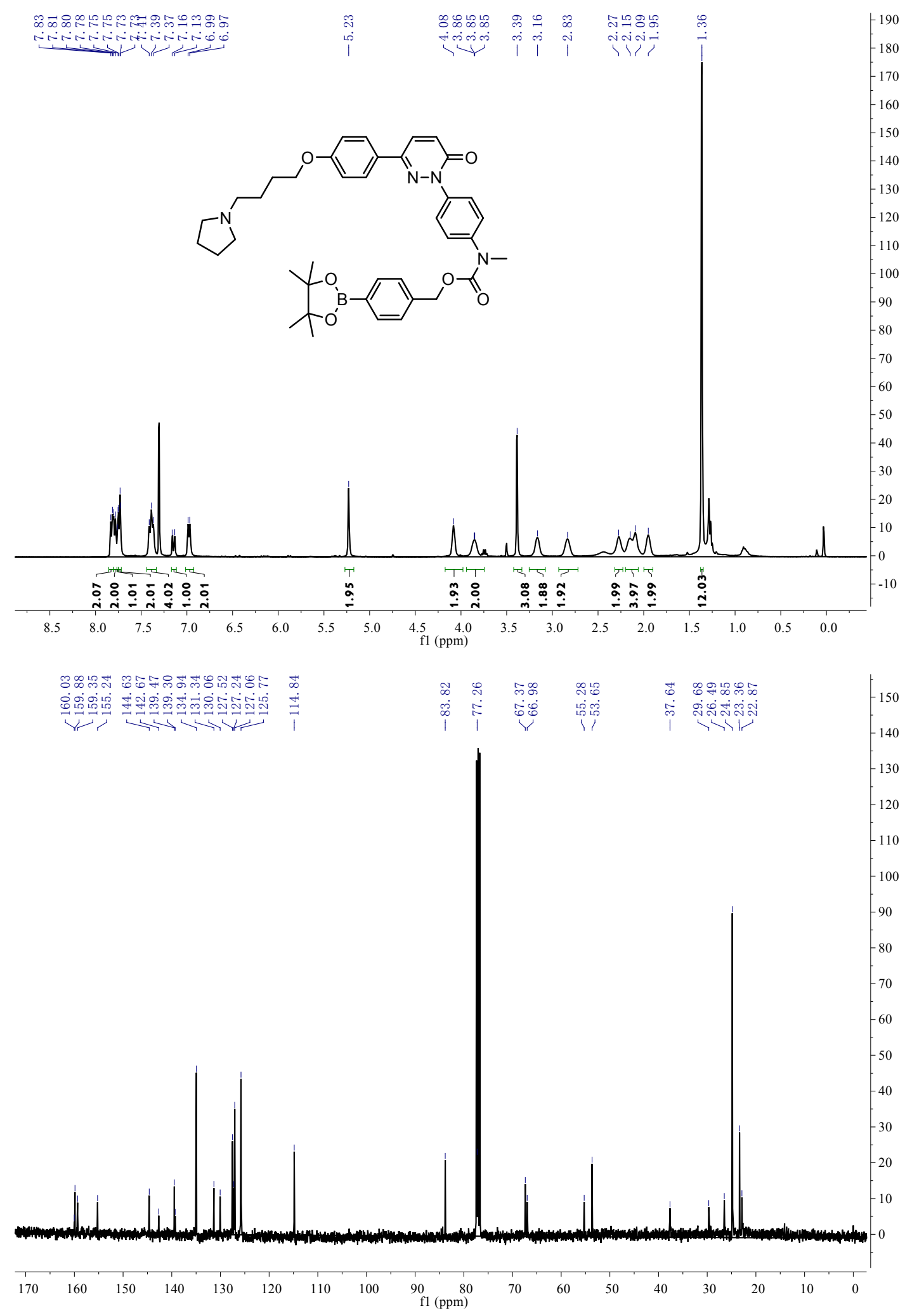


4-(4,4,5,5-tetramethyl-1,3,2-dioxaborolan-2-yl)benzylmethyl(4-(6-oxo-3-(4-(4-(piperidin-1-

yl)butoxy)phenyl)pyridazin-1(6H)-yl)phenyl)carbamate (10d)

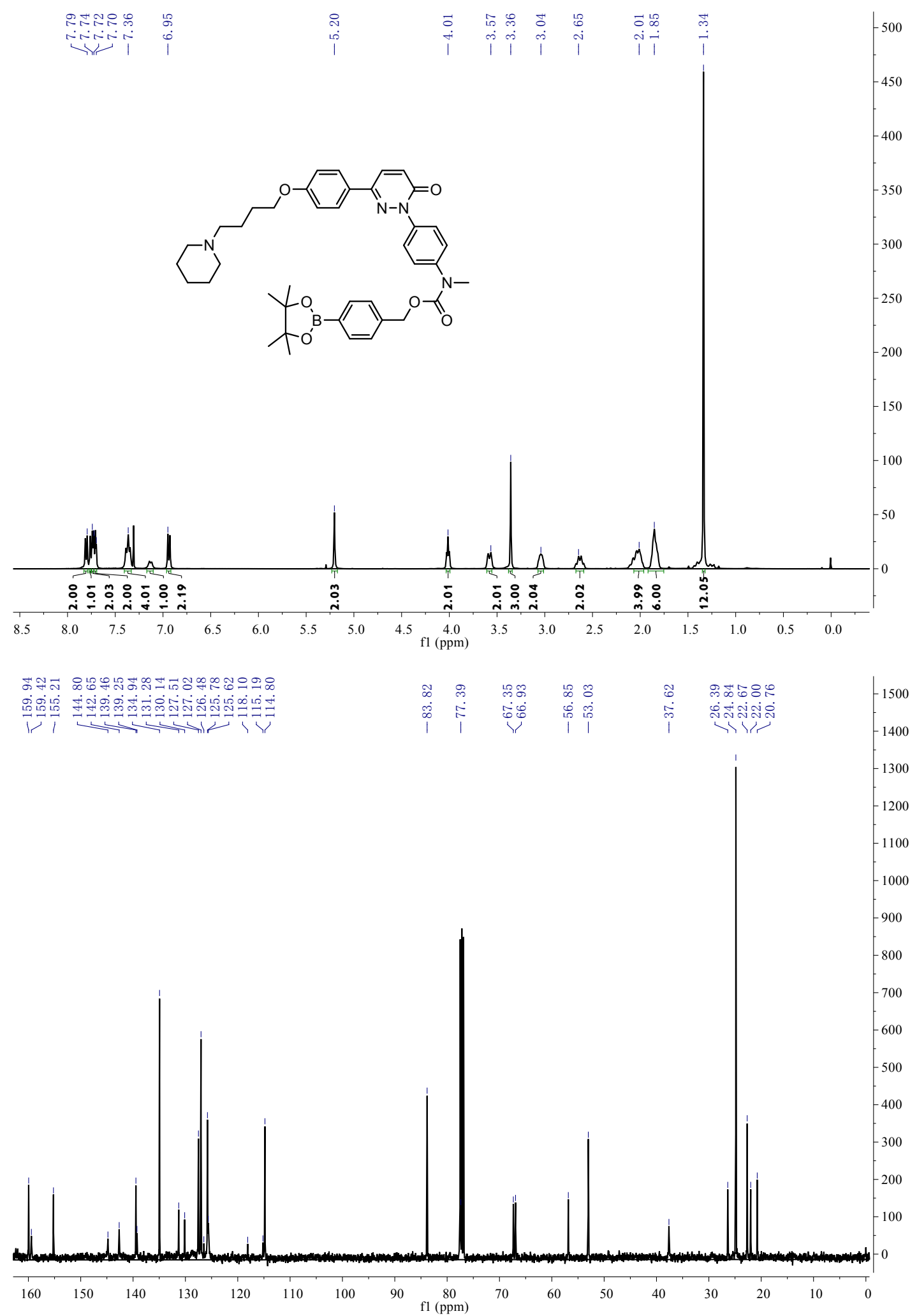


4-(4,4,5,5-tetramethyl-1,3,2-dioxaborolan-2-yl)benzylmethyl(4-(6-oxo-3-(4-(4-(piperidin-1-

yl)butoxy)phenyl)pyridazin-1(6H)-yl)phenyl)carbamate (10e)

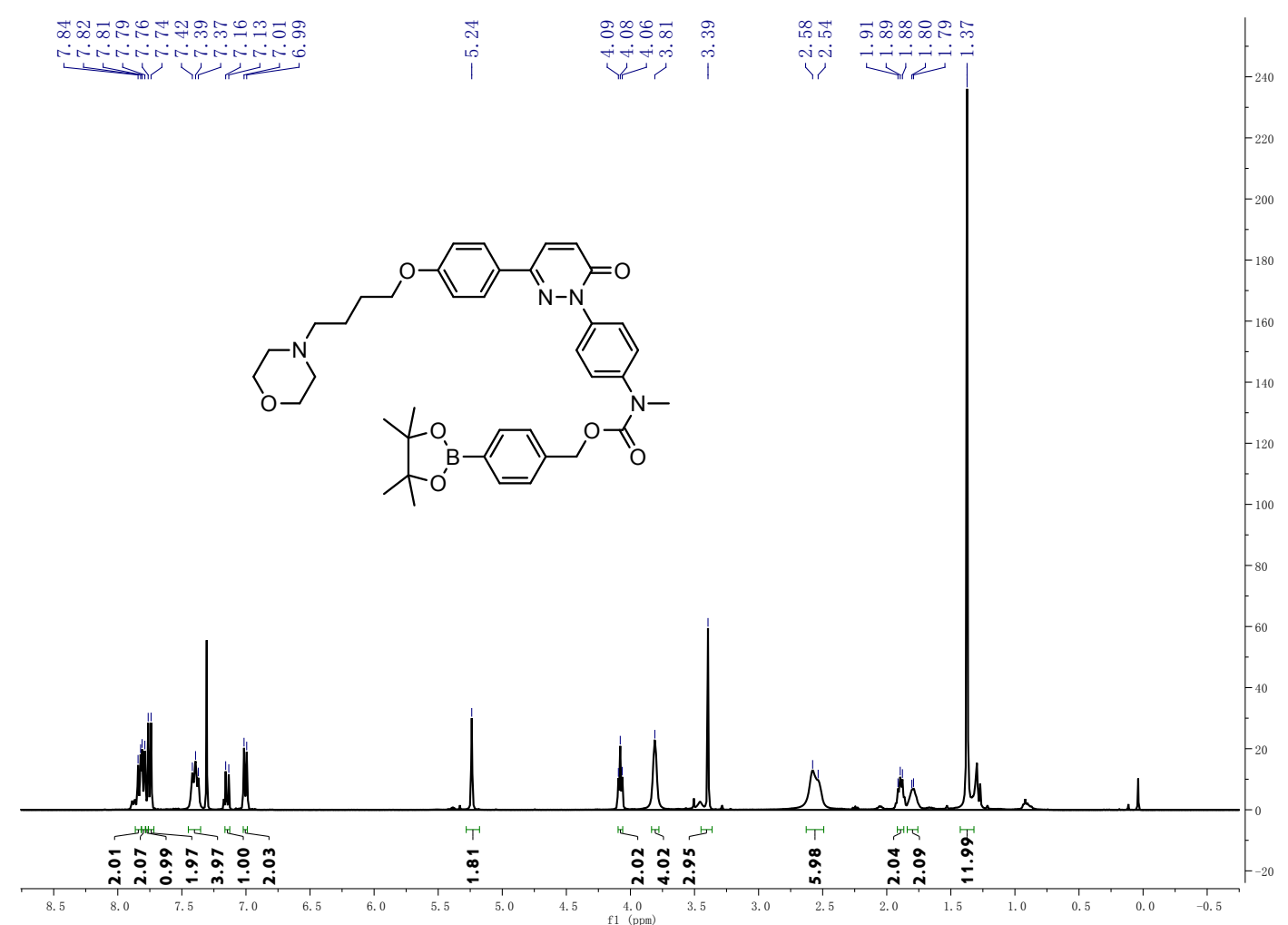

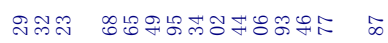

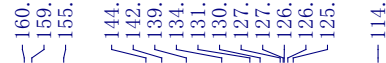

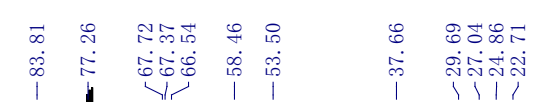

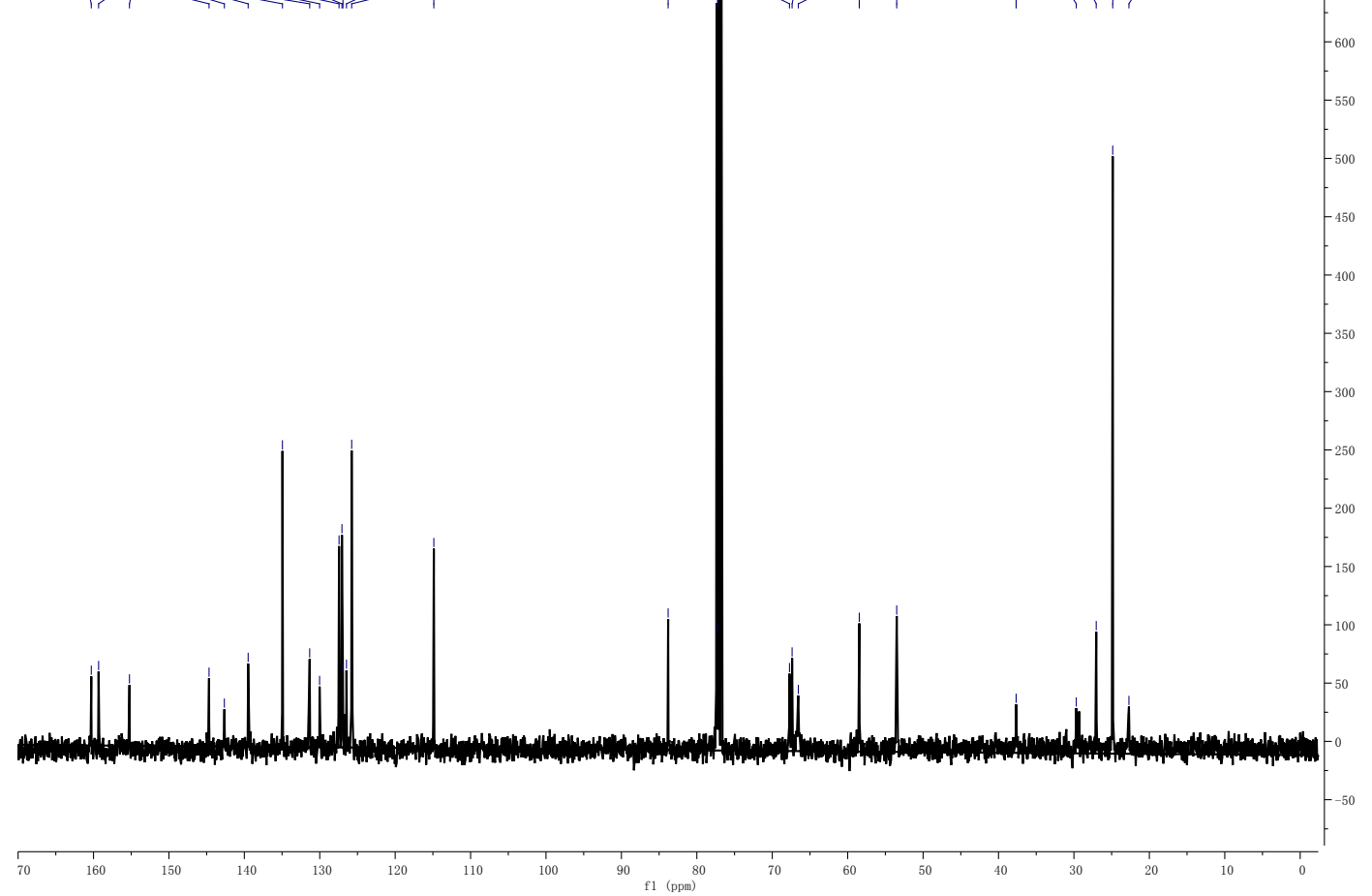




\section{References}

[1] R. Raddatz, R. L. Hudkins, J. R. Mathiasen, J. A. Gruner, D. G. Flood, L. D. Aimone, S. Le, H. Schaffhauser, M. Gasior, D. Bozyczko-Coyne, M. J. Marino, M. A. Ator, E. R. Bacon, J. P. Mallamo, M. Williams, CEP-26401 (irdabisant), a potent and selective histamine $\mathrm{H}_{3}$ receptor antagonist/inverse agonist with cognition-enhancing and wake-promoting activities. J. Pharmacol. Exp. Ther. 2012, 340, 124-133;

[2] R. L. Hudkins, R. Raddatz, M. Tao, J. R. Mathiasen, L. D. Aimone, N. C. Becknell, C. P. Prouty, L. Knutsen, M. Yazdanian, G. Moachon, M. A. Ator, J. P. Mallamo, M. J. Marino, E. R. Bacon, M. Williams, Discovery and characterization of 6-\{4-[3-(R)-2-methylpyrrolidin-1-yl)propoxy]phenyl\}-2H-pyridazin-3-one (CEP-26401, irdabisant): a potent, selective histamine $\mathrm{H}_{3}$ receptor inverse agonist. J. Med. Chem. 2011, 54, 4781-4792;

[3] T. Karstens, K. Kobs, Rhodamine B and Rhodamine101 as reference substances for fluorescence quantumyield mea-surements. J. Phys. Chem. 1980, 84, 1871-1872;

[4] G. A. Crosby, J. N. Demas, The Measurement of Photoluminescence Quantum Yields A Review. J. Phys. Chem. 1971, 75, 991-1024;

[5] C. Xu, W. W. Webb, Measurement of two-photon excitation cross sections of molecular fluorophores with data from 690 to $1050 \mathrm{~nm}$. J. Opt. Soc. Am. B. 1996, 13, 481-491;

[6] M. Ishiyama, Y. Miyazono, K. Sasamoto, Y. Ohkura, K. Ueno, A highly water-soluble disulfonated tetrazolium salt as a chromogenic indicator for NADH as well as cell viability. Talanta 1997, 44, 1299-1305;

[7] J. J. Wang, K. S. Liu, K. C. Sung, C. Y. Tsai, J. Y. Fang, Lipid nanoparticles with different oil/fatty ester ratios as carriers of buprenorphine and its prodrugs for injection. Eur. J. Pharm. Sci. 2009, 38, 138-146

[8] W. Wang, H. Fang, L. Groom, A. Cheng, W. Zhang, J. Liu, X. Wang, K. Li, P. Han, M. Zheng, J. Yin, M. P. Mattson, J. P. Kao, E. G. Lakatta, S. S. Sheu, K. Ouyang, J. Chen, R. T. Dirksen, H. Cheng, Superoxide flashes in single mitochondria. Cell 2008, 134, 279-290;

[9] M. Shui, X. Liu, Y. Zhu, Y. Wang, Exogenous hydrogen sulfide attenuates cerebral ischemia-reperfusion injury by inhibiting autophagy in mice. Can. J. Physiol. Pharmacol. 2016, 94, 1-6;

[10] Y. Zhu, Q. Bu, X. Liu, W. Hu, Y. Wang, Neuroprotective effect of TAT-14-3-3e fusion protein against cerebral ischemia/reperfusion injury in rats. PLoS One, 2014, 9, e93334. 